


\section{NIST STANDARD REFERENCE DATA PRODUCTS CATALOG 1994}

Malcolm W. Chase and Joan C. Saverwein, Editors

STANDARD REFERENCE DATA

NATIONAL INSTITUTE OF STANDARDS AND TECHNOLOGY

Gaithersburg, MD 20899

$$
\text { January } 1994
$$

Supersedes NIST Special Publication 782, 1993 Edition

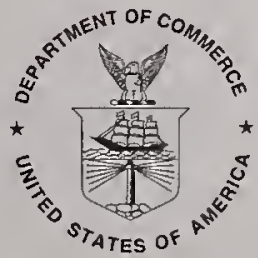

U.S. DEPARTMENT OF COMMERCE Ronald H. Brown, Secretary

TECHNOLOGY ADMINISTRATION Mary Lowe Good, Under Secretary for Technology

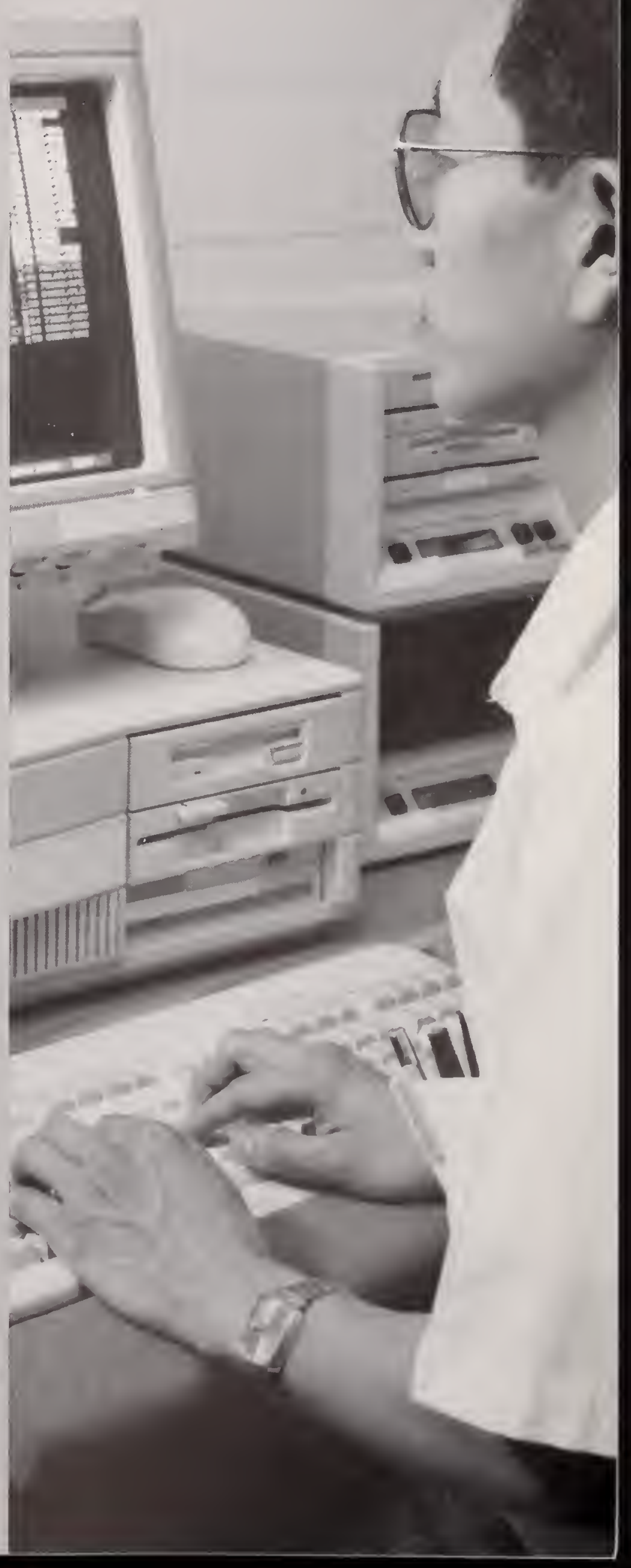


National Institute of Standards and Technology

Special Publication 782, 1994 Edition

Natl. Inst. Stand. Technol. Spec. Publ. 782, 1994 Ed. 109 pages (Jan. 1994)

CODEN: NSPUE2
U.S. Government Printing Office Washington: 1994

For sale by the Superintendent of Documents

U.S. Government Printing Office Washington, DC 20402 
The editors would like to acknowledge

\section{Acknowledgments}

Cheryl E. Williams: desktop publishing and design

Jeanne R. Bride: proofreading

H. M. Helfer: photography

Marilyn Ugiansky: design consultation

Warren Overman: printing coordination

Ernie Kunz: cover design. 


\section{Abstract and Key Words}

The National Institute of Standards and Technology's (NIST) Standard Reference Data Program provides reliable, well-documented data to scientists and engineers for use in technical problemsolving, research, and development. This catalog lists published data compilations and current databases in the Standard Reference Database Series. This edition of the catalog contains many new databases and updates current ones. These data compilations have been subdivided into ten categories. Prices and ordering information are located at the back of the document.

Key words: chemistry; compilations; databases; evaluated data; materials; numeric data; physics 

System dates from 1963, when the Federal Council for Science and Technology asked the then-National Bureau of Standards (now NIST) to assume primary responsibility in the Federal Government for promoting and coordinating the critical evaluation of numerical data in the physical sciences. The program was conceived as a decentralized national effort with financial support coming from a variety of government and private sources, but with NBS responsible for the overall planning and coordination. In 1968 Congress provided a specific legislative mandate for the program through passage of Public Law 90-396, the Standard Reference Data Act. This Act details the policy of Congress to make reliable, critically evaluated data compilations available to scientists, engineers, and the general public.

The Standard Reference Data Program has been providing evaluated, high-quality data for a wide range of applications to industry, government, and academic institutions for over 30 years. Standard reference data have been utilized to improve design efficiency of chemical processes, identify potentially toxic substances in the environment, improve materials durability, and calculate performance of chemical reactors, to name but a few applications. With the present availability of the personal computer at every scientist's fingertips, standard reference data are even more accessible and play a more critical role in technological advancement each year. With this, the fifth annual Standard Reference Data Products Catalog, we want to make the scientific community more aware of our highly evaluated, high-quality data in all of its many forms. We value your comments on any of our products. Please let us know how we can improve existing software and databases and what new areas to explore in order to fulfill your data needs and increase your productivity.

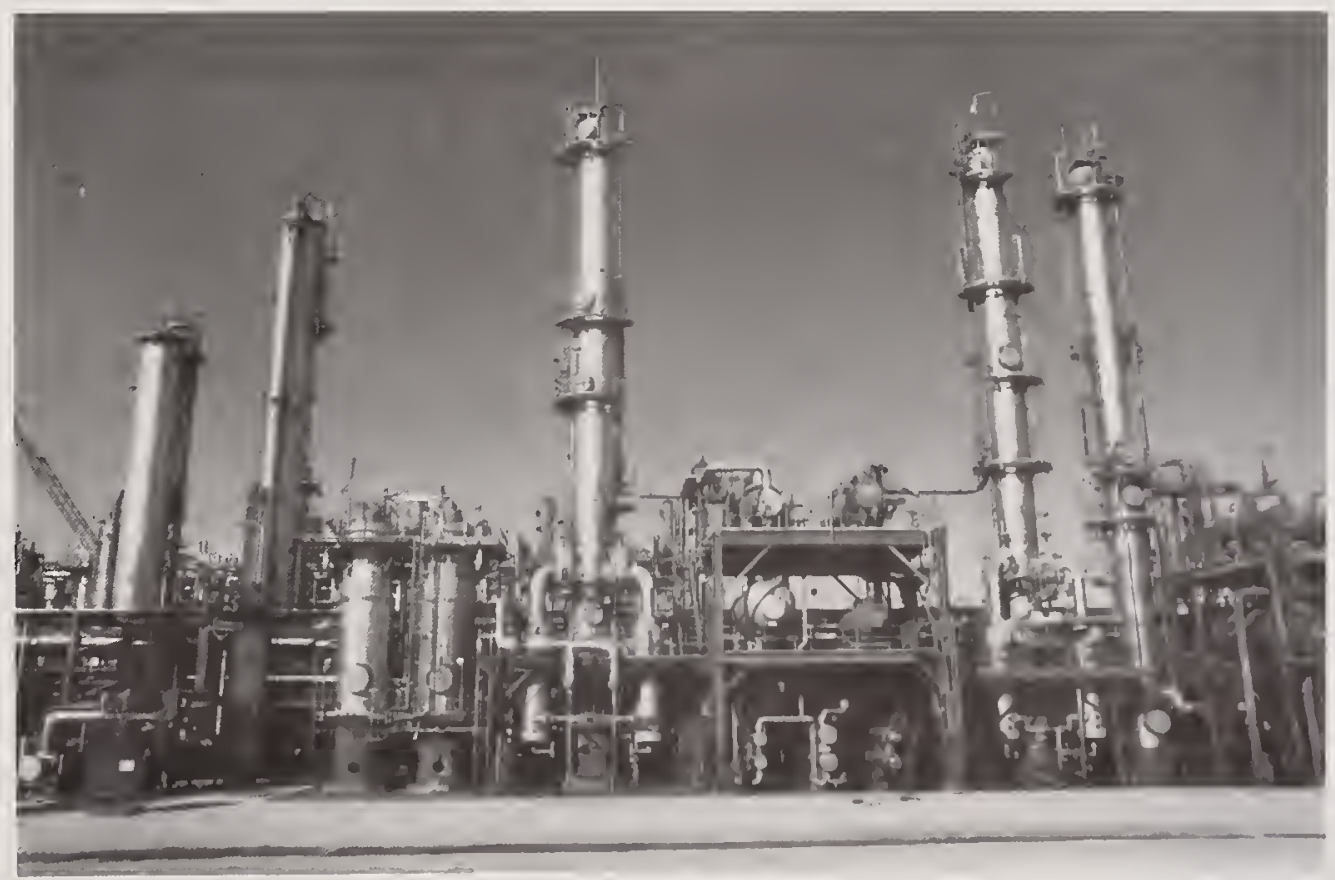

The SRD Program has provided valuable evaluated data to industry for over thirty years. 
ontents

RODUCTS

Conito

PROID

\section{Contents}

RODUCTS

Comiens

PRODER

\section{ontents}

RODUCTS

Gon

PROI

\section{ontents}

RODUCTS
ACKNOWLEDGMENTS . . . . . . . . . . . . . . . iii

ABSTRACT AND KEY WORDS $\ldots \ldots \ldots \ldots \ldots \ldots \ldots \ldots$ iv

PREFACE ........................

INTRODUCTION $\ldots \ldots \ldots \ldots \ldots \ldots \ldots \ldots \ldots \ldots \ldots \ldots \ldots \ldots$

ORDERING INFORMATION $\ldots \ldots \ldots \ldots \ldots \ldots \ldots \ldots$

STANDARD REFERENCE DATABASES

AND PUBLICATIONS

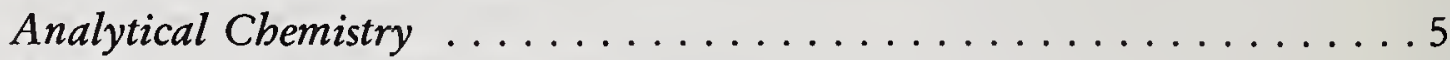

NIST/EPA/NIH Mass Spectral $\ldots \ldots \ldots \ldots \ldots \ldots \ldots \ldots \ldots \ldots$

NIST/EPA/NIH Mass Spectral PC Version . . . . . . . . . . . 8

NIST/NIH Desktop Spectrum Analyzer

Program and X-Ray Database . . . . . . . . . . . . . . 10

NIST Surface Structure . . . . . . . . . . . . . . . . . . 12

NIST Crystal Data . . . . . . . . . . . . . . . . . . . 14

NIST/Sandia/ICDD Electron Diffraction . . . . . . . . . . . 15

NIST X-Ray Photoelectron Spectroscopy . . . . . . . . . . . 16

NIST/EPA Gas-Phase Infrared . . . . . . . . . . . . . . . . . . . . . . 17

SRD Major Analytical Chemistry Publications $\ldots \ldots \ldots \ldots \ldots$

Atomic and Molecular Pbysics . . . . . . . . . . . . . . . . . . . 19

NIST Spectroscopic Properties of Atoms

and Atomic Ions . . . . . . . . . . . . . . . . . . . . 20

NIST Wavenumber Calibration Tables . . . . . . . . . . . . . 21

NIST Electron and Positron Stopping

Powers of Materials . . . . . . . . . . . . . . . . . 22

NIST X-Ray and Gamma-Ray Attenuation

Coefficients and Cross Sections .................. 23

NIST Atomic Transition Probabilities

Data Files (Scandium through Nickel) . . . . . . . . . . . . . 24

NIST Spectroscopic Properties of Diatomic

Molecules . . . . . . . . . . . . . . . . . . . . . . . 25

NIST Vibrational and Electronic Energy Levels

of Small Polyatomic Transient Molecules . . . . . . . . . . . . . . 26

SRD Major Atomic and Molecular Physics Publications . . . . . . . . . 27

Biotechnology . . . . . . . . . . . . . . . . . . 33

NIST/NASA/CARB Biological Macromolecule

Crystallization ........................ . . 34

Lipid Thermotropic Phase Transitions . . . . . . . . . . . 35

Chemical Kinetics $\ldots \ldots \ldots \ldots \ldots \ldots \ldots \ldots \ldots \ldots \ldots \ldots$

NIST Chemical Kinetics . . . . . . . . . . . . . . . . 38

NDRL/NIST Solution Kinetics . . . . . . . . . . . . . . 40

SRD Major Chemical Kinetics Publications . . . . . . . . . . . 41 
NIST Structural Ceramics . . . . . . . . . . . . . 46

NACE/NIST Corrosion Performance Databases . . . . . . . . 47

NIST Tribomaterials I (ACTIS) $\ldots \ldots \ldots \ldots \ldots \ldots \ldots \ldots \ldots$

NIST Ceramic Tribomaterials $\ldots \ldots \ldots \ldots \ldots \ldots \ldots \ldots \ldots . \ldots 48$

Phase Diagrams for Ceramists . . . . . . . . . . . . . 49

SRD Major Materials Properties Publications . . . . . . . . . 50

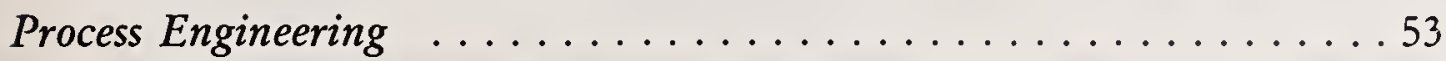

GRI/NIST Orifice Meter Discharge Coefficient .......... 54

Thermodynamics and Thermochemistry ................. 55

NIST Chemical Thermodynamics ................. 56

NIST JANAF Thermochemical Tables . . . . . . . . . . . 57

DIPPR $^{\circledR}$ Data Compilation of Pure Compound

Properties . . . . . . . . . . . . . . . . . . . . 58

DIPPR $^{\circ}$ Data Compilation Access Program II -

Student DIPPR ${ }^{\circ} \ldots \ldots \ldots \ldots \ldots \ldots \ldots \ldots \ldots \ldots$

NIST Positive Ion Energetics

with Structures and Properties Software . . . . . . . . . . . . 59

NIST Negative Ion Energetics . . . . . . . . . . . . 60

NIST Structures and Properties Database and

Estimation Program .........................61 61

NIST Estimation of the Thermodynamic Properties

for Organic Compounds at $298.15 \mathrm{~K}$. . . . . . . . . . . . . 62

NIST Critical Stability Constants of Metal Complexes . . . . . . . 63

NIST Molten Salts .....................664

NIST JANAF Thermochemical Tables -

Shomate Coefficients ........................665

NIST JANAF Thermochemical Tables -

NASA-Lewis Coefficients . . . . . . . . . . . . . . . . 66

NIST/DIPPR Properties of Aqueous Solutions . . . . . . . . 67

SRD Major Thermodynamics and Thermochemistry

Publications ..............................68 68

Thermophysical Properties of Fluids . .............. 73

NIST Thermophysical Properties of Pure Fluids . . . . . . . . . 74

NIST Thermodynamic Properties of Refrigerants and

Refrigerant Mixtures ...................... 75

NIST Thermophysical Properties of Hydrocarbon Mixtures . . . . . . 76

NIST Mixture Property . . . . . . . . . . . . . . . . 77

NIST Thermophysical Properties of Water . . . . . . . . . 78

PICT/NIST Heat Capacities of Liquid Hydrocarbons . . . . . . . . 79

SRD Major Thermophysical Properties of

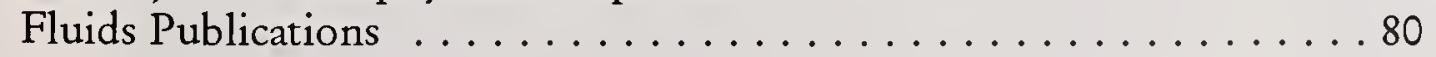

\section{PRODUC}

\section{PRODUC}

\section{Content:}

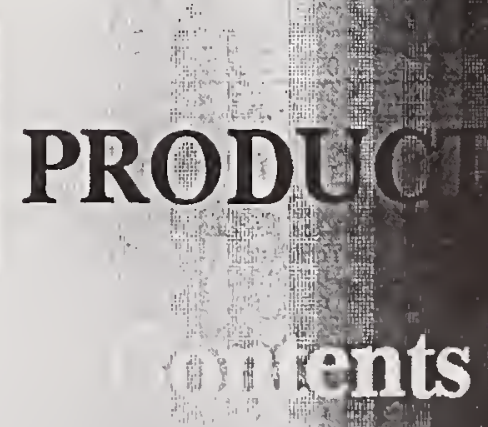

UCTS

\section{Conten}




\section{antents}

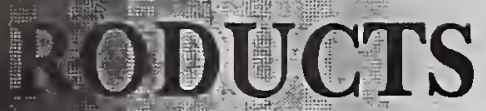

Con

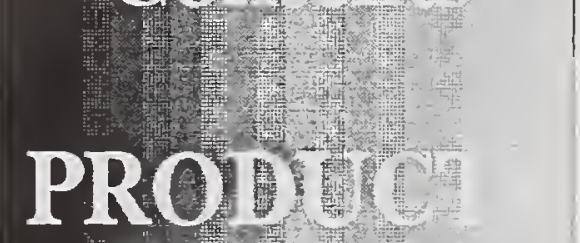

ontents

\section{RODUCTS}

Coti

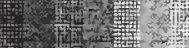

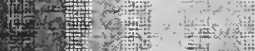

PROB

Contents

RODUCTS

Conven

PROO

Contents
NIST Special Databases

NIST Binary Images of Printed Digits,

Alphas, and Text

NIST Structured Forms Reference Set of

Binary Images . . . . . . . . . . . . . . . . . . . . . . . 82

NIST Binary Images of Handwritten

Segmented Characters . . . . . . . . . . . . . . . . . . 83

NIST 8-Bit Gray Scale Images of Fingerprint

Image Groups . . . . . . . . . . . . . . . . . . . . 84

IVTANTHERMO-PC $\ldots \ldots \ldots \ldots \ldots \ldots \ldots \ldots \ldots \ldots \ldots \ldots$

NIST Structured Forms Reference Set of

Binary Images II . . . . . . . . . . . . . . . . . . . . . . . . 86

NIST Test Data 1: Binary Images of Handprinted

Segmented Characters . . . . . . . . . . . . . . . . . . 88

NIST Machine-Print Database of Gray Scale

and Binary Images . . . . . . . . . . . . . . . . . . . . . . . . . 89

NIST 8-Bit Gray Scale Images of Mated

Fingerprint Card Pairs . . . . . . . . . . . . . . . . . . .990

NIST Supplemental Fingerprint Card Data . . . . . . . . . . . . . . . . 91

NIST Mated Fingerprint Card Pairs $2 \ldots \ldots \ldots \ldots . \ldots \ldots$

COMAR: International Data Bank on

Reference Materials

NIST Special Software . . . . . . . . . . . . . . . . . . 95

NIST Scoring Package . . . . . . . . . . . . . . . . 95

ORDER FORM AND PRICE LIST . . . . . . . . . . . . . . . 97 
$S$ ince 1968, the NIST Standard Reference Data (SRD) Program has been providing reliable, well-documented reference data to scientists and engineers for use in technical problem-solving, research, and development. Now, in the mid-nineties, SRD is providing a wide array of data compilations with sophisticated software. Our tradition of quality continues with a growing list of new and updated databases. We are also advancing into such new areas as biotechnology and process design with new databases in both of these categories.

Experts in the physical, chemical, and materials sciences critically evaluate data that result from experimental measurements, calculations, and theory. The evaluations are carried out through a network of data centers, projects, and cooperative programs that comprise the National Standard Reference Data System (NSRDS). Experienced researchers in each area assess the accuracy of the data, prepare compilations, and recommend best values. The outputs are widely distributed as publications and electronic databases.

Current activities in the Standard Reference Data Program are carried out in long-term data centers, located primarily at NIST, and numerous short-term projects, primarily at universities and industrial research centers. In addition, the Program maintains many long-term collaborations in cooperative data programs which draw support from both industry and other government programs.

\section{Introduction}

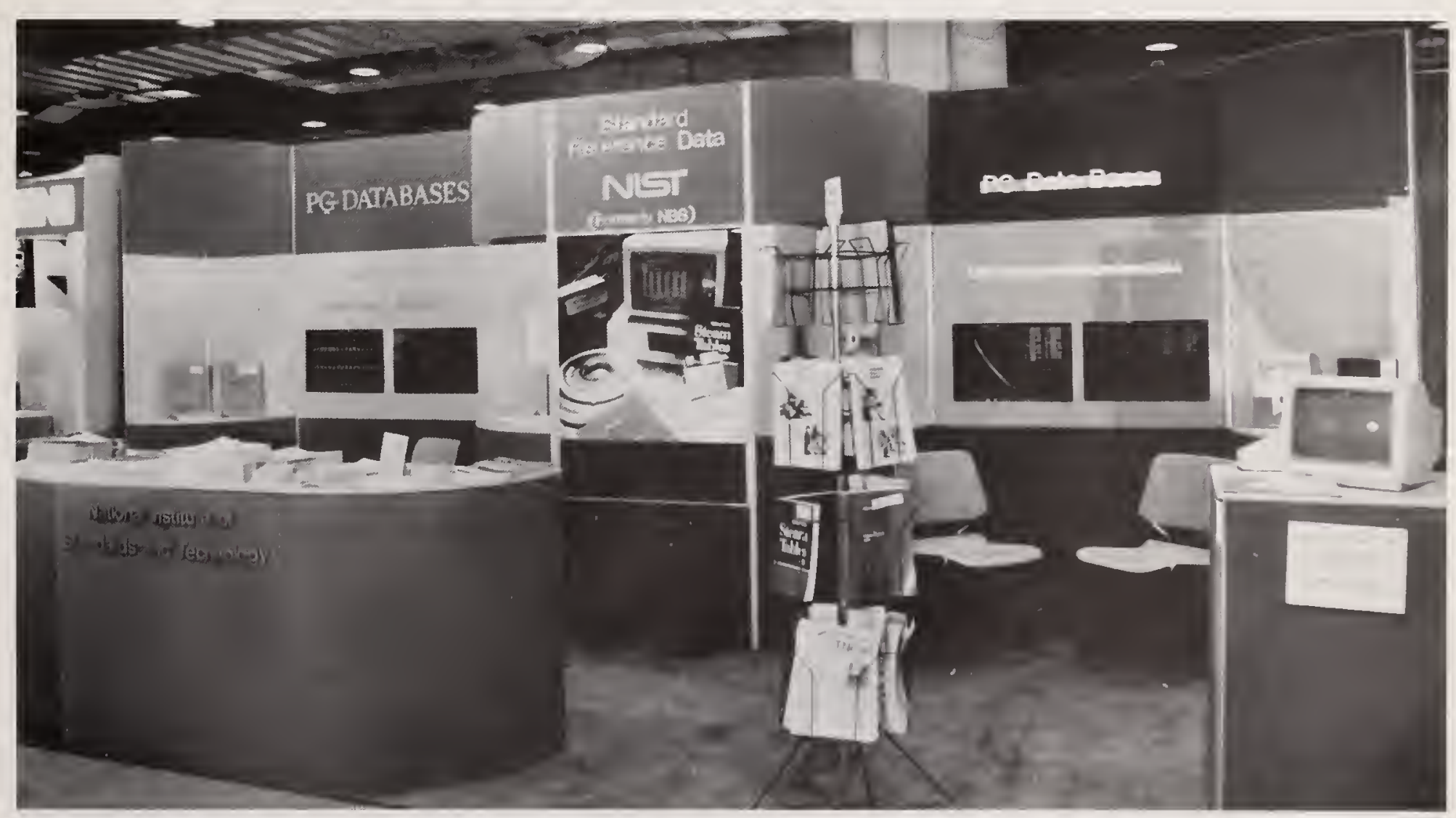

The SRD Booth appears at many technical conferences and meetings. 
The activities concentrate in the following disciplines:

Analytical Chemistry - mass spectral, $\mathrm{x}$-ray spectral, surface analysis, crystallographic, and electron diffraction data for chemical identification.

Atomic and Molecular Physics - atomic energy levels and wavelengths, transition probabilities, and collisional data used for diagnostics and modeling. Also includes evaluated molecular data at microwave and infrared frequencies and, for transient molecules, vibrational and electronic energy levels.

Biotechnology - data on important groups of molecules, such as lipids, and biological macromolecules, such as proteins, nucleic acids, and viruses.

Chemical Kinetics - rate data on gas-phase and solution reactions.

Materials Properties - structure and characterization of materials, performance properties, including tribology and mechanical corrosion, and phase equilibria.

Process Design - data to assist engineers with design and implementation of large systems.

Thermodynamics and Thermochemistry - reliable, widely-used tables of organic and inorganic species.

Thermophysical Properties of Fluids - thermophysical and transport properties of pure and mixed fluids, including refrigerants, that are of critical importance to industry.

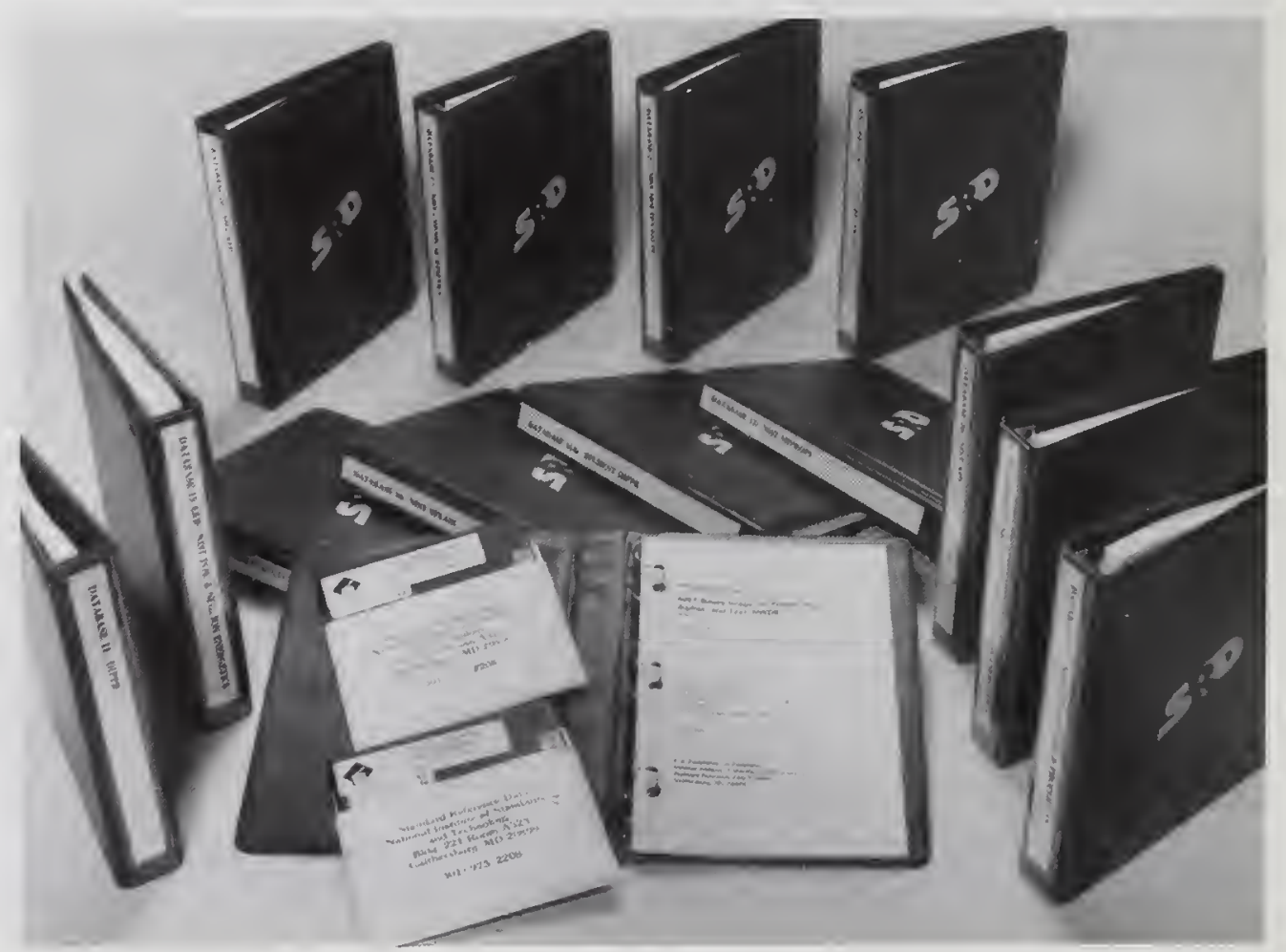

The SRD database series continues to expand and improve. This edition of the Catalog has many new databases and updates. 
The data collections resulting from the work of the SRD Program are disseminated in different ways:

National Standard Reference Database Series - Databases on diskettes, CD-ROM, magnetic tapes, and online systems.

Journal of Physical and Chemical Reference Data - A bimonthly Journal published jointly with the American Chemical Society and the American Institute of Physics. The 20-year-plus tradition of significant data compilations continues with a new Editor, Dr. Jean W. Gallagher.

Other Publications - Journal articles and books published with technical society and private publishers.

If you have programmatic questions about Standard Reference Data, please contact Malcolm W. Chase, Chief, at (301) $975-2200$ or Jean W. Gallagher at (301) $975-2204$.

If you have questions or suggestions for improvements on the SRD Databases, please contact Phoebe Fagan at (301) 975-2213.

\section{ORDERING INFORMATION}

$W_{\text {he }}$ database, checks, purchase orders, VISA, and Mastercard are accepted. Orders can be placed by phone or FAX for quick turnaround. For further information on both current and future SRD databases please contact:

Joan Sauerwein Standard Reference Data National Institute of Standards \& Technology Bldg. 221/Room A320 Gaithersburg, MD 20899

(301)975-2208 (VOICE) (301)926-0416 (FAX)

SRDATA@enh.nist.gov (E-MAIL) 

T $\mathrm{n}$ the field of analytical chemistry, the SRD Program provides 1 a set of comprehensive, easy-to-use databases and printed data compilations that help the analytical chemist identify unknown materials, and in many cases, once identified, avoid the need to recharacterize a substance. SRD databases cover a wide range of analytical techniques, including mass spectrometry, x-ray spectrometry, surface analysis, single crystal and electron diffraction.

In every case, the data have been fully evaluated using a variety of techniques. When appropriate, duplicate measurements have been included for completeness. All databases are updated and expanded on a regular basis. The PC version of these databases has sophisticated software that enables a search that will take only seconds of your time.

The NIST/EPA/NIH Mass Spectral Database continues to reach an ever-widening audience. Meticulously evaluated by mass spectrometry experts, all spectra have been reevaluated on an individual basis. It includes thousands of spectra of diverse compounds, such as pharmaceuticals, flavors and fragrances, and compounds of industrial and environmental interest. The new Version 4.5 is a significant enhancement of the software.

The new NIST Surface Structure Database is the only complete critical compilation of reliable surface crystallographic information now available. It brings instant access to detailed text and graphical displays of nearly 600 experimentally-determined atomic-scale structural analyses of surfaces and interfaces.

The NIST/EPA Gas-Phase Infrared Database contains FT-IR absorption spectra for over 5,200 compounds and is a combined compilation of spectra from NIST and the Environmental Protection Agency. It has the same easy-to-use software as the Mass Spectral Database.

The NIST/NIH Desktop Spectrum Analyzer Program and X-Ray Database performs rapid yet detailed generation, interpretation, and analysis of $\mathrm{x}$-ray spectra and is creating great interest in the microbeam analytical community. 


\section{Analytical Chemistry}

For information

or to order:

Phone (301) 975-2208 or FAX (301) 926-0416
SRD Analytical Chemistry Databases

Mass Spectra

NIST/EPA/NIH Mass Spectral

NIST/EPA/NIH Mass Spectral: PC Version

Infrared

NIST/EPA Gas-Phase Infrared

Surface Data

NIST X-Ray Photoelectron Spectroscopy

NIST Surface Structure

Diffraction Data

NIST/Sandia/ICDD Electron Diffraction

NIST Crystal Data

Spectrum Analysis

NIST/NIH Desktop Spectrum Analyzer Program and $\mathrm{X}$-Ray Database

\section{SRD Major Publications in Analytical Chemistry}

Crystal Data Determinative Tables (6 vols.)

Elemental and Interplanar Spacing Index 


\section{NIST/EPA/NIH Mass Spectral}

Sharon G. Lias

Mass Spectrometry Data Center

National Institute of Standards and Technology Gaithersburg, MD 20899

(301) 975-2562

sgl@micf.nist.gov

$T$ his database contains ionization mass spectra of well over 162,000 different compounds. Each spectrum has a "quality index" associated with it, the Chemical Abstracts Service (CAS) name, synonyms, the molecular weight and formula, and the CAS Registry Number. Structures are included for 97 percent of the compounds. Categories of substances identified are steroids, alkaloids, drugs, derivatives, amino acids, metals, carbohydrates, fatty acids and lipids, pesticides, and primary pollutants.

This new updated version has undergone a major data evaluation assessment program with retention of only the highest quality spectra. A new auxiliary file has been added with replicate spectra.

This database is available on diskettes in an ASCII Version and as a CD-ROM. It is widely used in the mass spectrometers of many commercial instrument manufacturers.

\section{Analytical Chemistry Databases}

For information or to order:

Phone (301) 975-2208 or FAX (301) 926-0416 


\section{Analytical Chemistry Databases}

\section{For information}

or to order:

Phone (301) 975-2208 or FAX (301) 926-0416

\section{A. NIST/EPA/NIH}

Mass Spectral Database

PC Version 4.5

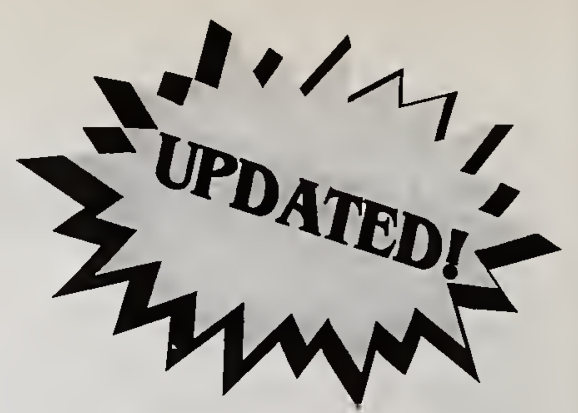

Stephen E. Stein

Mass Spectrometry Data Center

National Institute of Standards and Technology

Gaithersburg, MD 20899

(301) 975-2505

7 he first PC Version of the NIST/EPA/NIH Mass Spectral Database was released in September 1987. It was hailed at the
time as an impressive, well-designed breakthrough enabling easy searching of this important database. The new Version 4.5 consists of electron ionization mass spectra for 62,215 compounds (with structures for almost all compounds), various added index files for more rapid data retrieval, and related software for searching the database. A quickly-learned interface allows the data to be searched by:

- CAS Registry Number

- incremental chemical name (including tens of thousands of alternative names)

- molecular formula

- any peaks (up to 10 peaks of 4 classes with an intensity range for each)

- user input spectrum (choose identity, similarity, or extensive search options)

- neutral losses

- rank

Various display features are available:

- masses of major peaks

- expand scale

- autoscale

- dump to laser or dot-matrix printer

- spectrum scrolling

- difference plots

This important PC database provides a powerful tool for locating a particular spectrum or for identifying spectra of unknown compounds. It is regularly updated. It comes on both $31 / 2$ " and $51 / 4$ " high density disks and CD-ROM. 


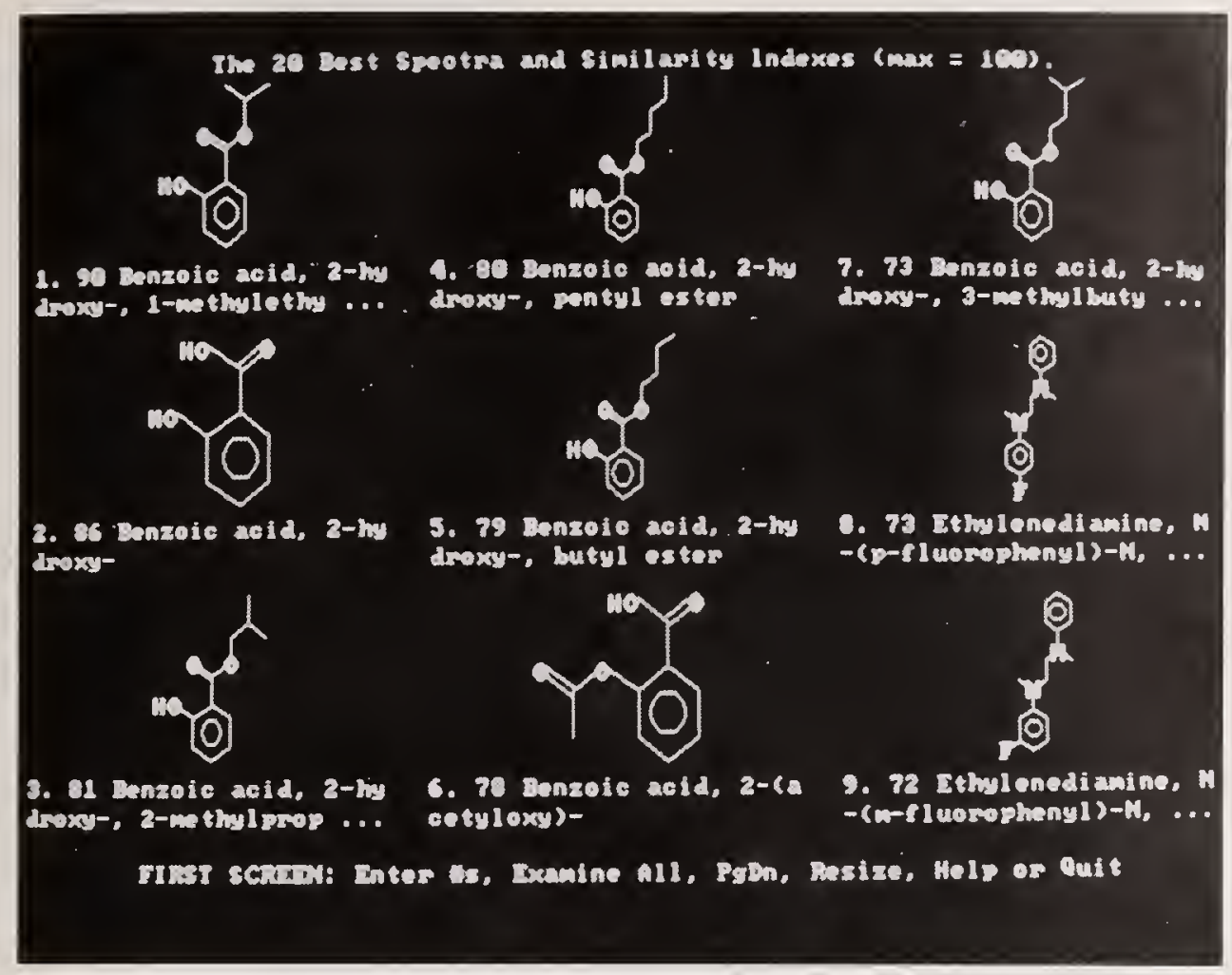

This collection consists of over 74,000 spectra of 62,215 compounds. You may also add your spectra to your personal library.

The database has spectra of diverse compounds such as pharmaceuticals, flavors, and fragrances, and compounds of industrial and environmental interest.

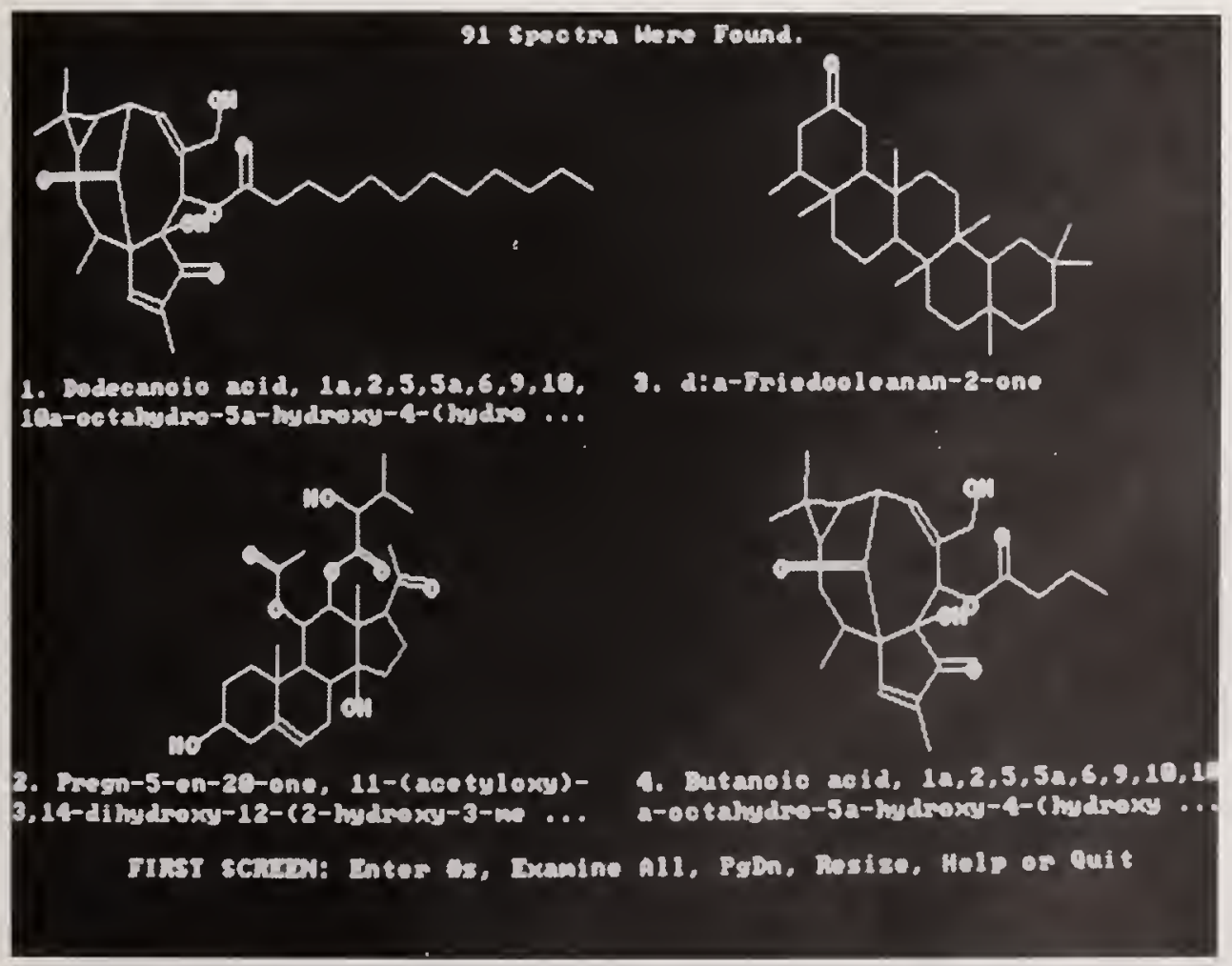

\section{Analytical Chemistry Databases}

For information or to order:

Phone (301) 975-2208 or FAX (301) 926-0416 


\section{Analytical Chemistry Databases}

For information or to order:

Phone (301) 975-2208 or FAX (301) 926-0416
36. NIST/NIH Desktop Spectrum Analyzer Program and X-Ray Database Version 2.0

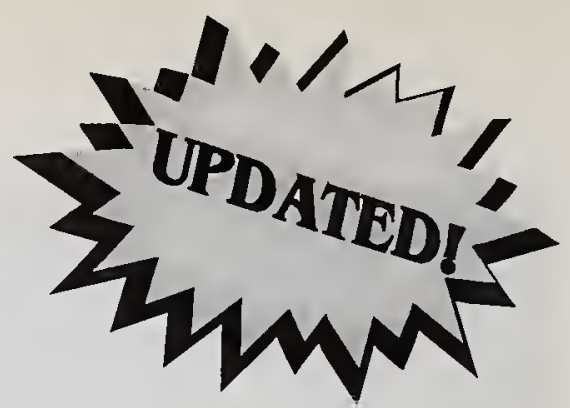

Robert L. Myklebust/Carol Swyt

Surface and Microanalysis Division

National Institute of Standards and Technology

Gaithersburg, MD 20899

(301) 975-3906/3926

myklebust@gapnet.nist.gov/swyt@micf.nist.gov

7 he NIST/NIH Desktop Spectrum Analyzer Program (DTSA)

1 generates, interprets and analyzes $\mathrm{x}$-ray spectra from specimens under electron bombardment. This remarkable software/database package simulates the experimental environment and emulates specimen properties to generate spectra reflecting the relevant physics, chemistry, and statistics of a real world application.

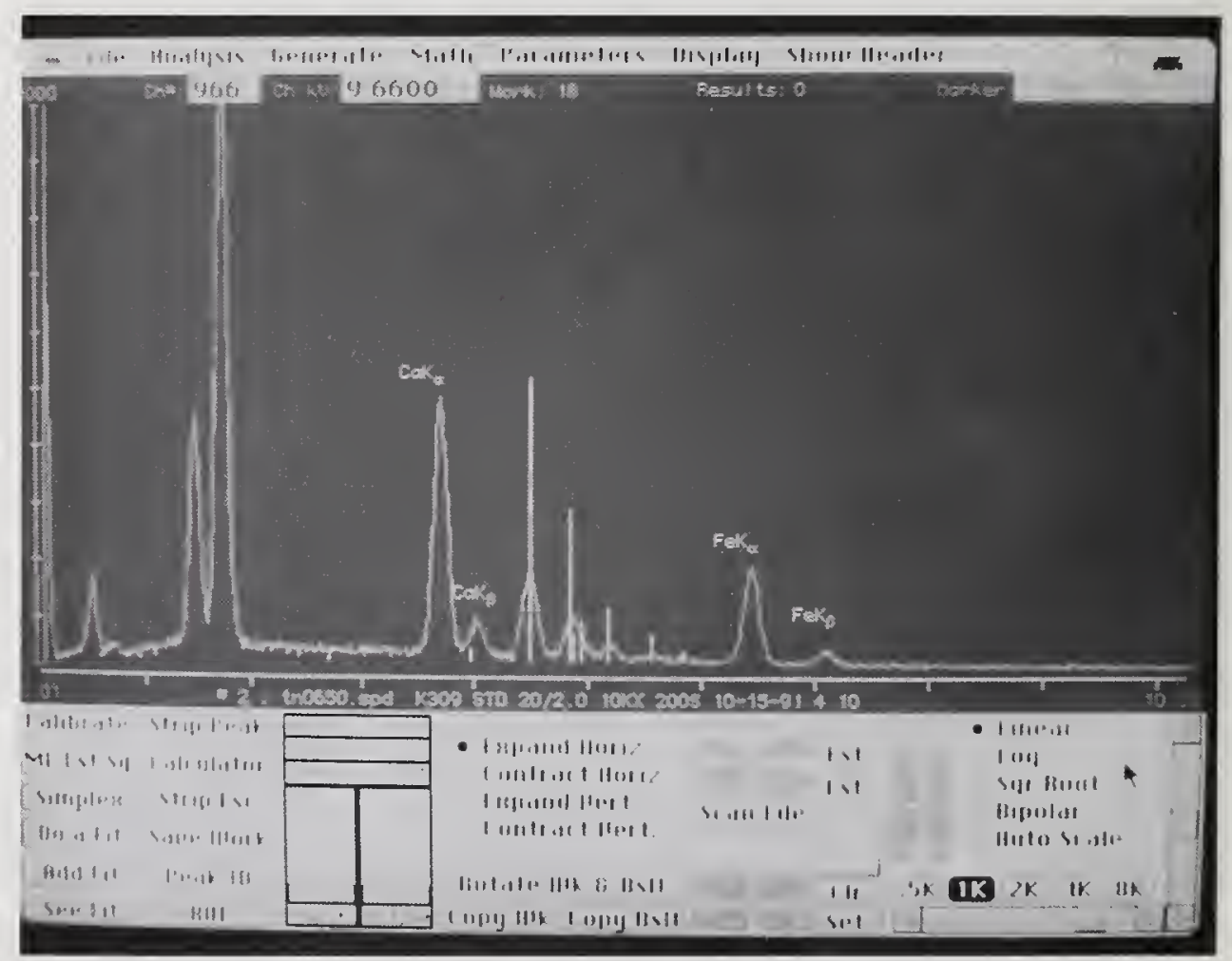

DTSA incorporates many widely accepted $x$-ray data analysis procedures developed over many years at NIST and NIH. 
Incorporating many widely accepted x-ray data analysis procedures developed over many years at the National Institute of Standards and Technology (NIST) and the National Institutes of Health (NIH), DTSA has many outstanding features:

- New quantitative analysis by CITZAF Cliff-Lorimer

- New automatic peak identification

- New automatic peak region (ROI) setup

- New user database for compositions

- Most commercial multichannel analyzer formats

- Linear and non-linear curve-fitting

- KLM markers including edges, lines, escapes, satellites

- Composition conversion calculator

- Automatic spectrum calibration

- Siegbahn peak labeling

- Graphical output to printer

- Spectral calculator containing many mathematical functions

- First principles spectrum simulation, with all relevant physics and true counting statistics

- Thick and thin specimen options

- Ten 8192 channel displays

- Accurate MDL estimates

- Outputs to text files or spreadsheets

The package works on any Macintosh computer with 5 megabytes of memory and math coprocessor.

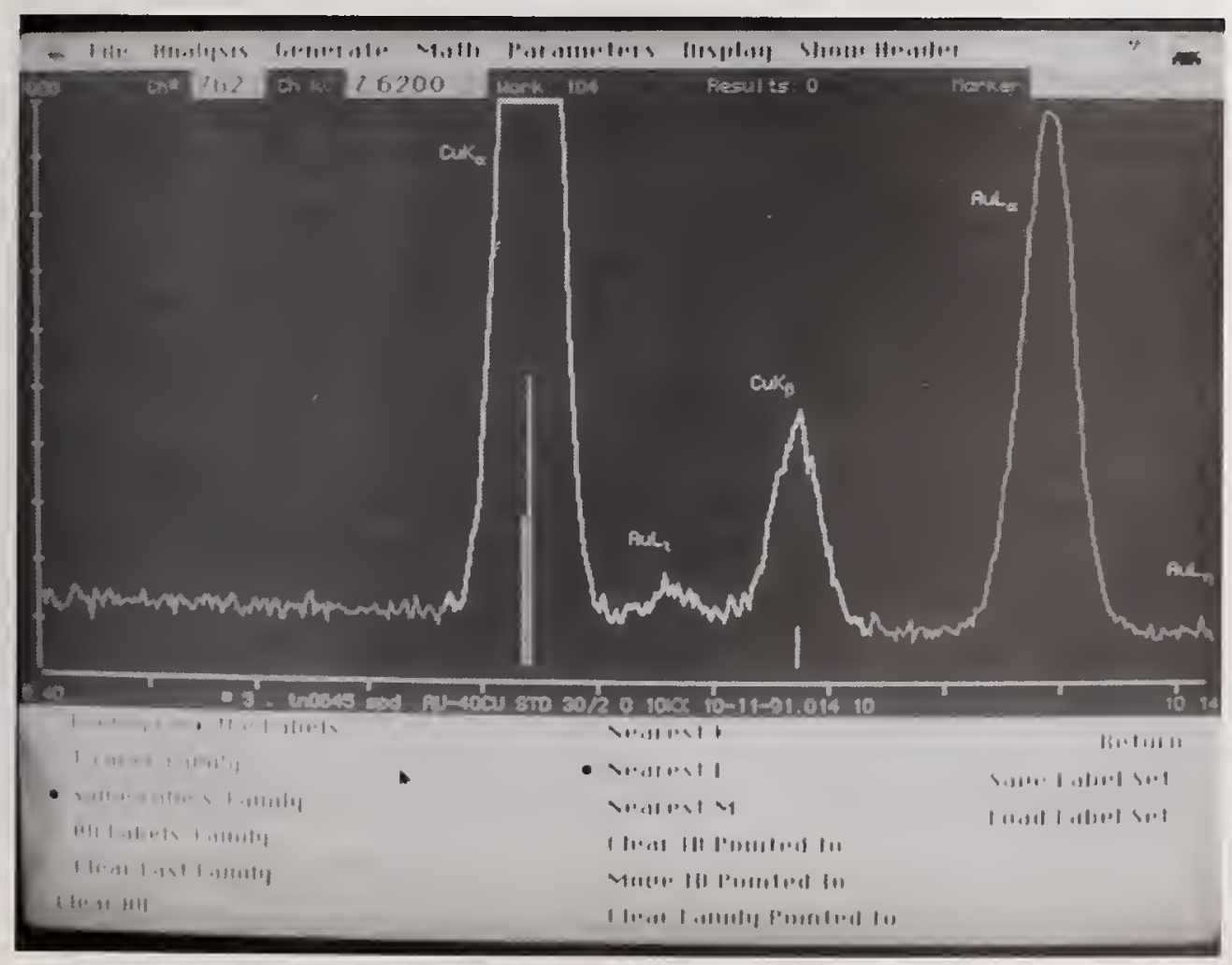

DTSA can perform a complete spectrum analysis at your desk.

\section{Analytical Chemistry Databases}

For information

or to order:

Phone (301) 975-2208 or FAX (301) 926-0416 


\section{Analytical Chemistry Databases}

For information or to order:

Phone (301) 975-2208 or FAX (301) 926-0416
42. NIST Surface Structure Database

Philip R. Watson

Department of Chemistry

Oregon State University

Corvallis, OR 97331-4003

(503) 737-2081

watsonp@ccmail.orst.edu

7 he NIST Surface Structure Database is a powerful tool to assess 1 and compare detailed atomic-scale structures of surfaces and interfaces obtained from experiments. Nearly 600 structure analyses are included, covering a wide variety of materials of scientific and technological importance. Extensive search facilities enable the user to locate desired structures rapidly.

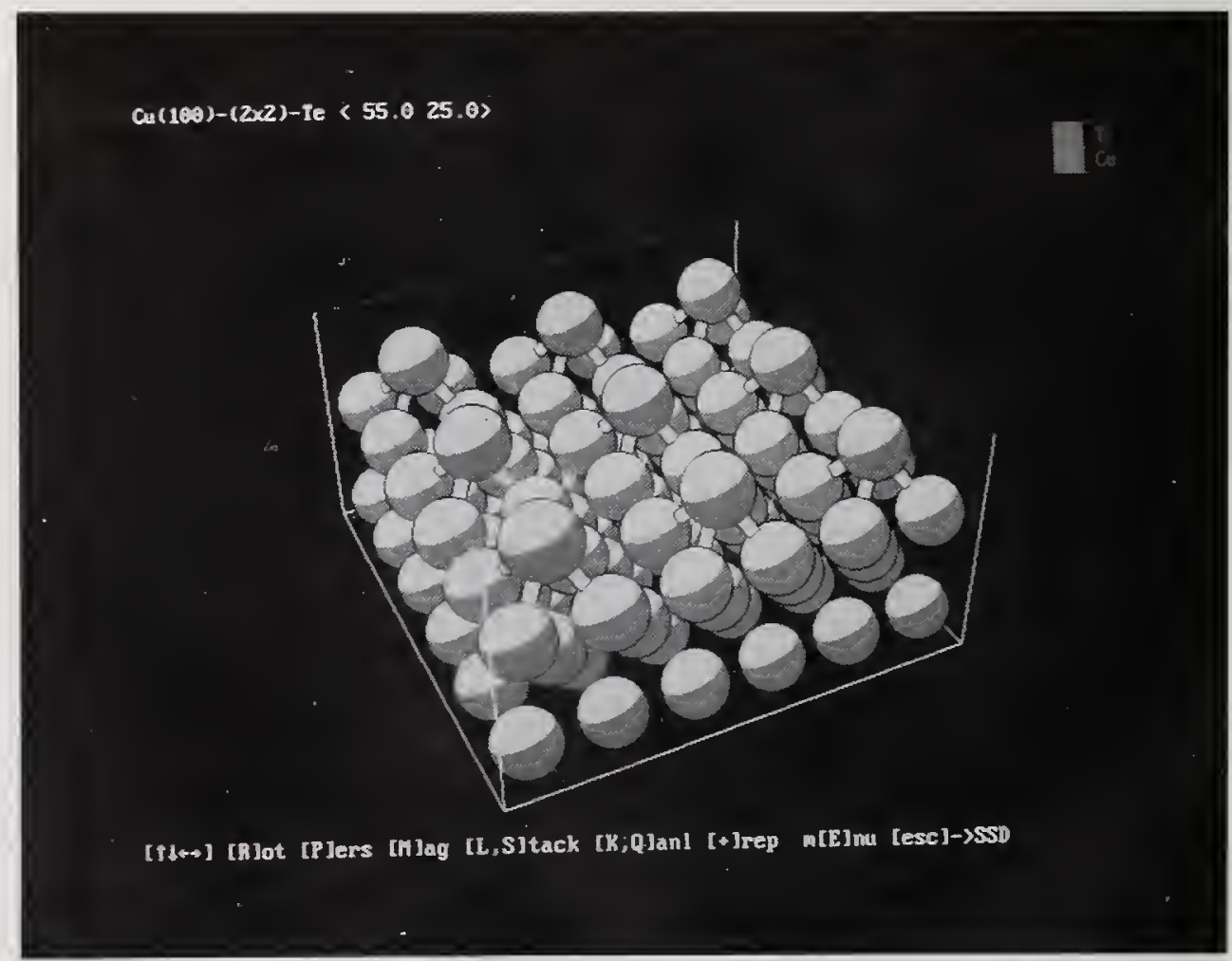

The powerful graphics of SSD allow detailed assessment of atomic scale structures of surfaces. 
Data:

- 597 structure analyses of over 300 different structures - verbal structure description

- atomic coordinates

- bond lengths and bond angles

- 2-dimensional unit cells

- experimental preparation

- experimental technique(s)

- theoretical analysis method(s)

- data through 1991

Search By:

- chemical element(s) in substrate or adsorbate

- crystallographic face of substrate

- substrate lattice

- surface superlattice

- substrate or overlayer space-group symmetry

- experimental technique

- author(s)

- journal

- year of publication

The data output includes printout of any numerical and textual data and on-screen 3-D visualization of surface structures. The software enables interactive evaluation of structural relationships. The database is available in $3 \frac{1 / 2}{2}$ and $51 / 4 "$ disks.

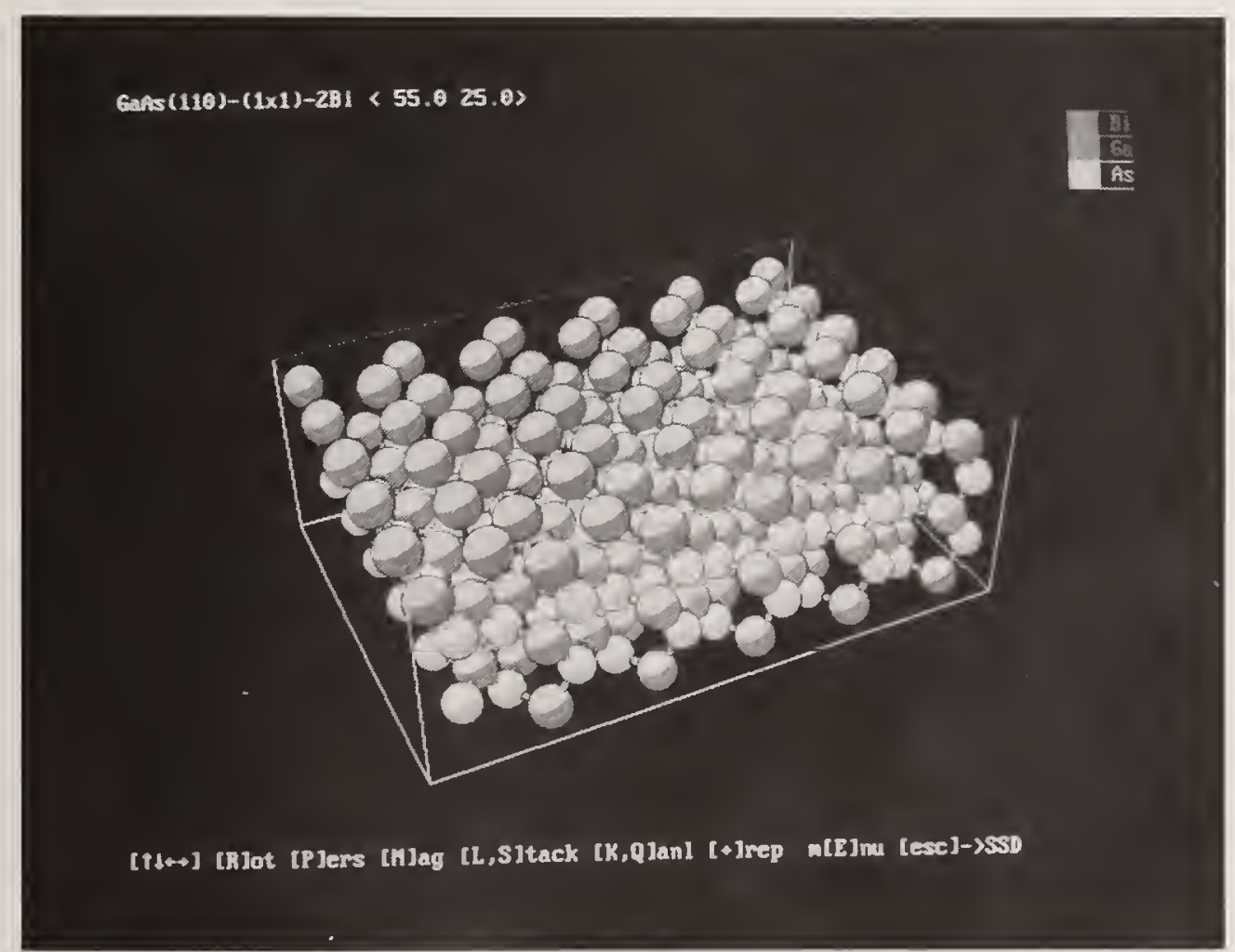

The data output includes printout of any numerical and textual data and on-screen 3-D visualization.

\section{Analytical Chemistry Databases}

\author{
For information \\ or to order:
}

Phone (301) 975-2208 or FAX (301) 926-0416 


\section{Analytical Chemistry Databases}

\section{NIST Crystal Data}

\section{Alan D. Mighell \\ Crystal Data and Electron \\ Diffraction Data Center \\ National Institute of Standards and Technology \\ Gaithersburg, MD 20899 \\ (301) 975-6255 \\ mighela@tiber.nist.gov}

$N$ IST Crystal Data contains chemical, physical, and $N$ crystallographic information useful to characterize more than 182,500 inorganic and organic crystalline materials. The data include the standard cell parameters, cell volume, space group number and symbol, the calculated density, and classification by chemical type, chemical formula, and chemical name. Each entry has an associated literature reference.

The database can be utilized as a practical analytical tool for compound identification because the lattice/formula combination uniquely characterizes a crystalline phase. The database is useful in conjunction with other data for materials design and properties prediction.

The file includes reliable data across the entire range of solid state materials including inorganics, organics, minerals, intermetallics, metals, alloys, drugs, antibiotics, and pesticides. Comprehensive chemical, crystallographic, and identification search software is provided with the database.

The database is available in magnetic tape and CD-ROM formats. In addition, it may be searched interactively via the Canada Institute for Scientific and Technical Information (CISTI's) online international service. For further information, please contact International Centre for Diffraction Data, Newtown Square Corporate Campus, 12 Campus Blvd., Newtown Square, PA 19073-3273. Phone (215) 325-9810.
For information

or to order:

Phone (301) 975-2208 or FAX (301) 926-0416 


\section{NIST/Sandia/ICDD Electron Diffraction Database}

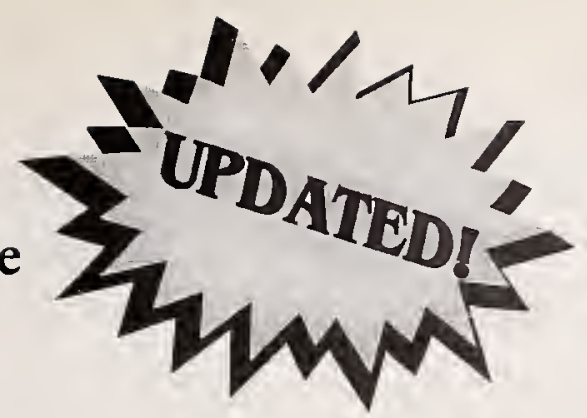

\section{Alan D. Mighell \\ Crystal Data and Electron Diffraction Data Center National Institute of Standards and Technology Gaithersburg, MD 20899 \\ (301) 975-6255 \\ mighela@tiber.nist.gov}

\section{Designed for phase characterization obtained by electron diffraction methods, this database and associated software} permit highly selective identification procedures for microscopic, as well as macroscopic, crystalline materials. The database contains chemical, physical, and crystallographic information on a wide variety of materials (over 81,534 ) including minerals, metals, intermetallics, and general inorganic compounds.

The Electron Diffraction Database has been designed to include all the data required to identify materials using computerized dspacing/formula matching techniques. The data for each entry include the conventional cell, reduced cell, lattice type, space group, calculated or observed d-spacings, chemical name, chemical and empirical formula, material class indicators, references, and other parameters.

This database and search software are available in magnetic tape format and in CD-ROM format. For further information, please contact International Centre for Diffraction Data, Newtown Square Corporate Campus, 12 Campus Blvd., Newtown Square, PA 19073-3273. Phone: (215) 325-9810.

\section{Analytical Chemistry Databases}

For information

or to order:

Phone (301) 975-2208

or FAX (301) 926-0416 


\section{Analytical Chemistry Databases}

For information or to order:

Phone (301) 975-2208 or FAX (301) 926-0416
20. NIST X-Ray Photoelectron

Spectroscopy Database

Version 1.0

Cedric Powell

Surface Data Center

National Institute of Standards and Technology

Gaithersburg, MD 20899

(301) 975-2534

cpowell@enh.nist.gov

$\chi$ PS gives easy access to photoelectron and Auger spectral data. $\triangle$ Resulting from a critical evaluation of the published literature through 1985, the database contains over 13,000 line positions, chemical shifts, and splittings. A highly interactive program allows the user to search by element, line type, line energy, and many other variables. Users can easily identify unknown measured lines by matching to all previous measurements.

Each record on the database contains: element and chemical compound, including names and formula; line type (photoelectron, Auger, Auger parameter, chemical shift, doublet splitting, other splittings); line energy or energy difference; experimental details such as calibration, charge reference, and physical state; and reference citation.

The database is available on both $3^{1 / 2}$ " and $5^{1 / 4}$ " disks. It may also be used on Macintosh computers with PC emulator software. 
35. NIST/EPA Gas-Phase

Infrared Database

\section{Stephen E. Stein}

Mass Spectrometry Data Center

National Institute of Standards and Technology Gaithersburg, MD 20899

(301) 975-2505

ontaining FT-IR absorption spectra for over 5,200 compounds,

$\checkmark$ this significant database represents a combined compilation of the National Institute of Standards and Technology and the Environmental Protection Agency. The spectra have been meticulously evaluated and low-quality spectra eliminated. This database has a modern intuitive user interface - built from the widely-used NIST/EPA/NIH Mass Spectral Database software.

Search Options:

- up to 10 absorption maxima (wavelength and intensity)

- chemical name

- empirical formula

Additional Search Constraints:

- name fragment

- molecular weight

- elemental composition

- presence in other specialized databases

More Features:

- directly compare up to 4 spectra

- read external FT-IR files for comparison plots

- context sensitive help

This database is available in $31 / 2$ " and $51 / 4$ " disks. A flat file of the infrared data in JCAMP format is also available.

\section{Analytical Chemistry Databases}

For information or to order:

Phone (301) 975-2208 or FAX (301) 926-0416 


\section{Analytical \\ Chemistry \\ Publications}

For information

or to order:

Phone (301) 975-2208 or FAX (301) 926-0416
Crystal Data

Determinative Tables, Third Edition, 6 vols.

International Centre for Diffraction Data, Newtown Square, PA.

\section{Elemental and} Interplanar Spacing Index

International Centre for Diffraction Data, Newtown Square, PA.
The NIST Crystal Data

Determinative Tables are the largest collection of crystallographic data available. These volumes contain data on over 43,000 organic and organometallic compounds, as well as 27,000 inorganic, metallic, and mineral compounds. Produced and edited by the NIST Crystal Data Center, these reference books are well-indexed by crystallographic system and determinative number. The data for each entry are comprehensive and include cell dimensions, space group or diffraction aspect, measured and calculated density, name, and literature reference.

Available from the International Centre for Diffraction Data, Newtown Square, PA (215) 325-9810, $\$ 370.00$ (set price, individual volumes available).

The Elemental and Interplanar Spacing Index (EISI) is designed to be used independently or in conjunction with a computer database for phase characterization using electron or $\mathrm{x}$-ray diffraction. The EISI Index is arranged to enable the diffractionist to readily identify a material with the chemical and diffraction data routinely collected on most modern analytical electron microscopes.

Available from the International Centre for Diffraction Data, Newtown Square, PA.

(215) 325-9810, $\$ 250.00$ (set price). 
$T$ he Standard Reference Data Program has worked together with 1 the world-famous NIST Atomic Physics Program to produce the most comprehensive set of reliable atomic data available anywhere. The NIST collection of atomic energy levels, transition probabilities, and collision data is widely used by groups for characterizing and modeling all types of gaseous systems, including plasmas, planetary atmospheres, and astrophysical media, and for health physics applications. Databases and publications make these data easy to find and easy to use. The SRD Program has also produced several important compilations of molecular data.

NIST Spectroscopic Properties of Atoms and Atomic Ions has reached a wide audience in the past year. This database provides easy access to prominent emission wavelengths for all neutral atoms and their first four stages of ionization. The new Wavenumber Calibration Tables Database contains the most accurate atlas available for the calibration of infrared spectrometers. Also, SRD proudly announces the release of the NIST Spectroscopic Properties of Diatomic Molecules Database.

\section{SRD Atomic and Molecular Physics Databases}

NIST Spectroscopic Properties of Atoms and Atomic Ions NIST Wavenumber Calibration Tables

NIST Electron and Positron Stopping Powers of Materials NIST X-Ray and Gamma-Ray Attenuation Coefficients and Cross Sections

NIST Atomic Transition Probabilities Data Files (Scandium through Nickel)

NIST Spectroscopic Properties of Diatomic Molecules

NIST Vibrational and Electronic Energy Levels of Small

Polyatomic Transient Molecules

\section{SRD Major Publications in Atomic and Molecular Physics}

1986 CODATA Recommended Values of the Fundamental Physical Constants

Atomic Transition Probabilities Publications

Atomic Energy Levels Publications

Tables of Spectra of Hydrogen, Carbon, Nitrogen and Oxygen Atoms and Ions 


\section{Atomic and Molecular Physics Databases}

For information or to order:

Phone (301) 975-2208 or FAX (301) 926-0416
38. NIST Spectroscopic Properties of Atoms and Atomic Ions Database

Jean W. Gallagher

Standard Reference Data

National Institute of Standards and Technology

Gaithersburg, MD 20899

(301) 975-2204

jwg@enh.nist.gov

$D$ roviding easy access to prominent emission wavelengths for all $P$ neutral atoms and their first four stages of ionization, the data in this interactive database originally appeared in the well-known and widely-used NSRDS-NBS 68 - Wavelengths and Transition Probabilities for Atoms and Atomic Ions. Part I. Wavelengths.

Atomic masses, ground-state configurations, and terms and ionization potentials for the neutrals and ions are also included. For stable isotopes, abundances, nuclear spins, and dipole and quadrupole moments are also given. Wavelength line lists for individual elements may be written to external files.

This database is available on both $3 \frac{1 / 2}{2}$ and $51 / 4$ " disks. It may also be used on Macintosh computers with PC emulator software. 


\section{NIST Wavenumber Calibration Tables Database}

Jean W. Gallagher

Standard Reference Data

National Institute of Standards and Technology Gaithersburg, MD 20899

(301) 975-2204

jwg@enh.nist.gov

$T$ he information in this diskette package is a supplement to NIST 1 Special Publication 821 - Wavenumber Calibration Tables from Heterodyne Frequency Measurements. This publication contains the most accurate atlas to date for the calibration of infrared spectrometers. Accuracy has been increased because data are based on frequency rather than wavelength measurement techniques for absolute references. The best Fourier transform measurements available were used for different frequency measurements. A description of the heterodyne frequency measurement techniques, details of the analysis including the Hamiltonians and least-squaresfitting and calculation procedures are also given. Intensities and lineshape parameters are included.

The primary calibration molecules are the linear triatomics, carbonyl sulfide (OCS) and nitrous oxide $\left(\mathrm{N}_{2} \mathrm{O}\right)$, which cover portions of the infrared spectrum ranging from 488 to $3120 \mathrm{~cm}^{-1}$. Some gaps in the coverage afforded by OCS and $\mathrm{N}_{2} \mathrm{O}$ are partially covered by $\mathrm{NO}$, $\mathrm{CO}$, and $\mathrm{CS}_{2}$. An additional region from 4000 to $4400 \mathrm{~cm}^{-1}$ based on $\mathrm{CO}$ is also included.

Statistically determined and documented uncertainties for the listed transitions are given as well as a discussion of the intensity calculations and pressure shifts and a bibliography of frequency and intensity measurements.

The data files are available on $3 \frac{1}{2}$ " and $51 \frac{1}{4}$ " disks. They may also be used on Macintosh computers with PC emulator software.

\section{Atomic and \\ Molecular \\ Physics \\ Databases}

For information or to order:

Phone (301) 975-2208 or FAX (301) 926-0416 


\section{Atomic and \\ Molecular \\ Physics \\ Databases}

For information

or to order:

Phone (301) 975-2208

or FAX (301) 926-0416

7. NIST Electron and Positron Stopping Powers of Materials Database

Stephen M. Seltzer

Photon and Charged Particle Data Center

National Institute of Standards and Technology

Gaithersburg, MD 20899

(301) 975-5552

seltzer@enh.nist.gov

$F$ PSTAR provides rapid calculations of stopping powers

$\mathcal{H}$ (collisional, radiative, and total), CSDA ranges, radiation yields and density effect corrections for incident electrons or positrons with kinetic energies from $1 \mathrm{keV}$ to $10 \mathrm{GeV}$, and for any chemically defined target material. The interactive database allows the user to specify an incident particle, an energy range, the target material and density, and for a gas, temperature and pressure. Clear instructions make the calculations easy to perform. Results can be saved to an external file for future use.

The database is available in PC diskette format. 


\section{NIST X-Ray and Gamma-Ray Attenuation Coefficients and Cross Sections Database}

\section{Stephen M. Seltzer \\ Photon and Charged Particle Data Center \\ National Institute of Standards and Technology Gaithersburg, MD 20899 \\ (301) 975-5552 \\ seltzer@enh.nist.gov}

$T$ his database (called XGAM) provides photon cross sections 1 (interaction coefficients) and attenuation coefficients for any substance. An interactive database enables the user to obtain data by entering chemical formulas or other defining composition for a mixture of component materials. The user may also select the energy range over which data are desired.

The system operates from a database of cross sections for coherent and incoherent scattering, photoionization, and pair production for the elements $Z=1$ to 100 at energies from $1 \mathrm{keV}$ to $100 \mathrm{GeV}$. These data were obtained by a critical data analysis combining theoretical and experimental results. The user may request data to be tabulated at the fixed energies stored in the database and or at an arbitrary set of user-specified energies, or at a combination of both. The tabulated results include the individual contributions and the total mass attenuation coefficient, both with and without coherent scattering.

This database is available in PC diskette format.

\section{Atomic and Molecular Physics Databases}

For information or to order:

Phone (301) 975-2208 or FAX (301) 926-0416 


\section{Atomic and \\ Molecular Physics \\ Databases}

\section{NIST Atomic Transition Probabilities Data Files (Scandium through Nickel)}

\author{
Jeffrey Fuhr \\ Atomic Transition Probabilities Data Center \\ National Institute of Standards and Technology \\ Gaithersburg, MD 20899 \\ (301) 975-3204 \\ fuhr@tiber.nist.gov
}

$T$ his diskette package provides computer access to the numerical 1 data given in Atomic Transition Probabilities, Scandium through Manganese and Atomic Transition Probabilities, Iron through Nickel, which were published as Supplements 3 and 4 to Volume 17 (1988) of the Journal of Physical and Chemical Reference Data. The diskettes contain two types of files: the numeric files containing the transition probabilities and related data and the bibliographic files of references pertaining to the numeric tables. There are separate numeric and bibliographic files for each of the eight elements from scandium through nickel. Within each element, the data files are ordered by the ionization stage. The numeric data files are suitable for direct use in modeling programs.

The data files are available on $3 \frac{1 / 2}{1}$ and $5 \frac{1}{4} 4^{\prime \prime}$ disks. It may also be used on Macintosh computers which have a PC emulator program.
For information

or to order:

Phone (301) 975-2208 or FAX (301) 926-0416 


\section{NIST Spectroscopic} Properties of Diatomic Molecules Database



Jean W. Gallagher

Standard Reference Data

National Institute of Standards and Technology Gaithersburg, MD 20899

(301) 975-2204

jwg@enh.nist.gov

$B$ ased on the classic volume Constants of Diatomic Molecules by B $\mathrm{K}$. Huber and G. Herzberg (Van Nostrand Reinhold Co., Publishers), this database provides spectroscopic parameters for approximately 700 diatomic molecules and ions, including complete footnotes discussing measurement techniques and evaluation procedures. References to original sources and an updated bibliography of related publications through 1994 are included.

The database may be searched by:
- molecule
- initial state
- final state
- band system names
- wavelength/energy

This database is available on $3 \frac{1 / 2}{2}$ and $51 / 4$ " disks.

\section{Atomic and Molecular Physics \\ Databases}

For information

or to order:

Phone (301) 975-2208 or FAX (301) 926-0416 


\section{Atomic and Molecular Physics Databases}

\section{NIST Vibrational and Electronic Energy Levels of Small Polyatomic Transient Molecules Database Version 3.0}

Marilyn E. Jacox

National Institute of Standards and Technology Gaithersburg, MD 20899

(301) 975-2547 jacoxm@tiber.nist.gov

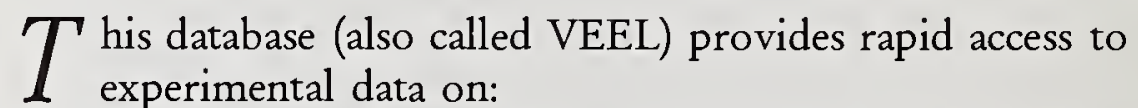
- the ground-state vibrational fundamentals of transient molecules with from 3 to 16 atoms

- the electronic energy levels of excited-state vibrational fundamentals of transient molecules with from 3 to 6 atoms and of selected transient molecules with from 7 to 16 atoms.

Version 3.0 represents a $15 \%$ increase in data; 1,569 molecules are now included. In addition, data for the fully deuterium-substituted counterparts of these molecules are included, where available.

The database can be searched by:

- molecule

- wavenumber

- wavelength range in which an electronic transition appears

Searches may be restricted to:

- molecules containing a specified chemical element

- the ground or excited state

- observations in the gas phase or a specified inert solid matrix

- data obtained using a specific technique

Searching speed has also been significantly increased in Version 3.0. All literature references from the published tables are included in the database. This database is available on both $3 \frac{1 / 2}{}$ " and $51 / 4$ " disks. It may also be used on Macintosh computers with PC emulator software.
For information

or to order:

Phone (301) 975-2208 or FAX (301) 926-0416 
The 1986 CODATA Recommended Values of the Fundamental Physical Constants

E. Richard Cohen and Barry N. Taylor. Journal of Physical and Chemical Reference Data 17, 1795 (1988).

Atomic Energy Levels of the Iron-Period Elements: Potassium through Nickel J. Sugar and C. Corliss. Journal of Physical and Chemical Reference Data 14, Supplement 2 (1985).

This supplement is a compilation of atomic energy levels of the iron-period elements, potassium through nickel, in all stages of ionization. The result of a critical evaluation of all literature published through 1985 , it gives for each energy level the position relative to the ground state, configuration term designation, J-value, and, where available, the g-value and the two leading percentages of the eigenvector
This article presents values of the basic constants and conversion factors of physics and chemistry resulting from the 1986 leastsquares adjustment of the fundamental physical constants as recommended for international use by the CODATA (Committee on Data for Science and Technology) Task Group on Fundamental Constants. The 1986 CODATA set of values replaces the 1973 set also developed by CODATA. Available from the American Chemical Society, JPCRD

Reprint 354, \$10.00

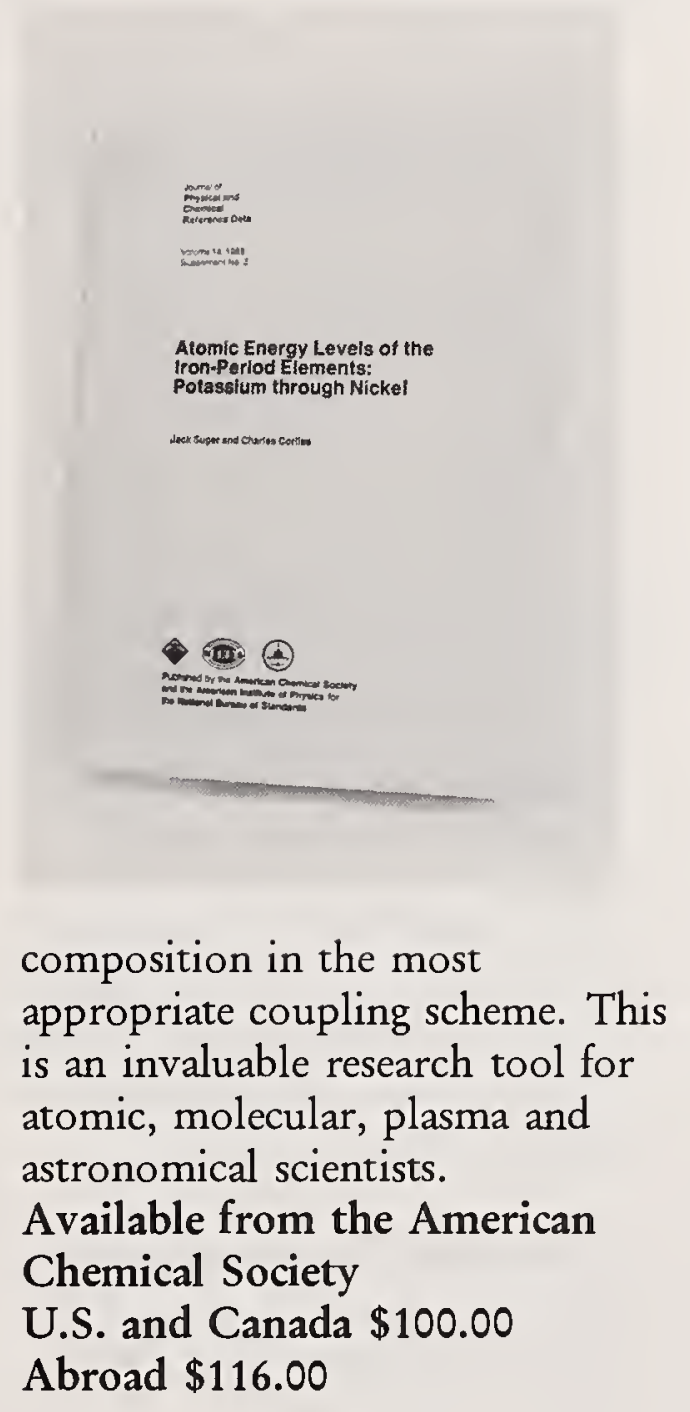

\section{Atomic and Molecular Physics Publications}

For information or to order:

Phone (301) 975-2208 or FAX (301) 926-0416 


\section{Atomic and Molecular Physics Publications}

For information

or to order:

Phone (301) 975-2208 or FAX (301) 926-0416
Atomic Transition Probabilities, Scandium through Manganese G.A. Martin, J.R. Fuhr, and W.L. Wiese. Journal of Physical and Chemical Reference Data 17, Supplement 3 (1988).

\section{Atomic Transition Probabilities, Iron through Nickel J.R. Fuhr, G.A. Martin, and W.L. Wiese. Journal of Physical and Chemical Reference Data 17, Supplement 4 (1988).}

These two supplements to the Journal of Physical and Chemical Reference Data contain almost 18,000 atomic transition probabilities. With over 1,000 pages of tables and critical discussion, it is the first and most comprehensive reference source for the transition probabilities of the eight transition metals, scandium through nickel. The data in these two volumes are presented by element and spectrum. Finding lists are provided to facilitate transition location. The tables include spectroscopic classification, wavelengths of the transitions, the upper and lower energy levels, and their statistical weights. For each line an uncertainty estimate, the result of careful, critical evaluation, is given.

Both available from the American Chemical Society U.S. and Canada $\$ 130.00$ each Abroad \$156.00 each 
Atomic Weights of the Elements 1989

J.R. de Laeter and

K.G. Heumann.

Journal of Physical and

Chemical Reference Data 20, 1313 (1991).

\section{Spectral Data and}

Grotrian Diagrams for Highly Ionized

Cobalt, Co VIII through Co XXVII

Toshizo Shirai, Alberto Mengoni,

Yohta Nakai, Jack Sugar, Wolfgang L. Wiese,

Kazuo Mori, and H. Sakai.

Journal of Physical and

Chemical Reference Data 21, 23 (1991).

\section{Spectral Data and \\ Grotrian Diagrams for Highly Ionized Vanadium, V VI through V XXIII \\ Toshizo Shirai, \\ Toshiaki Nakagaki, Jack Sugar, and Wolfgang L. Wiese. Journal of Physical and Chemical Reference Data 21, 273 (1992).}

The Commission on Atomic Weights and Isotopic Abundances monitored the literature over the past 2 years and evaluated the published data on atomic weights and isotopic compositions on an element-by-element basis.

Available from the American Chemical Society, JPCRD

Reprint 429, $\$ 10.00$

Recommended wavelengths, energy levels, and transition probabilities for highly ionized cobalt ions are tabulated. Grotrian diagrams are also presented to give an overview of the spectra.

Available from the American Chemical Society, JPCRD

Reprint 433, \$22.00

Recommended wavelengths, energy levels, and transition probabilities for highly ionized vanadium ions are tabulated. Grotrian diagrams are also presented to give an overview of the spectra.

Available from the American

Chemical Society, JPCRD

Reprint 437, \$24.00

\section{Atomic and Molecular Physics Publications}

For information or to order:

Phone (301) 975-2208 or FAX (301) 926-0416 


\section{Atomic and \\ Molecular \\ Physics \\ Publications}

Wavelengths and

Energy Level

Classifications for the Spectra of Sulfur

(S I through S XVI)

Victor Kaufman and

W. C. Martin.

Journal of Physical and

Chemical Reference Data 22, 279 (1993).

\section{Tables of Spectra of} Hydrogen, Carbon, Nitrogen, and Oxygen

Atoms and Ions

Charlotte E. Moore, edited by Jean W. Gallagher CRC Press, Boca Raton, Florida

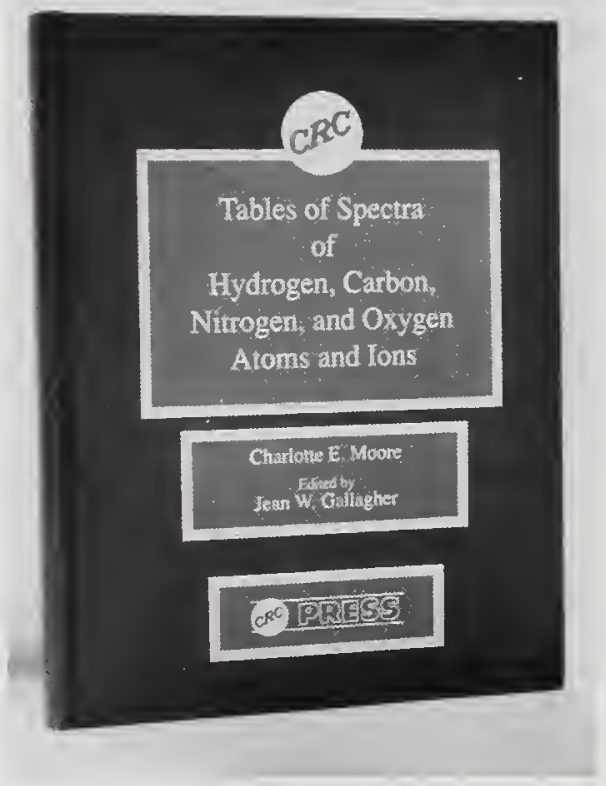

Wavelengths and their classifications have been compiled for the spectra of the atom and all positive ions of sulfur $(Z=16)$. Wavelengths calculated from the differences of the energy levels are given along with the observed values for all classified lines. Calculated wavelengths are also given for a number of lines that have not yet been observed, including some important forbidden transitions.

Available from the American Chemical Society, JPCRD Reprint 450, $\$ 22.00$

These highly regarded tables have been a fundamental reference of the astronomical, atomic physics, chemistry and plasma physics communities for over twenty years. This single, easy-to-use volume combines Moore's revised energy levels and multiplet tables for all spectra of hydrogen, carbon, nitrogen, and oxygen into one convenient source.

Available from CRC Press, Boca Raton, FL (800) 272-7737, $\$ 95.00$
For information or to order:

Phone (301) 975-2208 or FAX (301) 926-0416 
Vibrational and Electronic Energy Levels of Polyatomic Transient Molecules Marilyn E. Jacox. Journal of Physical and Chemical Reference Data Monograph 3 (in press).
A critical evaluation and summary of the experimentally determined vibrational fundamentals and electronic band origins of more than 1550 neutral and ionic transient molecules possessing from three to sixteen atoms is presented. Data are included for species containing the heavy elements. Radiative lifetimes and the principal rotational constants are included. Observations in the gasphase, in molecular beams, and in rare-gas and nitrogen matrices are evaluated.

Available from the American Chemical Society, JPCRD Monograph 3 (in press).

\section{Microwave Spectral Tables III. Hydrocarbons, $\mathrm{CH}$ to $\mathrm{C}_{10} \mathbf{H}_{10}$}

F.J. Lovas and R.D. Suenram. Journal of Physical and Chemical Reference Data 18, 1245 (1989).

All of the rotational spectral lines observed and reported in the open literature for 91 hydrocarbon molecules have been tabulated. The isotopic molecular species, assigned quantum numbers, observed frequency, estimated measurement uncertainty, and references are given for each transition reported.

\section{Atomic and Molecular Physics Publications} The derived molecular properties, such as rotational and centrifugal distortion constants, hyperfine structure constants, electric dipole moments, and rotational g-factors are listed.

Available from the American Chemical Society, JPCRD

Reprint 369, $\$ 44.00$
For information or to order:

Phone (301) 975-2208 or FAX (301) 926-0416 


\section{Atomic and Molecular Physics Publications}

Recommended Rest Frequencies for Observed Interstellar Molecular Microwave Transitions - 1991 Revision

Frank J. Lovas.

Journal of Physical and Chemical Reference Data 21, 181 (1992).
Observation of molecular microwave transitions in interstellar clouds have been critically reviewed and transition frequencies compiled. A complete list of recommended rest frequencies for all transitions is presented. Other information on the transitions, as well as full references is included.

Available from the American

Chemical Society, JPCRD

Reprint 436, $\$ 20.00$

For information or to order: 
tandard Reference Data has developed new databases for the $\int$ burgeoning new biotechnology field. These are providing valuable research tools for biochemists. A significant new upgrade to the NIST/NASA/CARB Biological Macromolecule Crystallization Database is available this year. The new Lipid Thermotropic Phase Transitions Database provides a convenient source of an increasingly important group of molecules.

\section{SRD Biotechnology Databases}

NIST/NASA/CARB Biological Macromolecule Crystallization Lipid Thermotropic Phase Transitions 
Biotechnology Databases
For information

or to order:

Phone (301) 975-2208 or FAX (301) 926-0416
21. NIST/NASA/CARB Biological Macromolecule Crystallization Database Version 3.0

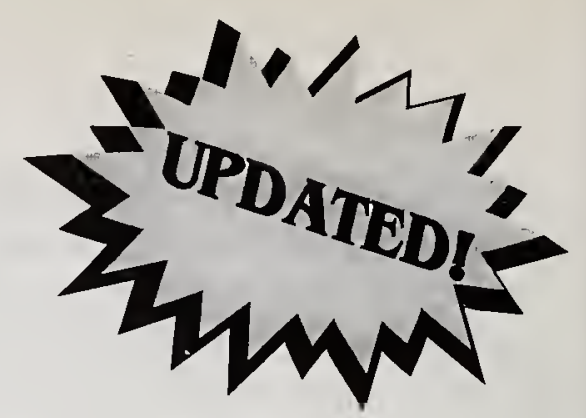

Gary L. Gilliland/Jane E. Ladner

Center for Advanced Research in Biotechnology

National Institute of Standards and Technology

9600 Gudelsky Drive

Rockville, MD 20850

(301) 738-6272

gary@iris8.carb.nist.gov

7 he database contains crystal data and the crystallization 1 conditions of over 2,100 crystal forms of more than 1,400 biological macromolecules. The data have been extracted from the scientific literature through 1993.

This system provides a fast and convenient method of searching the crystallization data for any of the parameters listed below:

\section{Macromolecule}

1. Macromolecule name

2. Biological source

3. Molecular weight

4. Subunit composition

5. Prosthetic group

6. Multiple crystal forms

Crystal Data

7. Space group

8. Unit cell dimension

9. $\mathrm{Z}$

10. Crystal density

\section{Crystallization Conditions}

11. Crystallization method

12. Macromolecule concentration

13. Temperature of crystallization

14. $\mathrm{pH}$ of crystallization

15. Crystal growth time

16. Chemical additions to crystallization solution

\section{Reference}

17. Author

18. Year reported

19. Journal

20. Database cross reference
The system provides a convenient method for verifying whether or not a particular biological macromolecule has been crystallized and, if so, provides the details for reproducing the crystallization procedure. Multiparameter searches can be done easily. The search results can be displayed, printed or spooled to a file in a number of different formats.

This database is available on $3 \frac{1 / 2}{2}$ and $51 / 4$ " disks. It may also be used on Macintosh computers with PC emulator software. 


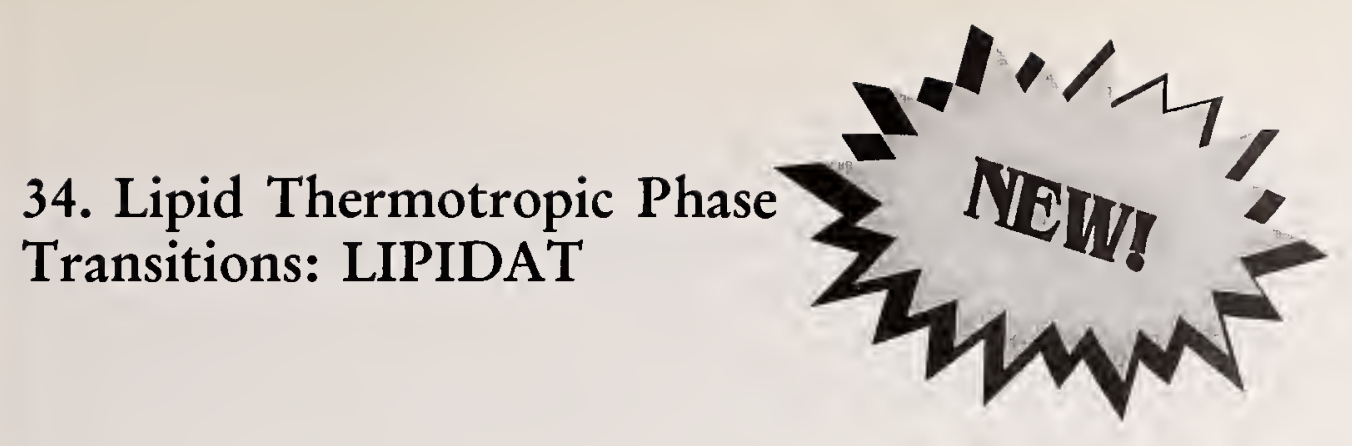

Martin Caffrey

Chemistry Department

The Ohio State University

Columbus, OH 43210-1063

(614) 292-8437

IPIDAT is a convenient, sophisticated, and centralized source of $L$ data on one of the most diverse and important groups of molecules which is currently the subject of intensive research. This database provides thermodynamic data on complex polar lipids.

LIPIDAT contains:

- thermodynamic data on over 900 lipids - enthalpies and transition temperatures

- complete literature referencing and list of authors through June 1990

- data for partially- and fully-hydrated lipids

- data on the effects of various other additives, such as proteins, drugs, etc.

- complete user manual

- over 10,000 records

This database is available on $3 \frac{1 / 2}{2}$ and $51 / 4$ " disks. It may also be used on Macintosh computers with PC emulator software.

\section{Biotechnology Databases}

For information

or to order:

Phone (301) 975-2208 or FAX (301) 926-0416 

$T$ he NIST Program on Chemical Kinetics has long been a source 1 of reliable, critically evaluated data on gas-phase reactions. Over the years, data provided by the program have been instrumental in modeling and predicting many important scientific systems such as combustion chemistry, atmospheric changes related to ozone depletion and warming, plasmas, and free-radical chemistry.

The best-selling NIST Chemical Kinetics Database is currently on Version 5.0. Updated every year, it allows scientists instant access to reaction rate data, as well as supporting information. SRD has made available an excellent complement to the Chemical Kinetics Database - the NDRL/NIST Solution Kinetics Database. This database is derived from the well-known data evaluations of the Radiation Chemistry Data Center at the University of Notre Dame.

\section{SRD Chemical Kinetics Databases}

NIST Chemical Kinetics

NDRL/NIST Solution Kinetics

\section{SRD Major Publications in Chemical Kinetics}

Kinetics and Mechanisms of the Gas-Phase Reactions of the Hydroxyl Radical with Organic Compounds Evaluated Kinetic Data for Combustion Modelling Biweekly List of Papers on Radiation Chemistry and Photochemistry 


\section{Chemical Kinetics Databases}

\section{For information}

or to order:

Phone (301) 975-2208 or FAX (301) 926-0416
17. NIST Chemical Kinetics

Database

Version 5.0

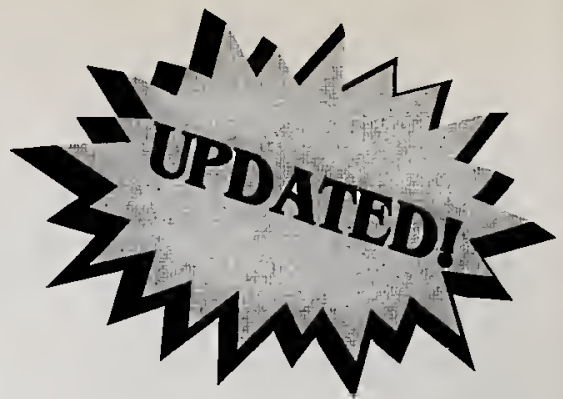

W. Gary Mallard

Chemical Kinetics Data Center

National Institute of Standards and Technology

Gaithersburg, MD 20899

(301) 975-2564

gmallard@enh.nist.gov

$T$ he NIST Chemical Kinetics Database is designed to provide rapid access to kinetics data for gas-phase reactions. Searches

provide a summary of all of the literature on a particular reaction, all of the reactions of a specific species, subsets of all of the reactions, and the data available from a given paper. Version 5.0 contains 23,500 rate constants, 7,800 reactions, 3,800 compounds, and 6,000 literature references. It is current through 1992.

Searching Modes:

- searching by reactants, including various logical screens

- search by author - all authors in a given paper are included

- search for reactions in a particular paper

- search for all reactions producing a given product

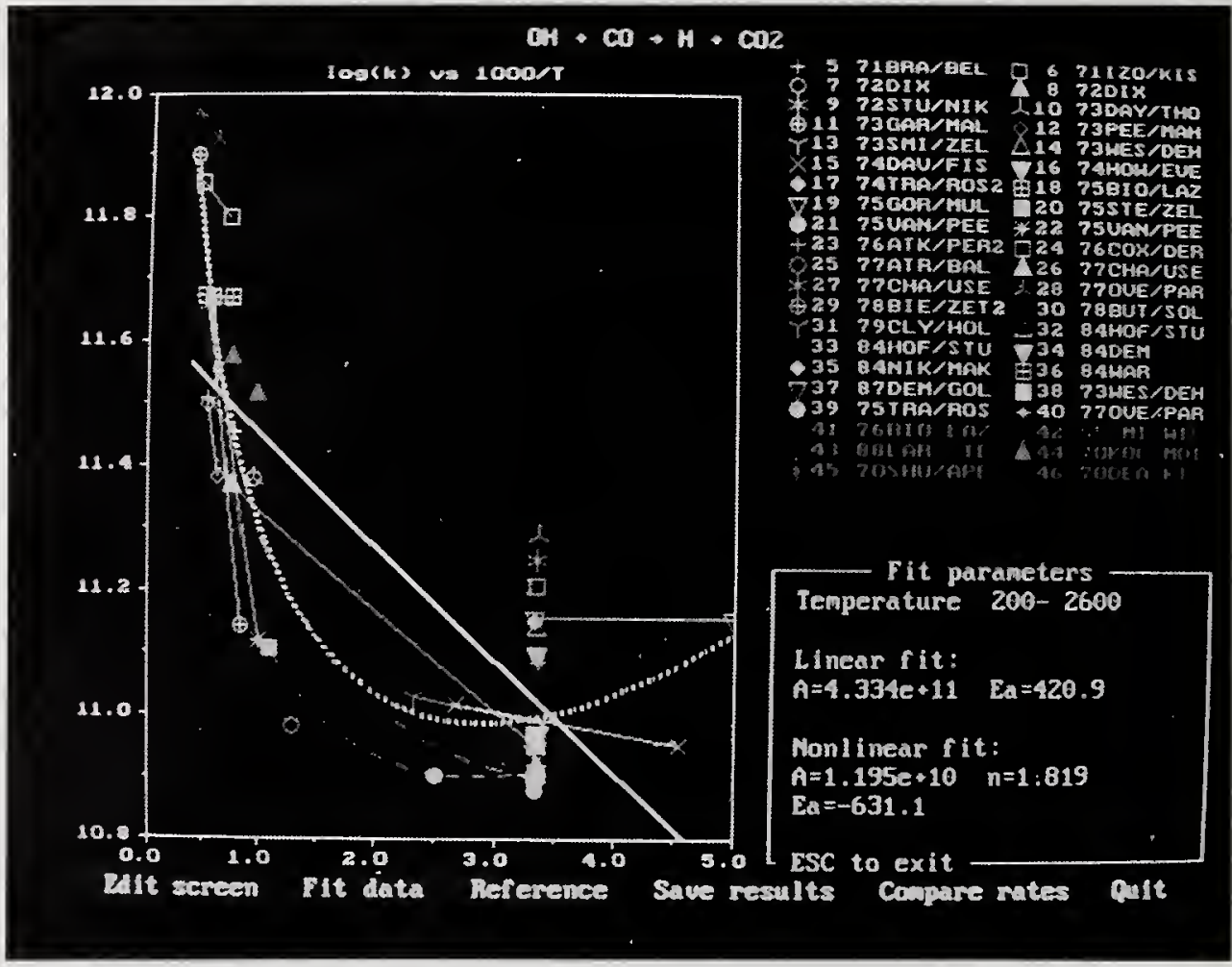

Arrbenius graphs of rate constants of NIST Chemical Kinetics Database. 


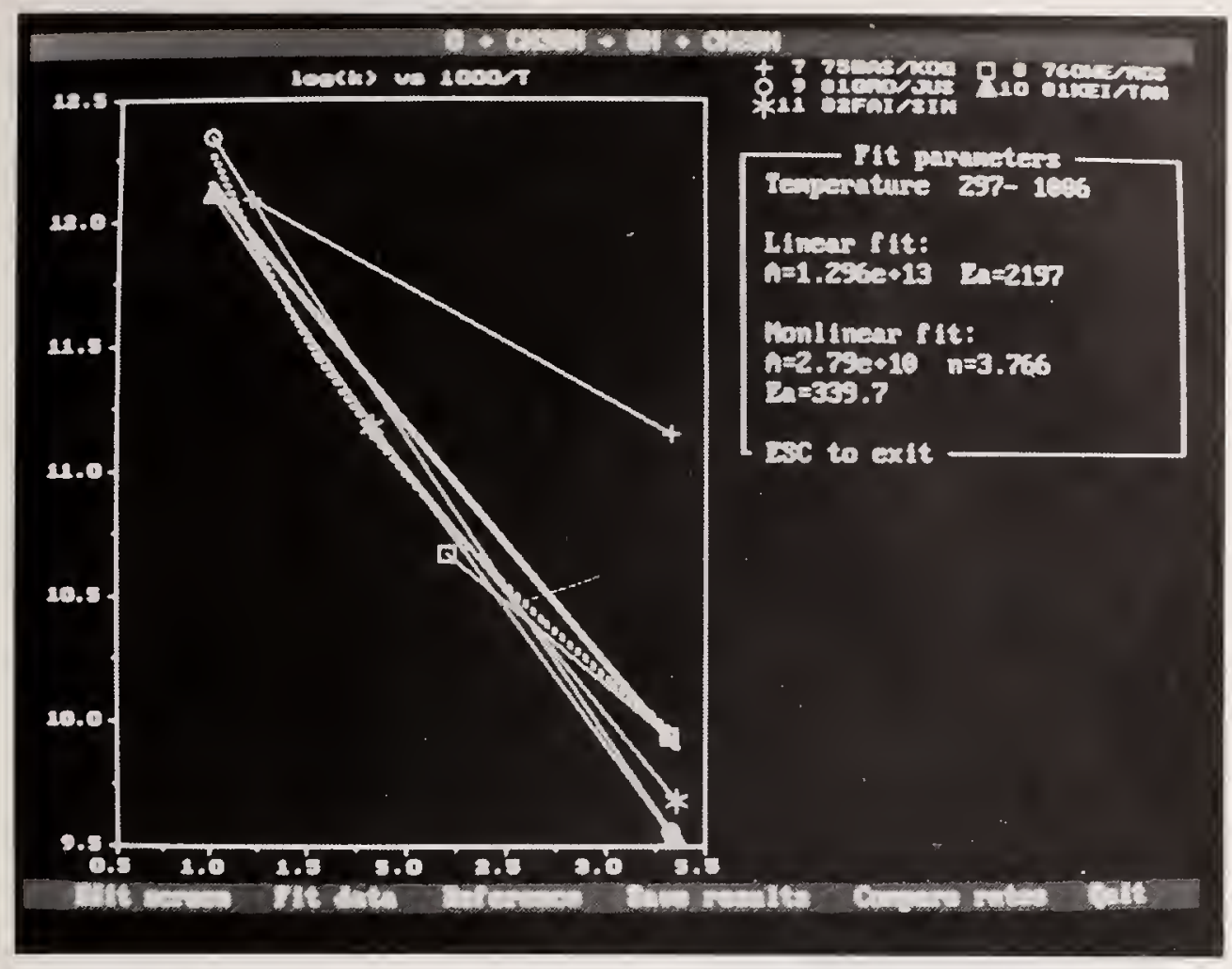

Updated every year, user input has been incorporated into enbancements of the database.

Reactant Search Modes:

- specific reactant pairs

- reaction of compounds containing a single element

- Boolean restrictions on reactants

- Elemental restrictions on reactants

Data Output:

- Individual abstracts or citations may be saved in a format suitable for use in word processors or may be printed directly.

- User selected sets of rate data may be fit to Arrhenius equations using least squares fitting. The resulting fits may be saved to a file suitable for use in a modeling program.

- Graphics of the data may be edited on the screen and fit only to user selected data.

- Graphics output to a wide variety of printers and plotters can be produced at full device resolution.

User Input:

- Users may enter their own data and comments which are then displayed and graphed with literature data

This database is available on $31 / 2$ " and $51 / 4$ " disks. It may also be used on Macintosh computers with PC emulator software. This database is updated yearly.

\section{Chemical Kinetics Databases}

For information

or to order:

Phone (301) 975-2208 or FAX (301) 926-0416 


\section{Chemical \\ Kinetics \\ Databases}

For information

or to order:

Phone (301) 975-2208

or FAX (301) 926-0416
40. NDRL/NIST Solution

Kinetics Database

Version 2.0

\section{Alberta B. Ross \\ Radiation Chemistry \\ Data Center \\ Radiation Laboratory \\ University of Notre Dame \\ Notre Dame, IN 46556 \\ (219) 631-6527}

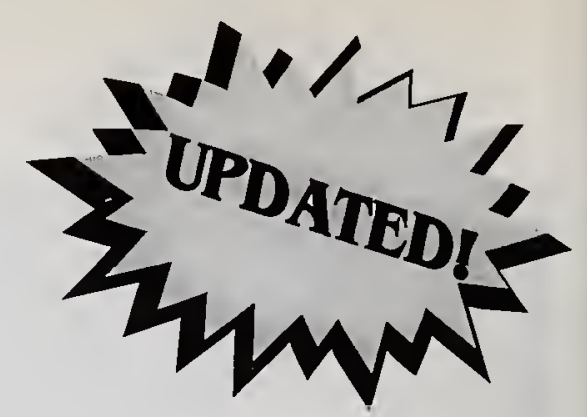

$V$

ersion 2.0 provides rapid access to rate constants for radical processes involving inorganic radicals and carbon-centered organic radicals in aqueous solution and organic peroxyl radicals in various solvents. Searches may be made for reactant pairs, for all reactions of a single reactant, for reactions of species containing a particular element, for reactions generating a particular product, and for authors' names. Software updates include the ability to search by chemical name fragments, as well as to collect various acid-base forms of a particular species in the same search. The database contains over 13,000 entries for over 9,500 reactions; searches may be made for over 7,500 chemical species which are reactants or products. The database was developed from data evaluations published in the Journal of Physical and Chemical Reference Data and the NSRDS-NBS series with additions of data from the scientific literature through 1992.

This database is available on $3 \frac{1 / 2}{1}$ and $51 / 4$ " disks. It may also be used on Macintosh computers with PC emulator software. 
Gas-Phase

Tropospheric

Chemistry of Organic

Roger Atkinson.

Chemical Reference Data,

Monograph 2 (in press). Compounds

Journal of Physical and

The gas-phase reactions of selected classes of organic compounds such as alkanes, alkenes (including isoprene and monoterpenes), alkynes, aromatic hydrocarbons and oxygen-containing organic compounds and their degradation products under tropospheric conditions are reviewed and evaluated.

Available from the American Chemical Society, JPCRD Monograph 2 (in press).

\section{Kinetics and}

Mechanisms of the Gas-Phase Reactions of the Hydroxyl Radical with Organic Compounds

Roger Atkinson.

Journal of Physical and Chemical Reference Data, Monograph 1 (1989).

This monograph reviews the entire literature through 1988 concerning the kinetics and mechanisms of gas-phase reactions of the hydroxyl radical with organic compounds and evaluates the data. Rate data for temperatures ranging from 220 to over $2000 \mathrm{~K}$ are included.

Recommended rate expressions are given. Each recommendation is accompanied by text discussion, the available data,

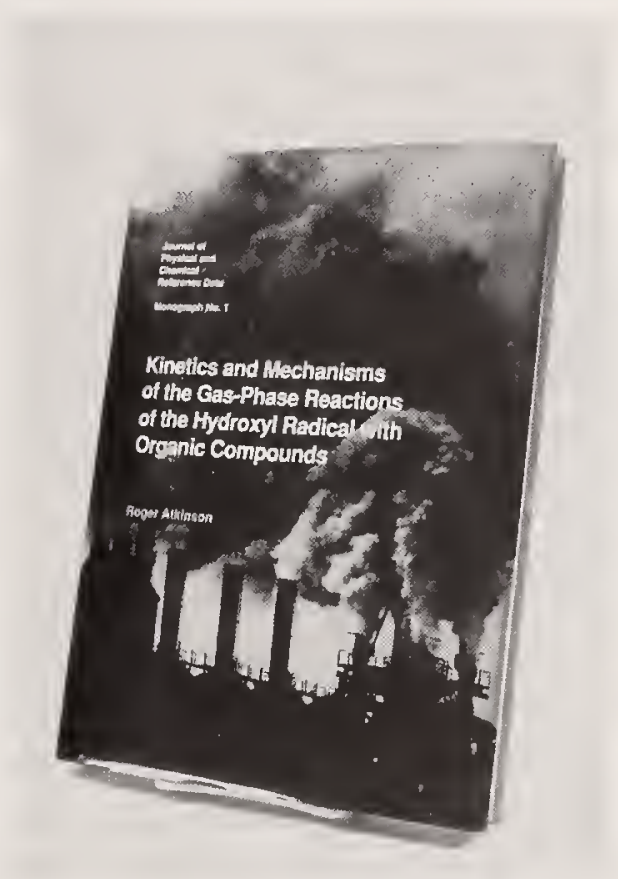

and the rationale behind the recommendation of best values. Also included are the estimated uncertainties in the recommended rate expression and discussions concerning the reaction mechanisms.

Available from the American Chemical Society

U.S. and Canada $\$ 110.00$

Abroad \$132.00

\section{Chemical Kinetics Publications}

For information

or to order:

Phone (301) 975-2208

or FAX (301) 926-0416 


\section{Chemical Kinetics Publications}

For information or to order: Phone (301) 975-2208 or FAX (301) 926-0416
Evaluated Kinetic

Data for Combustion

Modelling

D.L. Baulch, C.J. Cobos, R.A. Cox, C. Esser, P. Frank, Th. Just, J.A. Kerr, M.J. Pilling, J. Troe, R.W. Walker, and J. Warnatz. Journal of Physical and Chemical Reference Data 21, 411 (1992).

\section{Biweekly List of} Papers on Radiation Chemistry and Photochemistry

Radiation Chemistry Data Center, Notre Dame, IN.
This is a compilation of recommended data for nearly 200 elementary gas-phase chemical reactions which play an important part in combustion of simple hydrocarbons. Each data sheet presents the relevant thermodynamic data, rate coefficient measurements, reliability assessments, and recommended rate constants. The reasons for each choice of recommended values are discussed, and full references are given. Available from the American Chemical Society, JPCRD Reprint 438, $\$ 70.00$

This is a current-awareness publication with special emphasis on the kinetics and other properties of transient ions, radicals, and the excited species. Papers are included on the radiation chemistry and photochemistry of chemicallydefined systems containing organic and inorganic compounds, biological molecules, and polymers, with references to ESR and luminescence studies. The references listed are obtained from scanning 60 current journals, as well as Chemical Abstracts, INIS Atomindex, and other publications.

Available from Radiation Chemistry Data Center, Radiation Laboratory, University of Notre Dame, Notre Dame, IN 46556 $\$ 50.00 /$ year 
Chemical Kinetic

Data Sheets for

High-Temperature

Reactions. Part II

N. Cohen and K.R. Westberg. Journal of Physical and Chemical Reference Data 20, 1211 (1991).

Kinetics and

Mechanisms of the Gas-Phase Reactions of the $\mathrm{NO}_{3}$ Radical with Organic Compounds

Roger Atkinson.

Journal of Physical and

Chemical Reference Data 20, 459 (1991).

Evaluated Kinetic and Photochemical Data for Atmospheric

\section{Chemistry.}

Supplement IV. IUPAC Subcommittee on Gas Kinetic Data Evaluation for Atmospheric Chemistry

R. Atkinson, D.L. Baulch, R.A. Cox, R.F. Hampson, Jr., J.A. Kerr (Chairman) and J. Troe.

Journal of Physical and Chemical Reference Data 21 1125 (1992).
Kinetic data on over 50 reactions of interest in combustion and atmospheric chemistry have been evaluated. Results are presented in tabular and graphical form in a series of data sheets. Uncertainty limits and the basis of the recommendations are discussed. Available from the American Chemical Society, JPCRD Reprint 428, $\$ 22.00$

Kinetics and mechanisms of the gas-phase reactions of the $\mathrm{NO}_{3}$ radical in the gas-phase are reviewed and recommended rate constants are presented. Reactions with organic compounds are covered. Needs for additional data on $\mathrm{NO}_{3}$ are discussed.

Available from the American Chemical Society, JPCRD Reprint 413, $\$ 16.00$

The Subcommittee on Gas Kinetic Data Evaluation of the International Union of Pure and Applied Chemistry presents its latest recommendations on reaction rate constants and other kinetic and photochemical data needed as input to calculations which model atmospheric chemistry. Data sheets on 489 reactions are included, giving a summary of the experimental data and the basis for selection of the preferred value and assessment of its accuracy.

Summary tables of the recommended rate constants and associated thermodynamic data are given.

Available from the American Chemical Society, JPCRD

Reprint 446, $\$ 70.00$

\section{Chemical Kinetics Publications}

For information

or to order:

Phone (301) 975-2208 or FAX (301) 926-0416 

7 he NIST Materials Data Program provides evaluated data on 1 phase equilibria, structure and characterization, and performance properties.

Several materials performance property databases are now available. Version 2.0 of the NIST Structural Ceramics Database contains stateof-the-art materials property data for both research and commercial grades of silicon carbides and silicon nitrides with the addition of many new properties. Corrosion data (in conjunction with the National Association of Corrosion Engineers) and tribology data (together with ACTIS, Inc.) have been evaluated, and several databases produced by these programs have gained wide acceptance.

\section{NIST Materials Properties Databases}

NIST Structural Ceramics

NACE-NIST Corrosion Performance Databases

COR*SUR 1 - Corrosion Rate Data for Metals

COR*SUR 2 - Corrosion Rate Data for Non-Metals

NIST Tribomaterials I (ACTIS)

Phase Diagrams for Ceramists

NIST Ceramic Tribomaterials

\section{SRD Major Publications in Materials Properties}

Journal of Phase Equilibria (formerly Bulletin of Alloy

Phase Diagrams)

Phase Diagrams for Ceramists

Binary Alloy Phase Diagrams, 2nd edition 


\section{Materials Properties Databases}

\author{
For information \\ or to order: \\ Phone (301) 975-2208 \\ or FAX (301) 926-0416
}

\section{NIST Structural Ceramics Database Version 2.0}

\section{Ronald Munro}

Ceramics Division

National Institute of Standards and Technology Gaithersburg, MD 20899

(301) 975-6127

\section{munro_rg@enh.nist.gov}

V ersion 2.0 contains thermal, mechanical, and corrosion properties of silicon carbides and silicon nitrides in a standalone, user-friendly database system. Searches of the data are conducted by means of SCD's unique combination of menus, queryby-example technique, and computer-assisted entries. Users may search for properties of a selected ceramic or use specified property values to identify required ceramics. This database contains state-ofthe-art materials property data for both research and commercial grades of silicon carbides and silicon nitrides.

Primary properties in the Structural Ceramics Database:
Materials Specification

- Name

- Formula

- Chemical Composition

- Fabrication

- Physical Properties

- Microstructural Information

Processing

Thermal Properties

- Conductivity

- Diffusivity

- Expansion

- Specific Heat

- Shock Resistance

Corrosion Properties

- Oxidation Rate

- Oxidation Activation Energy

- Oxidation Diffusivity
Mechanical Properties

- Elastic Modulus

- Shear Modulus

- Poisson's Ratio

- Flexural Strength

- Tensile Strength

- Compressive Strength

- Vicker's Hardness

- Knoop Hardness

- Fracture Toughness

- Fracture Energy

- Weibull Modulus

- Creep Exponent

- Creep Rate

- Creep Activation Energy

Measurement Methods

- Specimen Preparation

- Apparatus

- Procedures
Bibliography

- Complete Documentation of Data Sources through 1991

This database comes on both $3 \frac{1 / 2}{2}$ and $5 \frac{1 / 4}{4}$ high and low density disks. It may also be used on Macintosh computers with PC emulator software. 


\section{NACE/NIST Corrosion Performance Databases}

Richard Ricker

Corrosion Data Center

National Institute of Standards and Technology

Gaithersburg, MD 20899

(301) 975-6023

\section{ricker@enh.nist.gov}

$C$ orrosion databases developed under the NACE-NIST Corrosion Data Program give users reference data for general guidance on the performance of engineering materials in corrosive environments. COR*SUR 1 includes data for 25 common metals for exposures in over 1,000 corrosive environments at various temperatures and concentrations. COR*SUR 2 provides similar data for 36 nonmetallic materials (elastomers, polymers, composites, thermoplastics, etc.) in over 850 environments. Data can be retrieved from both programs by:

- tabular listing of materials exhibiting a specified range of corrosion rates in selected environments

- graphic presentation of corrosion rate ranges for a given material in a matrix of environment, concentration, and temperature

- tabular listing of corrosion rate data for a specified material in a corrosive environment as a function of temperature and concentration

The programs are derived from the Corrosion Data Survey publications produced by the National Association of Corrosion Engineers (NACE) and are available in diskette form for use on IBM or compatible personal computer systems and are available from NACE, P.O. Box 218340, Houston, TX 77218.

Phone: (713) 492-0535.

\section{Materials Properties Databases}

For information or to order:

Phone (301) 975-2208 or FAX (301) 926-0416 


\section{Materials \\ Properties \\ Databases}

\section{For information}

or to order:

Phone (301) 975-2208 or FAX (301) 926-0416

\section{NIST Tribomaterials I (ACTIS) Database}

William Ruff

Tribology Data Center

National Institute of Standards and Technology

Gaithersburg, MD 20899

(301) 975-6010

ruffw@micf.nist.gov

7 his database contains property data for 261 materials commonly 1 used in tribology applications. The data cover a wide range of properties including basic physical and mechanical as well as tribology properties for both lubricated and unlubricated wear. This user-friendly PC database is available from ACTIS Inc., 1118 Highgate Road, Wilmington, DE 19808. Phone: (302) 998-8240.

A flat ASCII file on tribomaterials is also available from ACTIS. Please contact (302) 998-8240 for more information.

47. NIST Ceramic Tribomaterials Database

William Ruff

Tribology Data Center

National Institute of

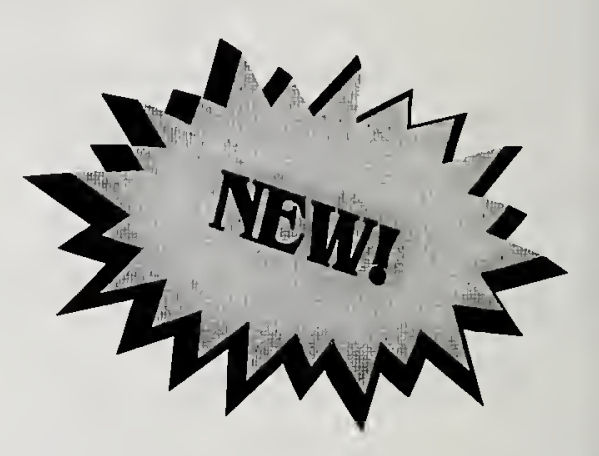

Standards and Technology

Gaithersburg, MD 20899

(301) 975-6010

ruffw@micf.nist.gov

NIST Ceramic Tribomaterials Database is the most extensive 1 tribology database on ceramics presently available. With data gathered from NIST research activities, selected published data, and national and international round-robin measurement programs, the database contains nearly 350 records covering 44 different ceramic materials. Focusing on ceramics with high industrial importance and for which data availability has been poor, it includes wear data, friction data, lubricated sliding data, and mechanical and physical design data. This database is available from ACTIS Inc., 1118 Highgate Road, Wilmington, DE 19808. Phone: (302) 998-8240. 


\section{Phase Diagrams for Ceramists Database}

\section{Stephen Freiman}

Phase Diagrams for Ceramists Data Center National Institute of Standards and Technology Gaithersburg, MD 20899 (301) 975-6119 freiman@micf.nist.gov

$T$ his PC package provides computer access to the well-known 1 and widely-distributed Phase Diagrams for Ceramists (PDFC). The software permits searches for diagrams by chemical system, author, or year of publication. All diagrams from volumes 5-8 in the PDFC series are included. After identifying figure numbers in a search, diagrams can be plotted on a screen. The graphics software permits diagram manipulation, such as magnification of selected regions, overlay of related diagrams, lever rule calculations, display of the cursor position in real units, and selection of the temperature scale. In addition, all bibliographic references and chemical systems from volumes 1-8 of the PDFC series are available.

This database comes on both $3 \frac{1 / 2}{1}$ and $51 / 4^{1}$ disks and is available from the American Ceramic Society, 735 Ceramic Place, Westerville, $\mathrm{OH}$ 43081. Phone: (614) 890-4700.

\section{Materials Properties Databases}

For information or to order: Phone (301) 975-2208 or FAX (301) 926-0416 


\section{Materials \\ Properties Publications}

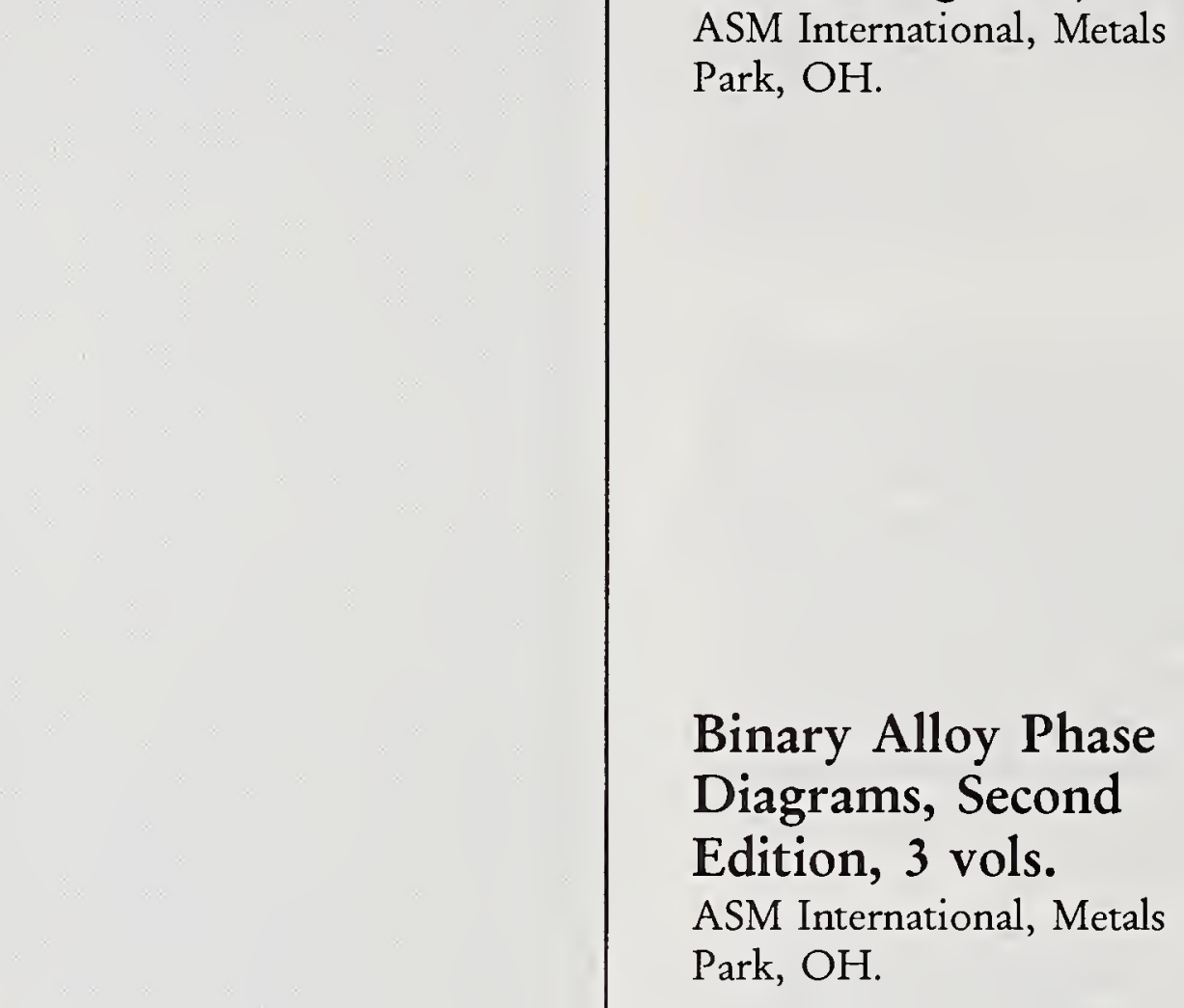

For information

or to order:

Phone (301) 975-2208 or FAX (301) 926-0416
Journal of Phase Equilibria (formerly the Bulletin of Alloy Phase Diagrams)

ASM International, Metals Park, $\mathrm{OH}$.

Binary Alloy Phase Diagrams, Second Edition, 3 vols. Park, $\mathrm{OH}$.

Phase Diagrams for Ceramists

American Ceramic Society, Westerville, $\mathrm{OH}$.
The Bulletin was retitled in 1991. It has been expanded to include original research on the generation and application of data to attain or prevent phase equilibria. It presents theoretical and experimental research on the determination of phase diagrams and provides critical phase diagram evaluations authored by international experts for scientifically and industrially important alloy systems and updates of systems previously published.

Available from ASM

International, Metals Park, $\mathrm{OH}$ (216) 338-5151

This is the most thorough alloy reference available. All systems published in the original set have been updated. This set contains 2,925 critical evaluations with key references, plus additional related citations.

Available from ASM

International, Metals Park, OH (216) 338-5151, $\$ 1290.00$

This publication series has become the definitive source of ceramic phase diagrams in the scientific community. These nine volumes contain commentaries and binary, ternary and higher order phase diagrams of oxide, metals-oxide, and metal-oxygen systems, halide, and other ceramic systems. Available from the American Ceramic Society, Westerville, $\mathrm{OH}$ (614) 890-4700, \$125.00/vol., Annual volume $\$ 69.00$ 
Critical Compilation of Surface Structures Determined by Ion Scattering Methods Philip R. Watson. Journal of Physical and Chemical Reference Data 19, 85 (1990).
This review critically compiles all surface structures derived by ion scattering techniques. These investigations cover all types of surfaces including clear and adsorbate-covered metal, semiconductor, and other nonmetallic substrates. The important experimental and theoretical aspects of such investigations have been extracted into easily understood tabular form supplemented by figures and ancillary tables and complete references.

Available from the American Chemical Society, JPCRD Reprint 376, $\$ 12.00$

A complete bibliographic search for all thermodynamic and phase diagram data on the 24 binary systems was carried out. A computer-assisted simultaneous evaluation of all data was performed in order to obtain optimized equations for the thermodynamic properties of the phases. These are considered to be the best evaluated phase diagrams which can be deduced from the data currently available.

Available from the American Chemical Society, JPCRD Reprint 398, $\$ 12.00$

\section{Materials Properties Publications}

Coupled Phase

Thermodynamic

Analysis of the 24

Binary Systems, $\mathrm{A}_{2}$ $\mathrm{AX}$ where $\mathrm{A}=\mathrm{Li}, \mathrm{Na}$, $\mathrm{K}$ and $\mathrm{X}=\mathrm{Cl}, \mathrm{F}$, $\mathrm{NO}_{3}, \mathrm{OH}$

Yves Dessureault, James Sangster, and Arthur D. Pelton. Journal of Physical and Chemical Reference Data 19, 1149 (1990).
For information or to order:

Phone (301) 975-2208 or FAX (301) 926-0416 


\section{Materials \\ Properties \\ Publications}

Critical Compilation of Surface Structures Determined by Surface Extended X-Ray Absorption Fine Structure (SEXAFS) and Surface Extended Electron Energy Loss Spectroscopy (SEELFS)

Philip R. Watson.

Journal of Physical and

Chemical Reference Data 21, 123 (1992).
This review critically compiles all surface structures derived by the technique of surface extended $\mathrm{x}$-ray absorption fine-structure spectroscopy (SEXAFS) and surface electron energy loss fine-structure spectroscopy (SEELFS) reported in the refereed literature prior to January 1990. They are compared with the extensive low-energy electron diffraction and ion scattering databases Watson has previously reported.

Available from the American Chemical Society, JPCRD Reprint 434, \$14.00

For information or to order:

Phone (301) 975-2208 or FAX (301) 926-0416 
IVJ ith the 1994 Catalog, the Standard Reference Data Program is expanding into the process engineering area. The GRI/NIST Orifice Meter Discharge Coefficient Database will enable process engineers to more easily make choices in designing and implementing systems. It contains nitrogen gas data for the nominal 2", 4", and 6" orifice meter and water for the 2" orifice meter.

\section{SRD Process Engineering Database}

GRI/NIST Orifice Meter Discharge Coefficient
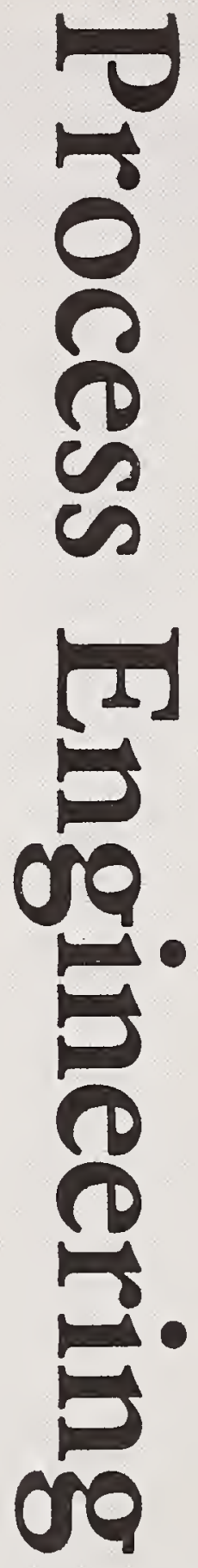


\section{Process Engineering Database}

For information

or to order:

Phone (301) 975-2208 or FAX (301) 926-0416

\section{GRI/NIST Orifice Meter Discharge Coefficient Database}

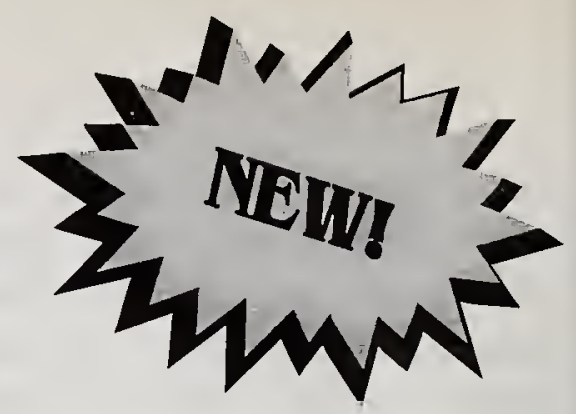

Jennifer Scott

Process Measurements Division

National Institute of Standards and Technology

Boulder, CO 80303

(303) 497-3684

S ponsored by the Gas Research Institute (GRI), Chicago, Illinois, $\int$ the database contains all orifice meter research data which was compiled at the National Institute of Standards and Technology at Gaithersburg and Boulder and Southwest Research Institute in San Antonio.

The database will contain nitrogen gas data for the nominal 2", 4", and 6 " orifice meter and water data for the 2 " orifice meter.

Information available will include:

- meter tube

size

surface roughness

flange pressure tap orientation

- installation conditions long upstream straight pipe elbow, tees, and reducers at varying positions

- Beta ratios

- Flow conditioning

None

Sprenkle, Zanker, etoile, or tube bundle

- Reference system

Primary

Secondary

A choice between SI and engineering units will be provided. Every data point in the database will include:

- Pipe Reynolds number

- ANSI/API 2530 equation values (1985 and 1992 version)

- Fluid properties (pressure, temperature, and density)

At the completion of any search of the database, the user may plot discharge coefficient vs. pipe Reynolds number and/or save the data found to an ASCII file to analyze as desired. Future versions will include orifice meter data from facilities both inside and outside the United States.

The database is available on $3 \frac{112 "}{2}$ and $5^{1 / 4}$ " disks. 
N IST has a long history as the source for reliable thermochemical data starting from the 1920's with the International Critical Tables. The tradition continues as new SRD databases on thermochemical properties of inorganic and small organic molecules gain acceptance.

The JANAF Thermochemical Tables contain the most complete compilations of evaluated temperature-dependent thermodynamic data for inorganic species. The new Positive and Negative Ion Energetics Database now has the sophisticated Structures and Properties software.

The DIPPR ${ }^{\circ}$ Data Compilation of Pure Compound Properties continues to represent an increasing number of chemicals of high industrial priority and provides 39 different properties to the user.

A new Special Database is available - IVTANTHERMO. This is an important collection of reference data developed for Soviet rocketspace technology and now readily accessible with thermodynamic properties of nearly 2300 compounds.

NIST thermochemical databases are available both in convenient PC formats and as online systems.

\section{SRD Thermochemical Databases}

NIST Chemical Thermodynamics

NIST JANAF Thermochemical Tables

DIPPR Data Compilation of Pure Compound Properties

DIPPR ${ }^{\circ}$ Data Compilation Access Program II - Student DIPPR ${ }^{\circ}$

NIST Positive and Negative Ion Energetics with Structures and

Properties Software

NIST Structures and Properties Database and Estimation Program

NIST Estimation of the Thermodynamic Properties for Organic

Compounds

NIST Critical Stability Constants of Metal Complexes

NIST Molten Salts

NIST JANAF Thermochemical Tables - Shomate Coefficients

NIST JANAF Thermochemical Tables - NASA-Lewis

Coefficients

NIST/DIPPR Properties of Aqueous Solutions

\section{SRD Major Publications in Thermochemistry}

NBS Tables of Chemical Thermodynamic Properties

JANAF Thermochemical Tables

Gas-Phase Ion and Neutral Thermochemistry

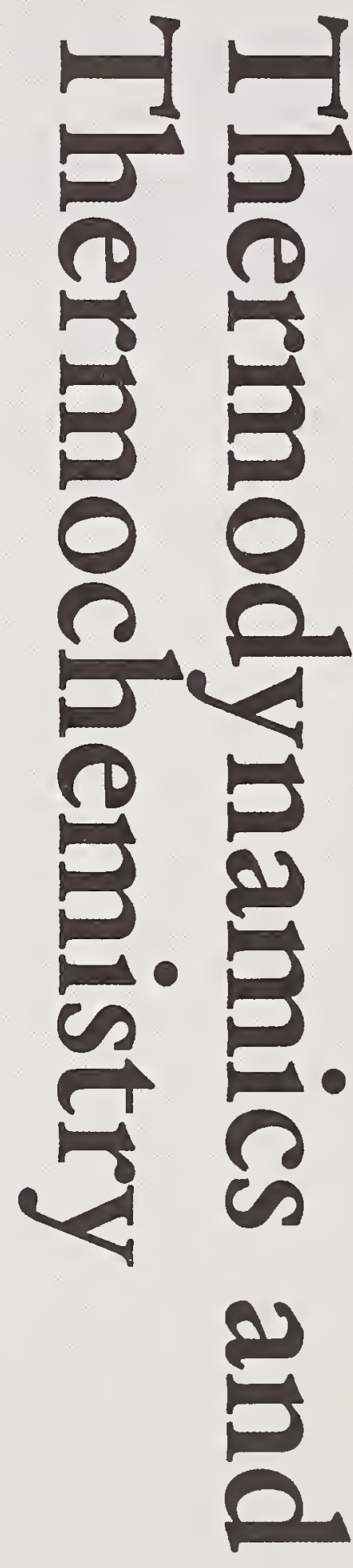




\section{Thermodynamic and Thermochemical Databases}

2. NIST Chemical Thermodynamics Database

David Neumann

Chemical Thermodynamics Data Center

National Institute of Standards and Technology Gaithersburg, MD 20899

(301) 975-2525

neumann@enh.nist.gov

$T$ his database contains recommended values for selected 1 thermodynamic properties of more than 15,000 inorganic substances. These properties include the following:

Standard state properties at $298.15 \mathrm{~K}$ and $1 \mathrm{bar}$

- enthalpy of formation from the elements in their standard state

- Gibbs energy of formation for the elements in their standard state

- enthalpy $\mathrm{H}^{\circ}(298.15 \mathrm{~K})-\mathrm{H}^{\circ}(\mathrm{O} \mathrm{K})$

- heat capacity at constant pressure

- entropy

Properties at $0 \mathrm{~K}$

- enthalpy of formation

The data files are available on diskette, and online through STN and CIS.
For information or to order: Phone (301) 975-2208 or FAX (301) 926-0416 


\section{NIST JANAF Thermochemical Tables Database}

Malcolm W. Chase

Standard Reference Data Program

National Institute of Standards and Technology Gaithersburg, MD 20899

(301) $975-2200$

chase@micf.nist.gov

$T$ he JANAF Thermochemical Tables provide a compilation of 1 critically evaluated thermodynamic properties of approximately 1800 substances over a wide range of temperatures. Recommended temperature-dependent values are provided for inorganic substances and for organic substances containing only one or two carbon atoms.

These tables cover the thermodynamic properties with single-phase and multi-phase tables for the crystal, liquid, and ideal gas multiphase stages. The properties tabulated are heat capacity, entropy, Gibbs energy function, enthalpy, enthalpy of formation, Gibbs energy of formation, and the logarithm of the equilibrium constant for formation of each compound from the elements in their standard reference states. This database is consistent with the Third Edition of the JANAF Thermochemical Tables published as Supplement No. 1 to Volume 14 of the Journal of Physical and Chemical Reference Data.

The data files are available on $3^{1 / 2}$ " and $51 / 4$ " disks. It is currently available online through STN.

\section{Thermodynamic and \\ Thermochemical Databases}

For information

or to order:

Phone (301) 975-2208

or FAX (301) 926-0416 


\section{Thermodynamic and \\ Thermochemical Databases}

\section{DIPPR ${ }^{\varpi}$ Data Compilation of Pure Compound Properties Database}

\section{T.E. Daubert/R.P. Danner}

The Pennsylvania State University

133 Fenske Laboratory

University Park, PA 16802-4400 (814) 863-4638

he 1994 version of the DIPPR ${ }^{*}$ database contains data on 39
properties for 1,405 chemicals of high industrial priority. Thermodynamic, physical, transport, and flammability property data are given. The database was prepared by The Pennsylvania State University with support from 22 members of the Design Institute for Physical Property Data (DIPPR) ${ }^{\oplus}$, a sponsored research organization under the auspices of the American Institute of Chemical Engineers.

For each chemical included, values are given for 26 single-valued property constants and for 13 properties as functions of temperature, calculated from correlation coefficients. The database also includes estimates of the accuracy of each property value and references to the sources of measured or predicted data which were used in selecting the recommended values. The database includes numeric values as well as interactive software which allows access to specific properties of the compounds included, in any specified set of units. Output can be in the form of calculated tabular data or plots.

This database is a set of ASCII files available on diskette. It is also available online through STN.

\section{A. DIPPR ${ }^{\circledR}$ Data Compilation Access Program II - Student DIPPR ${ }^{\circledR}$ Database}

1 he student version of NIST Standard Reference Database $11-$ contains data for 100 chemicals. For each chemical, values are given for 26 single-valued property constants and for 13 properties as functions of temperature. The user can construct a list of compounds of interest from the available database, select any unit system, select the type of output device, and then plot or tabulate the properties of interest. An invaluable teaching tool, this database is available on diskettes.

The Design Institute for Physical Property Data and the acronym DIPPR ${ }^{*}$ are registered trademarks of the American Institute of Chemical Engineers (AIChE). 
19A. NIST Positive Ion

Energetics Database

Version 2.0

with Structures and Properties

Software

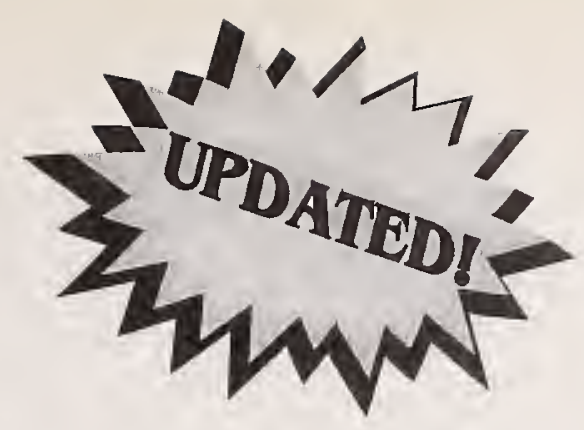

Sharon G. Lias/Rhoda D. Levin

Chemical Kinetics and Thermodynamics Division

National Institute of Standards and Technology Gaithersburg, MD 20899

(301) 975-2562

sgl@micf.nist.gov

Joel F. Liebman

(Univ. of Maryland Baltimore County) and

Sherif A. Kafafi

(Johns Hopkins Univ.)

$T$ his database provides rapid access to experimental data for 1 ionization energies and appearance energies, enthalpies of formation of ions and the corresponding neutral species, and a complete bibliography. The powerful Structures and Properties software by Stephen E. Stein (Standard Reference Database 25) used with Version 2.0 permits the user to (1) locate all species having an ionization energy equal or close to a pre-selected value, and (2) search by structure or sub-structure. The software also can perform additivity-type estimations of thermochemical data for neutral molecules, and carry-out on-screen calculations of enthalpies of reaction. Data from more than 22,000 measurements of ionization and appearance energies pertaining to about 11,000 molecules are included. Species covered are all atoms and organic and inorganic molecules, including radicals for which ionization energy or appearance energy data have been reported in the literature in the time period 1971-1991 plus data for a few selected species published before 1971.

The original source of the database was the positive ion table from "Gas-Phase Ion and Neutral Thermochemistry", J. Phys. Chem. Ref. Data 17 Suppl. 1, 1988 (the so-called GIANT Tables). Version 2.0 is an update of that publication and also includes enthalpies of formation and entropies taken from the NIST Chemical Kinetics Database (Standard Reference Database 17) and the NIST JANAF Thermochemical Tables.

The database is available on $3^{1 / 2}$ " and $5 \frac{1 / 4}{1}$ disks.
Thermodynamic and Thermochemical Databases

For information or to order:

Phone (301) 975-2208

or FAX (301) 926-0416 
Thermodynamic and

Thermochemical Databases
19B. NIST Negative Ion Energetics Database

John E. Bartmess

University of Tennessee

Knoxville, TN 37996

(615) 974-6578

bartmess@utkvx.utk.edu

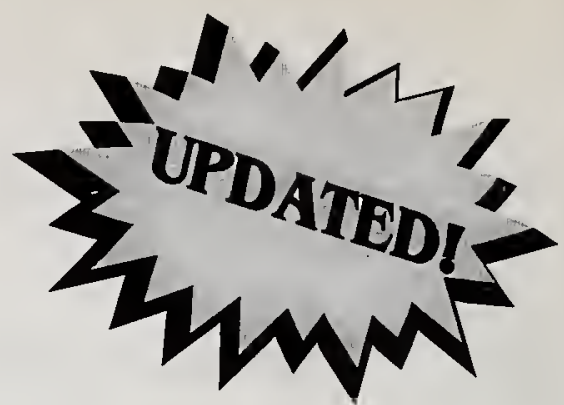

Cas-phase electron affinities, acidities, negative ion affinities to

$U$ neutral species, negative ion enthalpies of formation and a complete bibliography are provided in this database. Data from approximately 4,100 measurements pertaining to 2,600 negative ions are included. The initial source of the database was the negative ion table from "Gas-Phase Ion and Neutral Thermochemistry", J. Phys. Chem. Ref. Data 17 Suppl. 1, 1988. This version includes corrections to that publication, as well as subsequent data appearing through approximately the end of 1991 plus some additional data from 1992.

The database is available on $3^{1 / 2}$ " and $5^{1 / 4}$ " disks.

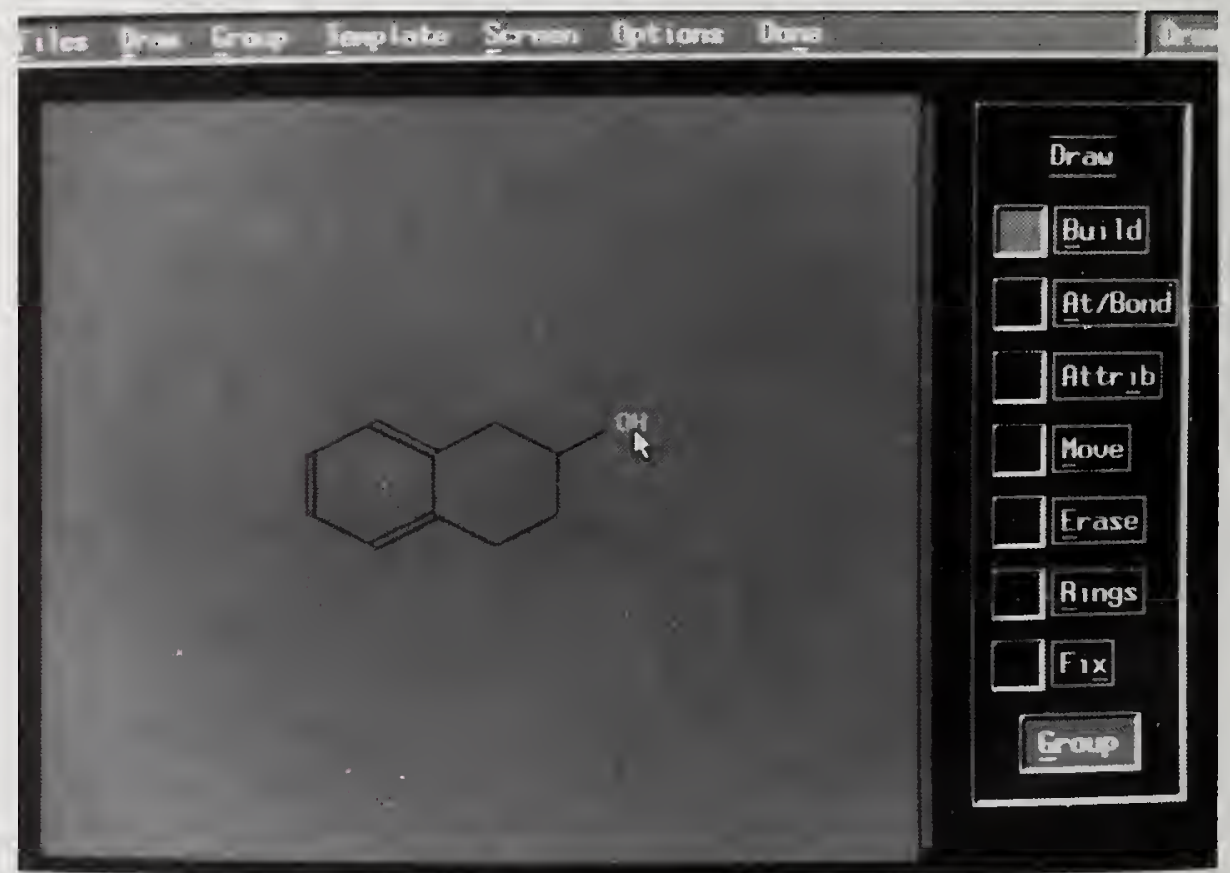

Use left button to mahe new atom. riaht to stoo.

The Structures and Properties software estimates properties solely from structures drawn on the screen using an easy-to-use structure-drawing module. 


\section{NIST Structures and Properties Database and Estimation Program}

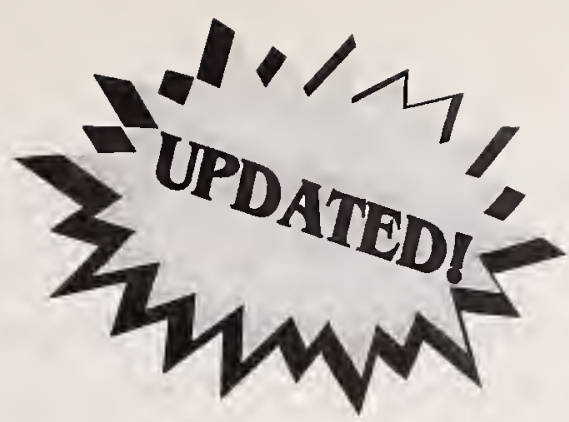

Stephen E. Stein

Chemical Kinetics and Thermodynamics Division National Institute of Standards and Technology Gaithersburg, MD 20899 (301) 975-2505

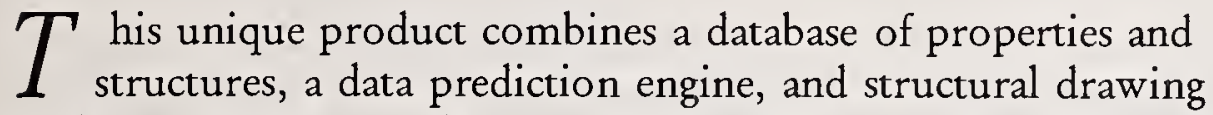
module in an integrated system for finding and estimating chemical property data. The database contains structural drawings, names and Chemical Abstracts Registry Numbers for approximately 11,000 compounds, and experimental enthalpies for formation and entropies for 5,000 compounds. In this update, the product has been combined with Standard Reference Database 19A, NIST Positive Ion Energetics, and therefore also contains a database of 22,000 measurements of ionization and appearance energies.

The structure drawing module is linked to a complete implementation of Benson's Group Additivity estimation method for gas-phase heats of formation, entropies, and heat capacities, so that properties of molecules drawn on the screen are automatically estimated without a need for the user to have any knowledge of such estimation methods. Also included is a structure-based method for estimating vapor pressures and boiling points.

This database is available on $3 \frac{1 / 2}{2}$ and $5 \frac{1 / 4}{}$ " disks.

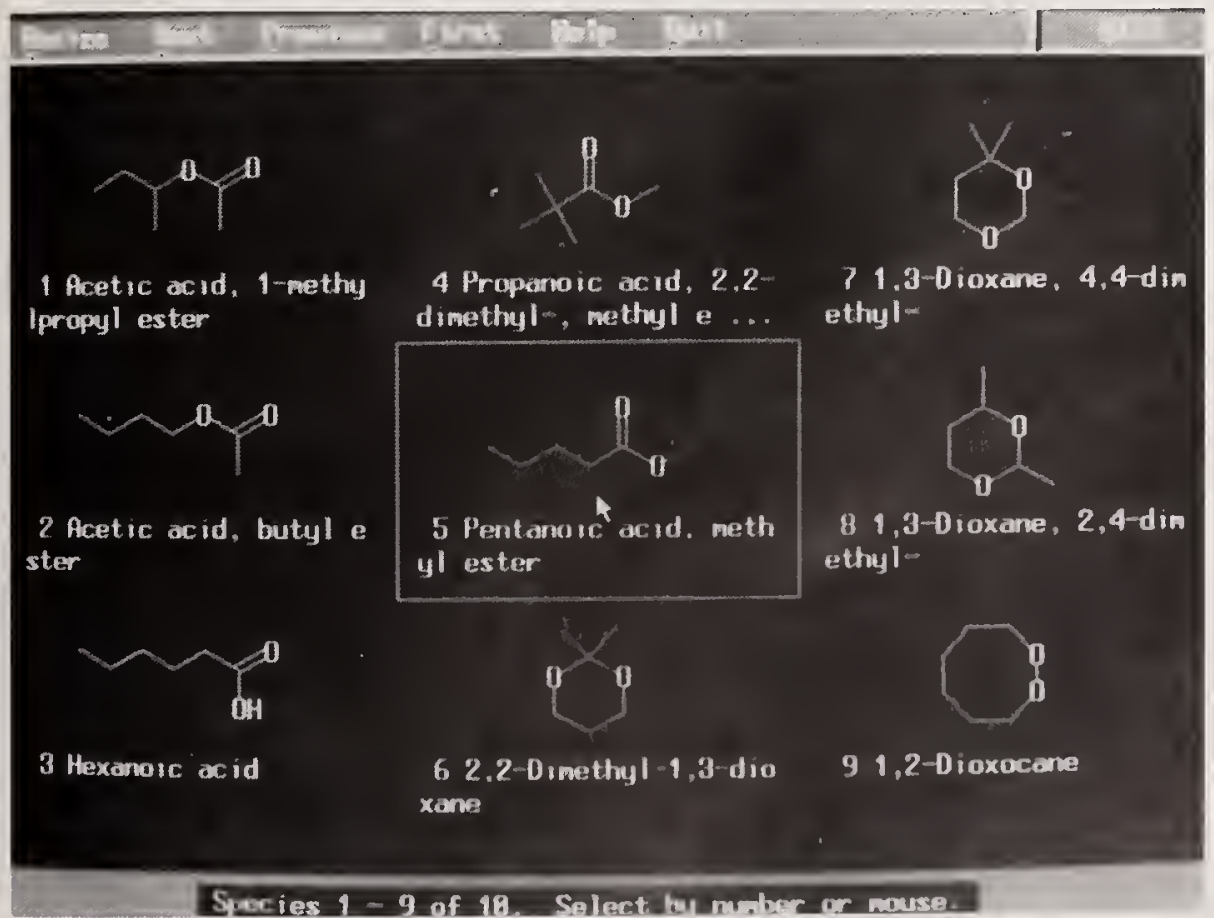

The database allows estimation of automatic perception of rings and long-range interactions.

\section{Thermodynamic and Thermochemical Databases}

\author{
For information \\ or to order: \\ Phone (301) 975-2208 \\ or FAX (301) 926-0416
}




\section{Thermodynamic and Thermochemical Databases}

For information

or to order:

Phone (301) 975-2208 or FAX (301) 926-0416
18. NIST Estimation of the Thermodynamic Properties for Organic Compounds at 298.15 K - Compounds Containing the Elements $\mathrm{C}, \mathrm{H}, \mathrm{N}, \mathrm{O}, \mathrm{S}$, and Halogens

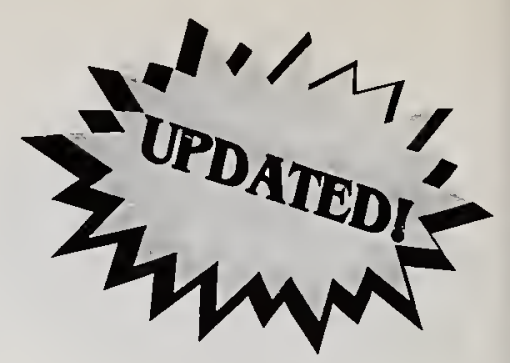

\section{Eugene S. Domalski}

Chemical Thermodynamics Data Center National Institute of Standards and Technology Gaithersburg, MD 20899

(301) 975-2529 domal@enh.nist.gov

$\prod \begin{aligned} & \text { his product (also called THERM/EST) provides a semi- } \\ & \text { automated means of carrying out additivity-type estimation }\end{aligned}$ schemes for thermodynamic properties of organic molecules at $298.15 \mathrm{~K}$ in the gas, liquid, and solid phases. A database with experimental data for approximately 1512 compounds is included. The thermodynamic properties calculated are:

- enthalpy of formation

- heat capacity

entropy

- entropy of formation

- Gibbs energy of formation

- equilibrium constant for the formation reaction

The thermodynamic properties have been developed for the gas, liquid, and solid phases. Data are provided for compound types, such as alcohols, diols, triols, phenols; linear, branched and cyclic ethers; aldehydes; ketones, etc.

The user is offered the option of retrieving data in energy units of joules, calories, or British Thermal Units. Some other features are the capacity to search the database by compound name or formula and a bibliography containing nearly 1000 references.

THERM/EST is available on $31 / 2$ " or $5 \frac{1 / 4}{4}$ disks. It may also be used on Macintosh computers with PC emulator software. 
46. NIST Critical

Stability Constants of

Metal Complexes Database

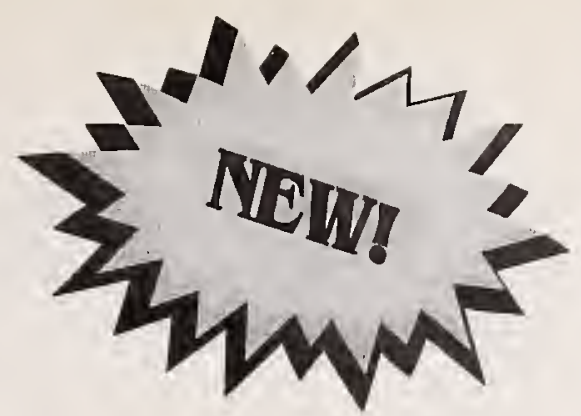

\section{A.E. Martell \\ Department of Chemistry \\ Texas A\&M University \\ College Station, TX 77843-3255 \\ (409) 845-2011}

$T$ his significant new database provides comprehensive coverage of ligands with protons and various metal ions. Based on the six-volume Critical Stability Constants by Martell and Smith, the data in this new database have been thoroughly reexamined and critically evaluated with correction of errors and addition of new material. It enables instant location of a needed equilibrium constant or associated heat of reaction with complete references. Every abstracted ligand possesses a structural formula for quick identification. The database has the following features:

For nearly 4000 ligands:

- protonation constants under specified conditions of temperature and ionic strength

- heats of protonation

- entropies of protonation

- stability constants and related equilibrium constants

- thermodynamic constants

- a complete bibliography

For an additional 1000 ligands:

- metal ions studied

- bibliographic citations

A three-part searching system provides quick visual recognition. The metal-ligand data and optional bibliographic information for each ligand-metal system are shown in one of two standard display screens.

The database is available on $31 / 2$ " and $51 / 4 "$ disks. It may also be used on Macintosh computers with PC emulator software.
Thermodynamic and Thermochemical Databases

\section{For information}

or to order:

Phone (301) 975-2208

or FAX (301) 926-0416 


\section{Thermodynamic and Thermochemical Databases}

For information

or to order:

Phone (301) 975-2208 or FAX (301) 926-0416
27. NIST Molten Salts Database

Single Salts and Mixtures Database

Version 2.0

George Janz

Molten Salts Data Center

Rensselaer Polytechnic Institute

Department of Chemistry

Troy, NY 12181

(518) 276-6344

$T$ his database provides easy and rapid access to the properties of

$\mathcal{i}$ inorganic salts in the molten state. As the culmination of a long-term data evaluation project at Rensselaer Polytechnic Institute, this database allows calculation of the following properties of approximately 320 single-salts and 4,000 multi-component systems (primarily binary).

- binary

- surface tension

- viscosity

- electrical conductance

Not all properties are given for all salts. Data can be extracted by chemical formula search or via a browse routine. For the salt system searched, results displayed are:

- temperature range of validity

- correlation equation

- accuracy estimates and reliability statements

A calculation routine lists properties at a single temperature or over a range of temperatures and does units conversion. This database is available on $31 / 2$ " and $51 / 4^{\prime \prime}$ disks. It can also be used on Macintosh computers with PC emulator software. 
50. NIST JANAF

Thermochemical Tables -

Shomate Coefficients

Database

\section{Thermodynamic and \\ Thermochemical Databases}

\section{Malcolm W. Chase}

Standard Reference Data Program

National Institute of Standards and Technology

Gaithersburg, MD 20899

(301) 975-2200

chase@micf.nist.gov

his database is a representation of the JANAF Thermochemical
Tables in an equation format consistent with use in the China Lake equilibrium package (often referred to as PEP - the propelleant evaluation program, which was developed at the Naval Weapons Center in China Lake, CA). These tabulations are represented by one or more sets of coefficients, which are derived from the following equation:

$$
C_{p}=a+b T+c T^{2}+e T^{3}+d / T^{2} .
$$

If possible, one set of coefficients is used to represent the entire thermochemical tabulation. Typically, however, two sets of coefficients are necessary with the temperature ranges being 298-1000 $\mathrm{K}$ and $1000-6000 \mathrm{~K}$. The selected coefficients can be written to a file for use with the PEP program.

This database is available on $3 \frac{1 / 2}{2}$ and $5 \frac{1}{4}$ " disks.
For information or to order:

Phone (301) 975-2208 or FAX (301) 926-0416 


\section{Thermodynamic and \\ Thermochemical Databases}

For information or to order:

Phone (301) 975-2208 or FAX (301) 926-0416
51. NIST JANAF

Thermochemical Tables -

NASA-Lewis Coefficients

Database

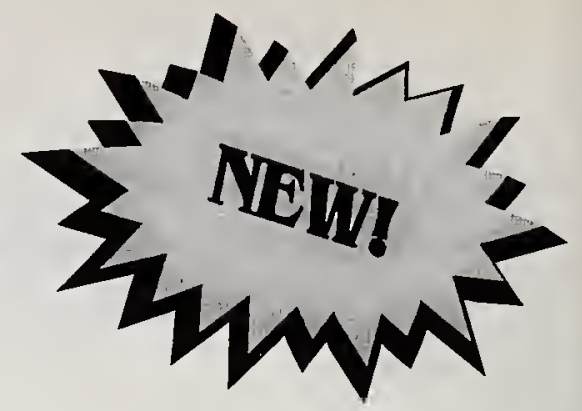

Malcolm W. Chase

Standard Reference Data Program

National Institute of Standards and Technology

Gaithersburg, MD 20899

(301) $975-2200$

chase@micf.nist.gov

$T$ his database is a representation on the JANAF Thermochemical

1 Tables in an equation format consistent with use in the NASALewis equilibrium code (often referred to as CEC - the chemical equilibrium calculation, which was developed at the NASA-Lewis Research Center in Cleveland, $\mathrm{OH}$ ). These tabulations are represented by one or more sets of coefficients, which are derived from the following equation:

$$
C_{p}=a+b T+c T^{2}+d T^{3}+e T^{4} .
$$

If possible, one set of coefficients is used to represent the entire thermochemical tabulation. Typically, however, two sets of coefficients are necessary with the temperature ranges being 298-1000 K and 1000-6000 K. The selected coefficients can be written to a file for use with the CEC program.

This database is available on $3 \frac{112}{2}$ and $51 / 4 "$ diskettes. 


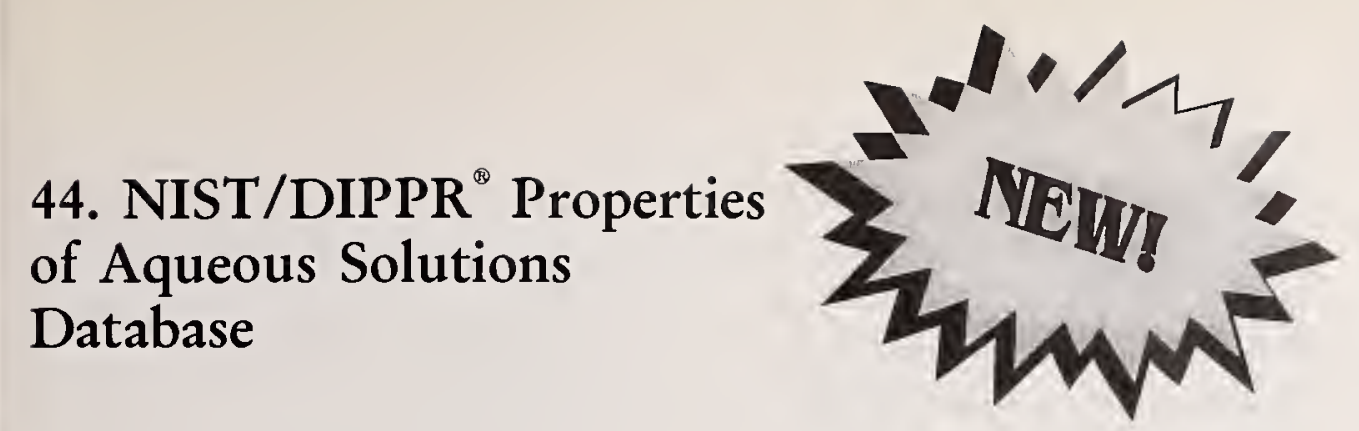

David Neumann

Chemical Thermodynamics Data Center

National Institute of Standards and Technology

Gaithersburg, MD 20899

(301) 975-2525

neumann@enh.nist.gov

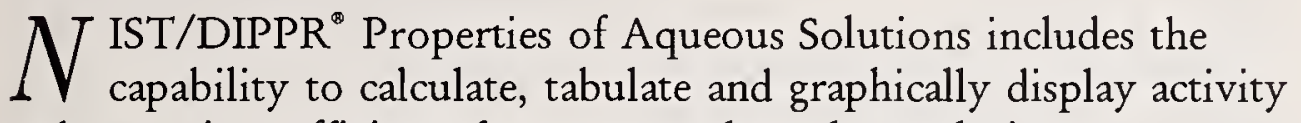
and osmotic coefficients for aqueous electrolyte solutions.

Approximately 350 solutes are represented. Temperature dependent properties are given for some species. Activities and osmotic coefficients for mixed electrolyte solutions are also provided. This software resulted from DIPPR ${ }^{\oplus}$ Project 861.

This database is available on $3 \frac{1 / 2}{2}$ and $5 \frac{1 / 4}{1}$ disks.

\section{Thermodynamic and Thermochemical Databases}

For information

or to order:

Phone (301) 975-2208 or FAX (301) 926-0416 


\section{Thermodynamic and Thermochemical Publications}

For information or to order:

Phone (301) 975-2208 or FAX (301) 926-0416
The NBS Tables of

Chemical

Thermodynamic

Properties. Selected

Values for Inorganic and $C_{1}$ and $C_{2}$ Organic

Substances in SI Units

Donald D. Wagman,

William $\mathrm{H}$. Evans,

Vivian B. Parker,

Richard H. Schumm,

Iva Halow, Sylvia M. Bailey,

Kenneth L. Churney, and

Ralph L. Nuttall.

Journal of Physical and

Chemical Reference Data 11,

Supplement 2 (1982).

This publication provides the chemical thermodynamic properties of inorganic substances and organic substances usually containing only one or two carbon atoms. Where available, values are given for the enthalpy of formation, Gibbs energy of formation, entropy and heat capacity at $298.15 \mathrm{~K}$, the enthalpy difference between 298.15 and $0 \mathrm{~K}$, and the enthalpy of formation at $0 \mathrm{~K}$.

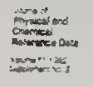

The NBS tables of chemical thermodynamic properties

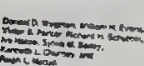

Aิ al.

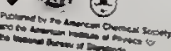

All values are given in SI units and are for a standard state pressure of 100,000 pascal. Gaseous, liquid, and crystalline substances, solutions in water, and mixed aqueous and organic solutions are given values. This publication supersedes the National Bureau of Standards Technical Note 270 series. Available from the American Chemical Society U.S. and Canada $\$ 80.00$ Abroad \$96.00 


\section{JANAF}

\section{Thermochemical}

\section{Tables. Third Edition}

M.W. Chase, Jr., C.A. Davies, J.R. Downey, Jr., D.J. Frurip, R.A. McDonald and

A.N. Syverud.

Journal of Physical and Chemical Reference Data 14, Supplement 1 (1985).

These updated volumes contain thermodynamic properties for more than 1,800 substances over a wide temperature range. All tables are in SI units and the notation has been made consistent with current

\section{Gas-Phase Ion} and Neutral

\section{Thermochemistry -}

S.G. Lias, J.E. Bartmess, J.L. Holmes, R.D. Levin, J.F. Liebman, and W.G. Mallard. Journal of Physical and Chemical Reference Data 17, Supplement 1 (1988).

This volume includes evaluated ionization energies of 4,000 atoms and molecules and proton affinities of 1,000 compounds, as well as electron affinities and gas-phase acidities of approximately 3,000 species. The thermochemistry of the related neutral species is also provided. international recommendations.

There are single-phase and multiphase tables in the crystal, liquid, and ideal gas states. The properties tabulated are heat capacity, entropy, Gibbs energy function, enthalpy of formation, Gibbs energy of formation, and the logarithm of the equilibrium constant for formation of each compound. Each tabulation is accompanied by a critical evaluation of the literature upon which the thermochemical table is based and literature references are given.

Available from the American

Chemical Society

U.S. and Canada $\$ 260.00$

Abroad \$312.00

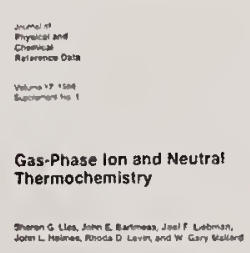

- III III

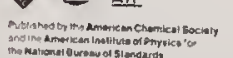

Available from the American Chemical Society U.S. and Canada $\$ 140.00$

Abroad \$168.00
Thermodynamic and

Thermochemical Publications
For information

or to order:

Phone (301) 975-2208

or FAX (301) 926-0416 


\section{Thermodynamic and Thermochemical Publications}

For information or to order: Phone (301) 975-2208 or FAX (301) 926-0416
Physical and

Thermodynamic

Properties of Pure

Chemicals

T.E. Daubert and

R.P. Danner.

Hemisphere Press, NY, 1989.

Hemisphere Press, NY.
This 4-volume looseleaf set offers an encyclopedic guide to pure chemical properties and contains more than 2,000 pages of recommended physical, thermodynamic, and transport property data for 900 of the most common chemicals. Approved by the AIChE and the NIST Standard Reference Data Program, this compilation contains critically evaluated, internally consistent data that follow the laws of physical chemistry. The data were developed on a project supported by the Design Institute for Physical Property Data (DIPPR) ${ }^{\star}$

Supplement 1 contains data on 121 additional chemicals and includes a synonyms list, references, errata for property constants, errata for references, tables for new compounds, and replacement tables for acids.

Supplement 2 provides data on 191 additional chemicals.

Supplement 3 contains data on 72 additional chemicals.

Supplement 4 contains data on 67 additional chemicals.

Available from Taylor and Francis, Bristol, PA, (800) 821-8312.

Core Set, 900 chemicals, $1989 \$ 362.00$

Supplement 1, 121 chemicals, $1991 \$ 110.00$

Supplement 2, 191 chemicals, $1992 \$ 150.00$

Supplement 3, 72 chemicals, $1993 \$ 125.00$

Supplement 4, 67 chemicals, $1994 \$ 140.00$ 


\section{Thermodynamic}

Properties of Individual Substances

Edited by L.V. Gurvich, I.V. Veyts, and C.B. Alcock. Two volumes in two parts. Hemisphere Press, NY, 1990.
This important resource, recently updated, contains thermodynamic properties of about 1,100 condensed and gaseous substances formed by 50 elements. The first volume studies 15 elements $(\mathrm{O}, \mathrm{H}$ (D, T), F, Cl, Br, I, He, Ne, AR, $\mathrm{Kr}, \mathrm{Xe}, \mathrm{Rn}, \mathrm{S}, \mathrm{N}, \mathrm{P}$ ) and has numerical values in tabular format for heat capacity, entropy, Gibbs energy function, enthalpy, and equilibrium constant.

Volume 2 deals with the properties of 5 elements (carbon, silicon, germanium, tin, and lead) and their compounds with oxygen, hydrogen, halogens, sulfur, and nitrogen.

Available from Taylor and Francis, Bristol, PA, (800) 821-8312,

Vol. $1 \$ 262.00$, Vol. $2 \$ 310.00$

\section{Heat Capacities and} Entropies of Organic Compounds in the Condensed Phase

Eugene S. Domalski, William H. Evans, and Elizabeth D. Hearing. Journal of Physical and Chemical Reference Data 13, Supplement 1 (1984).
Heat capacities and entropies have been compiled for approximately 1400 organic compounds in the liquid and solid phases. Values for the enthalpies and entropies of phase transitions - solid state, fusion, and vaporization - which were encountered as part of this evaluation and tabulation are included. Articles begin at approximately 1925 . The data given for each compound in the tabulation are: empirical formula, physical state, reference code, compound name(s), heat capacity, entropy, and, where available, phase-transition data, Wiswesser Line Notation for the compound, formula weight, and a rating which indicates the estimated overall quality of the reported data. Available from the American Chemical Society U.S. and Canada $\$ 80.00$

Abroad $\$ 96.00$

\section{Thermodynamic and Thermochemical Publications}

For information

or to order:

Phone (301) 975-2208 or FAX (301) 926-0416 


\section{Thermodynamic and \\ Thermochemical Publications}

For information

or to order:

Phone (301) 975-2208 or FAX (301) 926-0416
Estimation of the Thermodynamic

Properties of

C-H-N-O-S-Halogen

Compounds at

298.15 K

Eugene S. Domalski and

Elizabeth D. Hearing.

Journal of Physical and

Chemical Reference Data 22, 805 (1993).
Benson's method has been extended from calculation of thermodynamic properties of organic compounds in the gas phase to the liquid and solid phases for organic compounds at $298.15 \mathrm{~K}$ and 101.325 Pa. Comparisons of estimated enthalpies of formation, heat capacities, and entropies with the condensed phase is easy to apply and gives satisfactory agreement. Corresponding values for the entropy of formation, Gibbs energy of formation and natural logarithm of the equilibrium constant for the formation reaction are also calculated. The work covers 1512 compounds containing the elements: carbon, hydrogen, oxygen, nitrogen, sulfur, and halogens in the gas, liquid, and solid phases.

Available from the American Chemical Society, Reprint 458, $\$ 80.00$ 
$P$ roviding reliable data on the thermophysical properties of fluid mixtures has been a primary area of focus of the SRD Program. A set of combined theoretical and empirical predictive techniques have been developed that rest firmly on evaluated data. These techniques have been tested and incorporated into interactive computer programs that generate a large variety of properties based upon the specified composition and the appropriate state variables.

Databases are now available for hydrocarbon mixtures, including natural gas, as well as a number of pure and mixed fluids of industrial importance. REFPROP continues to be a timely and valuable tool for refrigeration engineers, chemical and equipment manufacturers, and others who use chlorofluorocarbons. It now provides data on 38 pure refrigerants and refrigerant mixtures.

The new NIST Thermophysical Properties of Pure Fluids has undergone a major update - now including 34 thermophysical properties of 17 pure fluids.

\section{SRD Fluids Properties Databases}

NIST Thermophysical Properties of Pure Fluids

NIST Thermodynamic Properties of Refrigerants and Refrigerant Mixtures

NIST Thermophysical Properties of Hydrocarbon Mixtures NIST Mixture Property

NIST Thermophysical Properties of Water

PICT/NIST Heat Capacities of Liquid Hydrocarbons

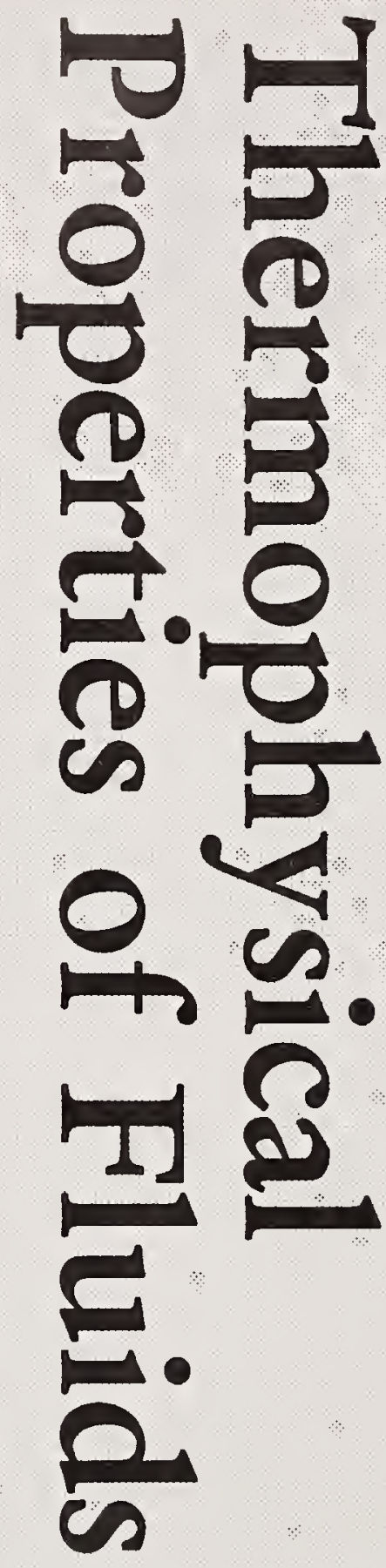


Thermophysical Properties of Fluids Databases
For information

or to order:

Phone (301) 975-2208 or FAX (301) 926-0416

\section{NIST Thermophysical Properties of Pure Fluids Database \\ Version 3.0}

\section{Daniel G. Friend \\ Fluid Mixtures Data Center \\ National Institute of Standards and Technology \\ Boulder, CO 80303 \\ (303) 497-5424 \\ dfriend@central.bldrdoc.gov}

7 his database is a major update of NIST Standard Reference Calculate Thermophysical Properties of Fluids - MIPROPS. Like the previous version, this new update computes thermophysical properties according to the extremely accurate and wide-ranging NIST Standard Reference correlations. This version provides great flexibility in the choice of units, output parameters, and input parameters. Properties at the desired state points or tabular information, in the form of isochores, isobars, isotherms, and isentropes may be displayed and saved in a file for further use. The FORTRAN source code may also be provided, enabling users to incorporate properties directly into design, simulation, or other property-dependent software.

The fluids available in this database are:
- Argon

- Butane (Iso)

- Butane (Normal)

- Carbon dioxide

- Carbon monoxide

- Deuterium

- Ethane

- Ethylene

- Helium (including superfluid states)
- Hydrogen (Normal)

- Hydrogen (Para)

- Methane

- Nitrogen

- Nitrogen trifluoride

- Oxygen

- Propane

- Xenon
The database provides equilibrium thermodynamic properties (based on a 32-term modified Bennedict-Webb-Rubin (MBWR) equation of state) for each fluid in addition to transport properties (viscosity and thermal conductivity) and dielectric constants for most of the fluids. There are a total of 34 thermophysical properties included in this database.

This database is available on $3 \frac{1 / 2}{2}$ and $51 / 4 "$ disks. 


\section{NIST Thermodynamic Properties of Refrigerants and Refrigerant Mixtures Database (REFPROP) Version 4.0}

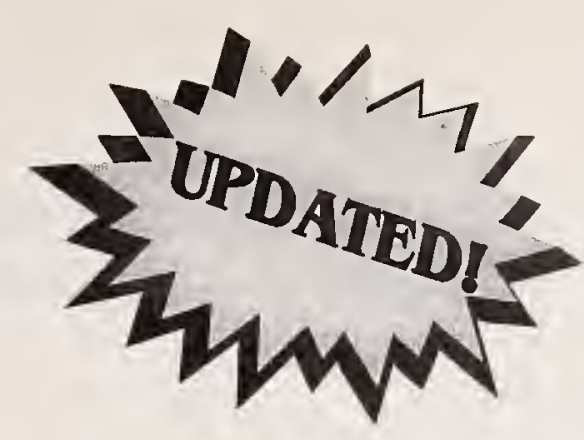

\section{Mark McLinden}

Fluid Mixtures Data Center

National Institute of Standards and Technology Boulder CO 80303

(303) 497-3580 markm@boulder.doc.gov

\begin{abstract}
N IST REFPROP calculates thermodynamic and transport
$N$ properties of 38 pure refrigerants and refrigerant mixtures. The package enables the user to evaluate a wide range of refrigerants and refrigerant mixtures (with up to five components) including the new environmentally acceptable ethane-based refrigerants. Version 4.0 is a significant enhancement of this important database.
\end{abstract}

The database includes the following fluids:

$\begin{array}{lll}\text { R11 } & \text { R123a (NEW) } & \text { R245cb (NEW) } \\ \text { R12 } & \text { R124* } & \text { R290* } \\ \text { R13 } & \text { R125* } & \text { E134 } \\ \text { R13B1 } & \text { R134 } & \text { RC270 } \\ \text { R14 } & \text { R134a* } & \text { n-Butane (NEW)* } \\ \text { R21 } & \text { R141b } & \text { i-Butane (NEW)* } \\ \text { R22 } & \text { R142b } & \text { n-Pentane (NEW)* } \\ \text { R23 } & \text { R143 } & \text { i-Pentane (NEW)* } \\ \text { R32 (NEW)* } & \text { R143a } & \text { Ammonia (NEW) } \\ \text { R113 } & \text { R152a } & \text { RC318 } \\ \text { R114 } & \text { R218 } & \text { E245 (NEW) } \\ \text { R115 } & \text { R227ea (NEW) } & \text { Carbon Dioxide (NEW)* } \\ \text { R123* } & \text { R236ea (NEW) } & \end{array}$

Based upon new measurements, values of the mixture interaction parameter are now available for 65 binary mixture pairs. Combined with an algorithm for estimating interaction parameters where measurements are not available, reliable estimates of the properties of all mixtures can be obtained. For eleven fluids (indicated by a * on the above list) there is now also a highly accurate MBWR equation of state for the pure fluid properties. Ammonia properties are calculated with a special, high-accuracy equation of state. Fourteen properties are available, including enthalpy, entropy, viscosity, and thermal conductivity, and the user may choose which of these to display. The user may store the responses to oft-repeated questions to shorten the dialog process before calculation begins. FORTRAN source code is also included for those wishing to access the property routines from their own applications.

The database is available on $31 / 2$ " and $51 / 4 "$ disks. It may also be used on Macintosh computers with PC emulator software.
Thermophysical Properties of Fluids Databases

For information

or to order:

Phone (301) 975-2208

or FAX (301) 926-0416 


\section{Thermophysical Properties of Fluids Databases}

For information or to order: Phone (301) 975-2208 or FAX (301) 926-0416

\section{NIST Thermophysical Properties of Hydrocarbon Mixtures Database}

\section{Marcia Huber \\ Fluid Mixtures Data Center \\ National Institute of Standards and Technology Boulder, CO 80303 \\ (303) 497-5252 \\ huber@enh.nist.gov}

$T$ his powerful database (also called SUPERTRAPP) is an 1 interactive program for predicting thermodynamic properties of pure fluids and fluid mixtures of up to 20 components. The components are selected from a database of 116 components, mostly hydrocarbons. SUPERTRAPP performs phase equilibria calculations and gives the thermodynamic properties of all phases and the feed. These results include:

\section{Equilibrium properties}

- density

- compressibility factor

- enthalpy

- entropy

- $\mathrm{Cp}$

- $\mathrm{Cp}_{\mathrm{p}} / \mathrm{Cr}_{\mathrm{V}}$

- sound speed

- Joule-Thomson coefficient

SUPERTRAPP features commands that allow you to:

- perform bubble point pressure calculations

- perform dew point pressure calculations

- perform isothermal flash calculations

- obtain properties of pure components along the saturation boundary

- produce tables of properties along isobars or isotherms

- change units

- learn (and remember) a new component not in the current database

- enter data from the keyboard or from data files

- save results in a file

SUPERTRAPP comes on both $3 \frac{1}{2} "$ and $51 / 4 "$ high and low density disks. 


\section{NIST Mixture Property Database}

\section{Daniel G. Friend}

Fluid Mixtures Data Center

National Institute of Standards and Technology Boulder, CO 80303

(303) 497-5424

\section{dfriend@central.bldrdoc.gov}

$T$ he NIST Mixture Property Database (also called NIST14) is a 1 database which calculates various thermodynamic and transport properties of mixtures of fluids selected from any of 17 possible pure components. The emphasis of the database is on density prediction (especially for $\mathrm{CO}_{2}$-rich mixtures), but it will provide accurate results for other properties and mixtures.

All phase equilibrium calculations are performed with the PengRobinson equation of state, and coexisting phase properties are calculated with the NIST extended corresponding states model. Mixtures formed from any of 17 pure components (including hydrocarbons, nitrogen, oxygen, argon, carbon monoxide, carbon dioxide, and hydrogen sulfide) are handled by the database.

NIST14 predicts the following outputs for any specified mixture:

- bubble point pressure and temperature

- dew point pressure and temperature

- saturation properties

- tables of density, enthalpy, entropy, and heat capacity as functions of $\mathrm{T}$ or $\mathrm{P}$

- isothermal flash calculation yielding density, enthalpy, entropy, heat capacity, viscosity, and thermal conductivity of feed and vapor

This database is available on $5^{1 / 4}$ " and $3 \frac{1}{2} "$ disks.

\section{Thermophysical Properties of Fluids Databases}

For information or to order: Phone (301) 975-2208 or FAX (301) 926-0416 


\section{Thermophysical Properties of Fluids Databases}

\section{For information or to order: \\ Phone (301) 975-2208 or FAX (301) 926-0416}

\section{NIST Thermophysical Properties of Water Database}

\author{
John S. Gallagher \\ Thermophysics Division \\ National Institute of Standards and Technology \\ Gaithersburg, MD 20899 \\ (301) 975-2455 \\ gall@tiber.nist.gov
}
$T$ his database consists of an interactive program which calculates 1 the thermodynamic properties of fluid $\mathrm{H}_{2} \mathrm{O}$ (liquid and vapor) using the formulation as approved by the International Association for the Properties of Steam (IAPS) at its Tenth International Conference in 1984.

The interactive FORTRAN 77 program consists of three parts. The first part contains a package of subroutines to calculate the thermodynamic and transport properties of fluid $\mathrm{H}_{2} \mathrm{O}$. The other parts are main programs which call these routines to generate properties of $\mathrm{H}_{2} \mathrm{O}$ interactively.

The main program allows the calculation and display of all properties at a single pair of independent variables:

$$
\begin{aligned}
& \text { pressure - temperature } \\
& \text { density - temperature } \\
& \text { entropy - temperature } \\
& \text { enthalpy - temperature } \\
& \text { enthalpy - pressure }
\end{aligned}
$$

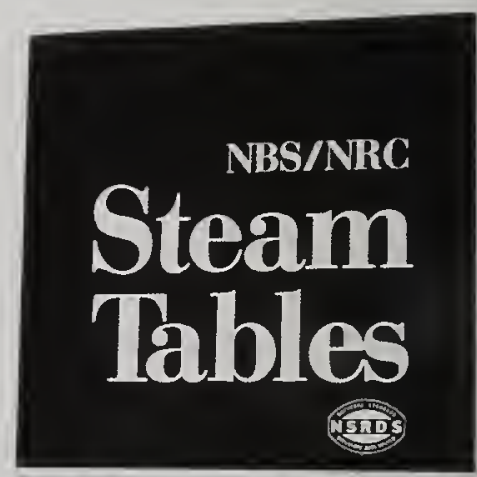

The second main program allows the generation of tables of properties along isotherms, isobars, or isochores. To keep the tabular form compact, the user may choose which properties are to be displayed.

The range approved by IAPS for this formulation includes temperatures from 0 to $1000{ }^{\circ} \mathrm{C}$ and pressures up to $1500 \mathrm{MPa}$. The range over which usable results will be obtained extends to $2500 \mathrm{~K}$ and to $3000 \mathrm{MPa}$. This database is available in a PC diskette version. It can also be used on Macintosh computers which have a PC emulator program.

The printed version of this database, which includes a description of the data selection and evaluation procedures, is found in NBS/NRC Steam Tables - L. Haar, J.S. Gallagher, and G.S. Kell, Taylor and Francis, Bristol, PA. 
41. PICT/NIST Heat

Capacities of Liquid

Hydrocarbons Database

E.S. Domalski

Chemical Thermodynamics Data Center

National Institute of Standards and Technology

Gaithersburg, MD 20899

(301) 975-2529

domal@enh.nist.gov

$D$ eveloped at the Prague Institute of Chemical Technology, this

1 database provides rapid and convenient access to critically assessed data on heat capacities of liquid hydrocarbons. The database provides:

- parameters of a correlating equation accompanied by the temperature interval to which the parameters relate and by an estimate of the overall percent error of the equation values

- tables of heat capacities in a specified temperature interval

- enthalpy and entropy difference between two specified temperatures

Selected data are displayed on the screen and can optionally be directed to an output device or disk file. The database can be searched by:

- chemical class

- molecular formula

- Chemical Abstracts Service Registry Number

- serial number

The hydrocarbon compounds are subdivided into: saturated aliphatic hydrocarbons; saturated cyclic hydrocarbons; unsaturated aliphatic hydrocarbons; aromatic and unsaturated cyclic hydrocarbons.

This database is available on $5 \frac{1}{4} 4$ and $31 / 2$ " disks. It can be used on Macintosh computers which have PC emulator software.
Thermophysical Properties of Fluids Databases
For information or to order:

Phone (301) 975-2208 or FAX (301) 926-0416 


\section{Thermophysical Properties of Fluids Publications}

Evaluation of Solubility Data of the System $\mathrm{CO}_{2}-\mathrm{H}_{2} \mathrm{O}$ from $273 \mathrm{~K}$ to the Critical Point of Water

Rosa Crovetto.

Journal of Physical and

Chemical Reference Data 20, 590 (1991).

\section{Thermophysical} Properties of Ethane Daniel G. Friend, Hepburn Ingham, and James F. Ely.

Journal of Physical and Chemical Reference Data 20, 275 (1991).

Sixteen Thousand

Evaluated

Experimental

Thermodynamic Property Data for Water and Steam H. Sato, K. Watanabe, J.M.H. Levelt Sengers, J.S. Gallagher, P.G. Hill, J. Straub, and W. Wagner. Journal of Physical and Chemical Reference Data 20, 1023 (1991).
Measurements on the solubility of carbon dioxide in water in the range of $273-647 \mathrm{~K}$ are reviewed and evaluated. Recommended values of the solubility are presented in the form of Henry's constants as a function of temperature and density. Available from the American Chemical Society, JPCRD Reprint 416, $\$ 10.00$

Data on the thermodynamic and transport properties of ethane have been reevaluated and correlated using a new set of functions. A new equation of state is presented, which is accurate in the range of 90-625 K at pressures up to 70 $\mathrm{MPa}$. Tables of recommended thermophysical properties are also provided.

Available from the American Chemical Society, JPCRD Reprint $410, \$ 18.00$

As part of the activities of the International Association for the Properties of Water and Steam, all reliable sources of experimental data on the thermodynamic properties of ordinary (light) water and steam have been collected and converted to common temperature, pressure, volume, mass, and heat scales. Properties include the volume, enthalpy, heat capacities, sound velocity, internal energy, and Joule-Thomson and related coefficients.

Available from the American Chemical Society, JPCRD Reprint 424, $\$ 12.00$
For information

or to order:

Phone (301) 975-2208 or FAX (301) 926-0416 


\section{NIST Binary Images of Printed Digits, Alphas, and Text (HWDB)}

\section{Charles Wilson}

\section{Advanced Systems Division}

National Institute of Standards and Technology Gaithersburg, MD 20899 (301) $975-2080$ wilson@magi.ncsl.nist.gov

$T$ he NIST handprinted character database consists of 2,100 pages 1 of bilevel, black-and-white image data of handprinted numerals and text with a total character count of over $1,000,000$ characters. This database totals approximately 3 gigabytes of image data with 273,000 numerals and 707,700 alphabetic characters. With the sample taken from the Bureau of Census field staff and also geographically sampled, the database has the following features:

- over $1,000,000$ character images

- $300 \mathrm{pixel} /$ inch resolution

- images of full pages of data

- images of numbers with 2, 3, 4, 5, and 6 digits

- images of full alphabets

- images of unconstrained text

Suitable for both character recognition system research, development, and evaluation, the data set can be used for:

- field isolation: locating the text on the page

- character segmentation: separating the text into characters

- character recognition: identifying specific characters

The database is also a valuable tool for measurement of system performance and system comparison.

The system requirements are a CD-ROM drive with software to read ISO-9660 format. 


\section{NIST \\ Special \\ Databases}

For information

or to order:

Phone (301) 975-2208

or FAX (301) 926-0416

\section{NIST Structured Forms Reference Set of Binary Images (SFRS)}

\section{Charles Wilson}

Advanced Systems Division

National Institute of Standards and Technology

Gaithersburg, MD 20899

(301) 975-2080

wilson@magi.ncsl.nist.gov

FRS consists of 5,590 pages of binary, black-and-white images of $\int$ synthesized documents. The documents in this database are 12 different tax forms from the IRS 1040 Package X for the year 1988. These include Forms 1040, 2106, 2441, 4562, and 6251 together with Schedules A, B, C, D, E, F, and SE. Eight of these forms contain two pages or form faces; therefore, there are 20 different form faces represented in the database. The document images in this database appear to be real forms prepared by individuals, but the images have been automatically derived and synthesized using a computer. There are 900 simulated tax submissions represented in the database averaging 6.2 form faces per submission. This significant new database totals approximately 5.9 gigabytes of uncompressed image data including image format documentation and example software.

The database has the following features:

- 900 simulated tax submissions

- 5,590 images of completed structured form faces

- $300 \mathrm{pixel} /$ inch resolution

- 5,590 text files containing entry field answers

- 20 tables of entry field types and contexts

- image format documentation and example software

This database is a valuable tool for measurement of system performance and system comparison on complex forms.

The system requirements are a CD-ROM drive with software to read ISO-9660 format. 


\section{NIST Binary Images of Handwritten Segmented Characters (HWSC)}

\section{Charles Wilson}

Advanced Systems Division

National Institute of Standards and Technology Gaithersburg, MD 20899

(301) 975-2080

wilson@magi.ncsl.nist.gov

W WS contains 313,389 isolated character images segmented $\Pi$ from the 2,100 full-page images distributed with NIST Special Database 1. The database includes the 2,100 pages of binary, blackand-white, images of handprinted numerals and text. This significant new database contains 223,125 digits, 44,951 upper-case, and 45,313 lower-case character images. Each character image has been centered in a separate 128-by-128 pixel region and has been assigned a classification which has been manually corrected so that the error rate of the segmentation and assigned classification is less than $0.1 \%$. The uncompressed database totals approximately 2.75 gigabytes of image data and includes image format documentation and example software.

NIST Special Database 3 has the following features:

- 313,389 isolated character images including classifications

- 223,125 digits, 44,951 upper-case, and 45,313 lower-case character images

- 2,100 full-page images

- 12 pixel per millimeter resolution

- image format documentation and example software

Suitable for automated hand-print recognition research, the database can be used for:

- algorithm development

- system training and testing

The database is a valuable tool for training recognition systems on a large statistical sample of handprinted characters. The system requirements are a $51 / 4$ " CD-ROM drive with software to read ISO-9660 format.

\section{NIST \\ Special \\ Databases}

\section{For information \\ or to order:}

Phone (301) 975-2208 or FAX (301) 926-0416 


\section{NIST \\ Special \\ Databases}

\section{NIST 8-Bit Gray Scale Images of Fingerprint Image Groups (FIGS)}

\section{Craig Watson Advanced Systems Division National Institute of Standards and Technology Gaithersburg, MD 20899 (301) 975-4402 craig@magi.ncsl.nist.gov}

$T$ he NIST database of fingerprint images contains 2000 8-bit gray with 32 rows of white space at the bottom and classified using one of the five following classes: $A=A r c h, L=L e f t$ Loop, $R=$ Right Loop, $\mathrm{T}=$ Tented Arch, $\mathrm{W}=$ Whirl. The database is evenly distributed over each of the five classifications with 400 fingerprint pairs from each class. The images are compressed using a modified JPEG lossless compression algorithm and require approximately 636 megabytes of storage compressed and 1.1 gigabytes uncompressed (1.6:1 compression ratio). The database also includes format documentation and example software.

NIST Special Database 4 has the following features:

- 2000 8-bit gray scale fingerprint image pairs including classifications

- 400 fingerprint pairs from each of the five classifications Arch, Left and Right Loops, Tented Arch, Whirl

- each of the fingerprint pairs are two completely different rollings of the same fingerprint

- 19.6850 pixels per millimeter resolution

- image format documentation and example software

Suitable for automated fingerprint classification research, the database can be used for:

- algorithm development

- system training and testing

The database is a valuable tool for evaluating fingerprint systems on a statistical sample of fingerprints which is evenly distributed over the five major classifications. The system requirements are a 51/4" CD-ROM drive with software to read ISO-9660 format.
For information

or to order:

Phone (301) 975-2208 or FAX (301) 926-0416 


\section{IVTANTHERMO-PC}

\section{Malcolm W. Chase \\ Standard Reference Data Program \\ National Institute of Standards and Technology Gaithersburg, MD 20899 \\ (301) $975-2200$ \\ chase@micf.nist.gov}

VTANTHERMO is a computerized system providing
information on the thermodynamic properties of about 2,300 substances (containing 85 elements and the electron) in the standard state over a wide temperature range. It was developed by scientists at the Institute of High Temperatures in Moscow. The software permits the calculation of thermodynamic parameters of chemical reactions and the composition of chemical systems. All recommended values are cited with a reliability assessment.

This database is capable of thermodynamic analysis of:

- new high-temperature processes, including combustion processes

- the optimization of chemical processes, including synthesis of refractory materials and microelectronic materials

- stability of materials at high temperatures and in various media

- chemical processes occurring in power-generating facilities, including nuclear plants

- the optimization of raw materials; use and waste management

- the emissions of incinerators and industrial exhaust gases into the atmosphere

The database contains the following information on each substance:

- substance name and chemical formula

- accuracy of thermodynamic properties

- isobaric heat capacity; entropy; change of enthalpy; Gibbs energy function

- equation(s) fitting tabulated values of Gibbs energy function

- enthalpy of formation; equilibrium constant

The software provides a choice of formats, temperature scales, and energy units.

The methodology of the evaluation process of IVTANTHERMO is described in Volume 1 of the hard copy series Thermodynamic Properties of Individual Substances which is available from CRC Press, Inc. The data contained in this database will be included in a series of publications (5 volumes) available from CRC Press, Inc.

The database is available on $51 / 4$ " and $31 / 2$ " disks. It can also be used on Macintosh computers which have PC emulator software.

\section{NIST \\ Special \\ Databases}

For information

or to order:

Phone (301) 975-2208

or FAX (301) 926-0416 


\section{NIST \\ Special \\ Databases}

For information

or to order:

Phone (301) 975-2208 or FAX (301) 926-0416

\section{NIST Structured Forms Reference Set of Binary Images II (SFRS2)}

\section{Darrin Dimmick \\ Advanced Systems Division \\ National Institute of Standards and Technology \\ Gaithersburg, MD 20899 \\ (301) 975-4147 \\ dld@magi.ncsl.nist.gov}

$T$ he second NIST database of structured forms contains full page The structured forms used in this database are 12 different forms from the 1988, IRS 1040 Package X. These include Forms 1040, 2106, 2441, 4562, and 6251 together with Schedules A, B, C, D, E, F, and SE. Eight of these forms contain two pages or form faces making a total of 20 form faces represented in the database.

Each image is stored in bi-level black-and-white raster format. The images in this database appear to be real forms prepared by individuals, but the images have been automatically derived and synthesized using a computer and contain no "real" tax data. The entry field values on the forms have been automatically generated by a computer in order to make the data available without the danger of distributing privileged tax information.

In addition to the images, the database includes answer files, one for each image. Each answer file contains an ASCII representation of the data found in the entry fields on the corresponding image. Image format documentation and example software are also provided.

SFRS2 has the following features:

- full-page images of completed structured form faces

- answer files

- 12 pixel per millimeter resolution

- 20 tables of entry field types and context

- image format documentation and example software 
Suitable for both document processing and automated data capture research, development and evaluation, the database can be used for:

- forms identification

- field isolation: locating entry fields on the form

- character segmentation: separating entry field values into characters

- character recognition: identifying specific handprinted characters.

The database is a valuable tool for measurement of system performance and system comparison on complex forms. The system requirements are a $5 \frac{1 / 4}{}$ " CD-ROM drive with software to read ISO-9660 format.

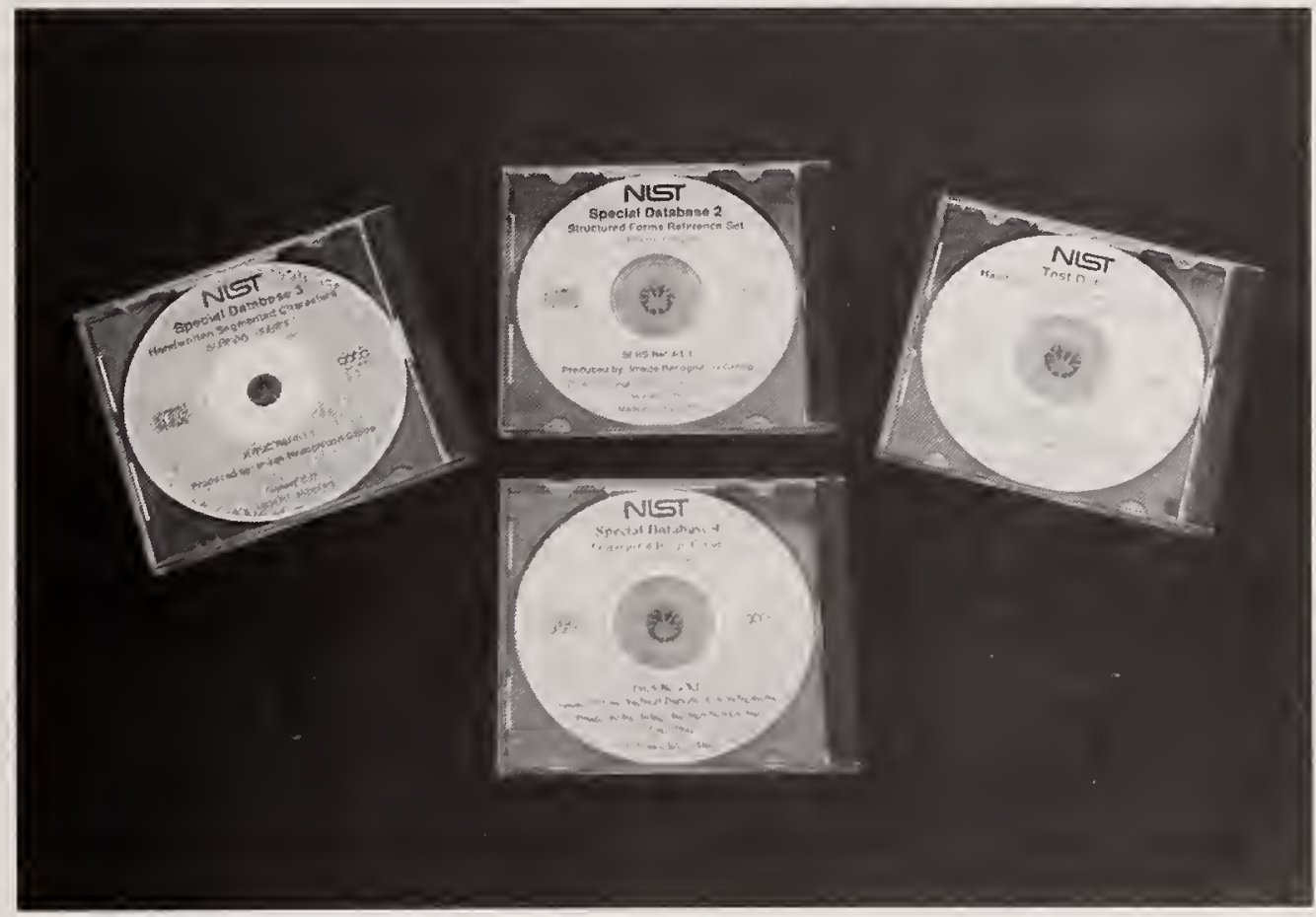

The NIST Special Database Series on CD-ROM continues to expand.

\section{NIST \\ Special \\ Databases}

\section{For information}

or to order:

Phone (301) 975-2208 or FAX (301) 926-0416 


\section{NIST \\ Special \\ Databases}

For information

or to order:

Phone (301) 975-2208 or FAX (301) 926-0416

\section{NIST Test Data 1: Binary Images of Handprinted Segmented Characters (TST1)}

\section{Jon Geist}

Advanced Systems Division

National Institute of Standards and Technology

Gaithersburg, MD 20899

(301) 975-2066

geist@sed.eeel.nist.gov

7 his NIST database contains almost 83,000 binary, black-and-

1 white images of handprinted numerals and letters segmented from 500 forms of the same type used for NIST Special Database 3 - NIST Binary Images of Handwritten Segmented Characters. However, the forms were filled out by a writer population very different from that of the Bureau of Census field workers who filled out the 2,100 forms used for that database. NIST Test Data 1 is the database that was used for testing in the First Census OCR Systems Conference in May, 1992.

NIST Test Data 1 has the following features:

51/4" CD-ROM

- approximately 83,000 isolated character images without classifications

- approximately 59,000 digits and 24,000 upper-case and lower-case images

- 12 pixel per millimeter resolution

51/4" floppy disk

- keyed classifications for all character images on CD-ROM

- keyed index to 500 writers

This database is suitable for use in testing OCR systems against the results obtained by over 40 systems in the First Census OCR Systems Conference, and for use as a database for training OCR systems. The system requirements are a 51/4" CD-ROM drive with software to read ISO-9660 format and a 51/4" floppy drive with the software to read high-density MS-DOS format. 


\section{NIST Machine-Print Database of Gray Scale and Binary Images (MPDB)}

\section{Allen Wilkinson \\ Advanced Systems Division \\ National Institute of Standards and Technology \\ Gaithersburg, MD 20899 \\ (301) 975-3383 \\ urt@magi.ncsl.nist.gov}

$M$ PDB contains gray scale and binary images of machine printed pages. There are 360 digitized pages on three CD-ROM discs. There are a total of $3,063,168$ characters in the set which is an average of 8509 characters per page. A reference file is included for each page. These reference files are the ASCII text pages that were used to generate the original hardcopy that was digitized. This database is being distributed for use in the development and testing of Optical Character Recognition (OCR) systems on a common set of images. This allows vendors to report results with respect to this common image set.

The database has the following features:

- 3 font styles: Bold, Italics, and Normal

- 6 font types: Courier, Helvetica, New Century Schoolbook, Optima, Palatino, and Times Roman

- 10 point sizes; $4,5,6,7,8,10,11,12,15,17$, and 20

- randomly generated order and sequential ordered pages

- 360 unique pages each having a gray scale and binary representation

- 12 pixels $/ \mathrm{mm}$ resolution

- 360 text files containing page reference answers

- image format documentation and example software

Suitable for automated machine-print research, development, and evaluation, the data set can be used for:

- algorithm development

- system training and testing

- character segmentation: separating full page image into characters

- character recognition: identifying specific machine-printed characters

The database is a valuable tool for measurement and comparison of system performance on machine-print pages.

The system requirements are a CD-ROM drive with software to read ISO-9660 format.

\section{NIST \\ Special \\ Databases}

For information

or to order:

Phone (301) 975-2208

or FAX (301) 926-0416 


\section{NIST \\ Special \\ Databases}

\section{For information \\ or to order: \\ Phone (301) 975-2208 or FAX (301) 926-0416}

\section{NIST 8-Bit Gray Scale} Images of Mated Fingerprint Card Pairs (MFCP) Volumes 1-5

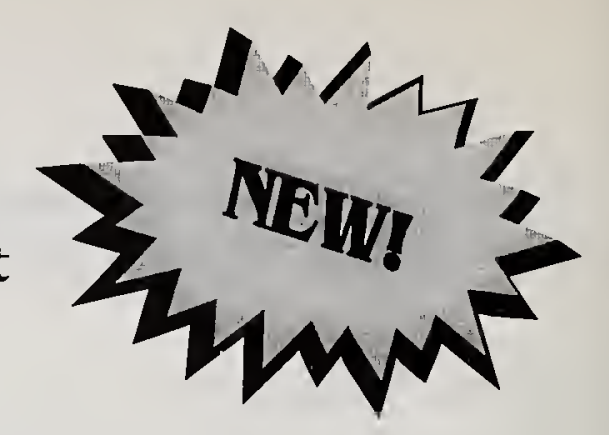

\section{Craig Watson}

Advanced Systems Division

National Institute of Standards and Technology

Gaithersburg, MD 20899

(301) 975-4402

craig@magi.ncsl.nist.gov

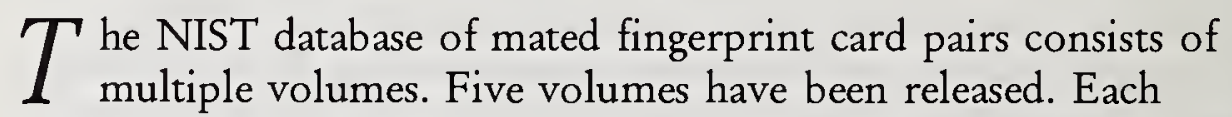
volume will be a 3 -disk set with each CD-ROM containing 90 mated card pairs of segmented 8-bit gray scale fingerprint images (900 fingerprint image pairs per CD-ROM). Each segmented image is 832 by 768 pixels and classified using the National Crime Information Center (NCIC) classes given by the FBI. The images are compressed using a modified JPEG lossless compression algorithm. Each CDROM requires approximately 630-660 megabytes of storage compressed and 1.0-1.2 gigabytes uncompressed (1.8:1 average compression ratio). The database also includes example software which was written on a SUN 4/470 SPARCserver. The software is the same code used with NIST Special Database 4.

NIST Special Database 9 has the following features:

- Each volume has 270 mated card pairs of segmented 8-bit gray scale fingerprint images

- NCIC classifications given by the FBI

- Cards selected randomly thus approximating a natural horizontal slice of the NCIC classifications

- Resolution of approximately 11.0 line pairs per millimeter resolution. Scanned at 19.6850 pixels per mm

- Image format documentation and example software (written on a SUN 4/470 SPARCserver)

- Software is the same code used with NIST Special Database 4

Suitable for automated fingerprint classification research, the database can be used for:

- algorithm development

- system training and testing

The database is a valuable tool for evaluating fingerprint systems using a statistical sample of fingerprints which approximate a natural horizontal slice of the NCIC classifications. 
10. NIST Supplemental

Fingerprint Card Data

(SFCD)

(for Special Database 9-

8-Bit Gray Scale Images)

Craig Watson

Advanced Systems Division

National Institute of Standards and Technology

Gaithersburg, MD 20899

(301) 975-4402

\section{craig@magi.ncsl.nist.gov}

$T$ he NIST database of supplemental fingerprint card data provides $I$ a larger sample of fingerprint patterns that have a low natural frequency of occurrence and transitional fingerprint classes in NIST Special Database 9. The data in NIST Special Database 10 are a 3disk set with the first CD-ROM containing 2160 images and the last 2 CD-ROMs containing 1680 images each. Each segmented image is 832 by 768 pixels and classified using the National Crime Information Center (NCIC) classes given by the FBI. The images are compressed using a non-standard implementation of the JPEG lossless compression algorithm. The first CD-ROM requires approximately 690 megabytes of storage and the second and third CD-ROM require approximately 590 megabytes of storage compressed and 1.4 and 1.1 gigabytes uncompressed (1.9:1 average compression ratio). The database also includes example software which was written on a SUN SPARCserver. The software is the same code used with NIST Special Database 4 and 9.

NIST Special Database 10 has the following features:

- 552 non-mated cards of supplemental data concentrating on arches, tented arches, low ridge count loops and whorls

- NCIC classifications given by the FBI

- Resolution of approximately 11.0 line pairs per millimeter resolution. Scanned at 19.6850 pixels per mm.

- Image format documentation and example software (written on a SUN SPARCserver)

- Software is the same code used with NIST Special Databases 4 and 9.

Suitable for automated fingerprint classification research, the database can be used to aid with:

- algorithm development

- system training or testing

The database is a valuable tool for evaluating fingerprint systems using a sample of fingerprints which provides more examples of low natural occurrence classes and transition NCIC classifications.

\section{NIST \\ Special \\ Databases}

For information

or to order:

Phone (301) 975-2208

or FAX (301) 926-0416 
NIST

Special

Databases
For information

or to order:

Phone (301) 975-2208 or FAX (301) 926-0416
14. NIST Mated Fingerprint Card Pairs 2 (MFCP2)

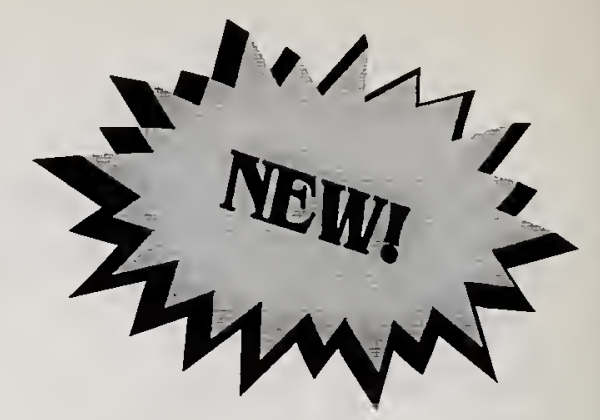

Craig Watson

Advanced Systems Division

National Institute of Standards and Technology

Gaithersburg, MD 20899

(301) 975-4402

craig@magi.ncsl.nist.gov

$W_{\text {IST Special Database } 14 \text { is being distributed for use in }}^{\text {development and testing of automated fingerprint classification }}$ and matching systems on a set of images which approximate a natural horizontal distribution of the National Crime Information Center (NCIC) fingerprint classes and were compressed using an implementation of the wavelet scalar quantization (WSQ) compression specification. The database consists of three CD-ROM disks, each containing 9,000 image pairs and requiring approximately 670 megabytes of storage compressed and 11.5 gigabytes uncompressed (18.0:1 average compression ratio). Each segmented image is 832 by 768 pixels and classified using the NCIC classes given by the FBI. The database also includes example software which was written on a SUN SPARCserver.

NIST Special Database 14 has the following features:

- 27,000 pairs of segmented 8-bit gray scale fingerprint images

- Images compressed with an implementation of the WSQ compression specification

- NCIC classifications given by the FBI

- Cards selected randomly thus approximating the natural horizontal distribution of the NCIC classifications.

- Resolution of approximately 11.0 line pairs per millimeter resolution. Scanned at 19.6850 pixels per $\mathrm{mm}$.

- Image format documentation and example software (written on a SUN SPARCserver)

- The first 13,500 fingerprint images are the same as the images losslessly archived in NIST Special Database 9, Volumes 1-5.

Suitable for automated fingerprint classification research, the database can be used for:

- algorithm development

- system training and testing

The database is a valuable tool for evaluating fingerprint systems using a statistical sample of fingerprints which approximate a natural horizontal distribution of the NCIC classifications and were compressed with an implementation of the WSQ compression specification. 


\section{Data Bank on Reference Materials}

15. COMAR: International

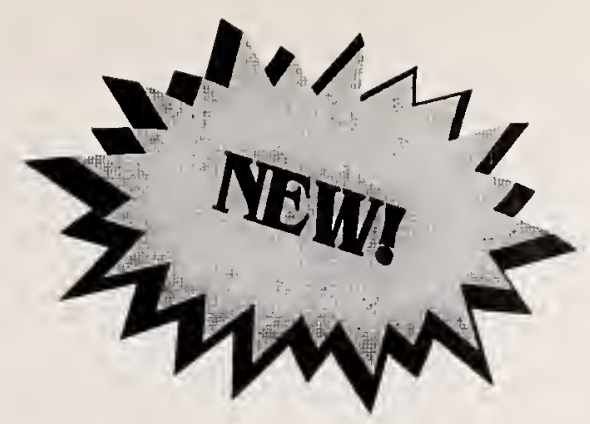

Carmelita S. Davis

Standard Reference Materials

National Institute of Standards and Technology Gaithersburg, MD 20899

(301) 975-6439

carmen@micf.nist.gov

7 his database has its roots in the late 1970s when the Reference

1 Materials Service of the Laboratoire National d'Essais proposed an index COde of Reference MAterials to catalog the various characteristics of Certified Reference Materials (CRM) and Reference Materials (RMs) in a form easily understood and accessible to the international community. Standard Reference Materials are extremely critical because every measurement, particularly chemical analyses or testing of materials, involves the application of standards or references to establish the calibration and verify the accuracy of the measurement. The establishment of COMAR as an international data bank is an effective and efficient means of tracking the continuing development of CRMs, their application and properties.

The Data Bank provides:

- Basic area of application (classified into eight categories and then broken down further into ten sub-categories)

- Certified or reference properties, such as: chemical composition molecular composition physical properties conventional properties

- Form, shape of samples

- Country of origin

- Producer

- Producer CRM

The interrogation software used in the Data Bank makes searching simple by displaying the CRMs that the user has chosen by indicating various qualitative and quantitative criteria. Some of these criteria are the area and sub-area of utilization, the nature and amount of the major element, and the nature and amount of the certified elements.

\section{NIST \\ Special \\ Databases}

For information

or to order:

Phone (301) 975-2208

or FAX (301) 926-0416 


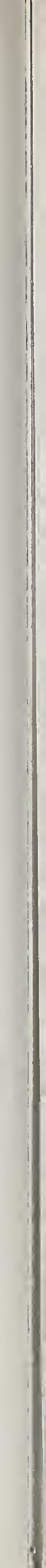


1. NIST Scoring Package

Release 1.0

\section{Michael Garris}

\section{Advanced Systems Division}

National Institute of Standards and Technology

Gaithersburg, MD 20899

(301) 975-2928

\section{mdg@magi.ncsl.nist.gov}

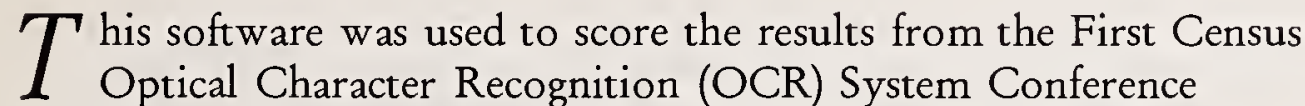
sponsored by the Bureau of the Census and hosted by NIST. A User's Guide is provided which presents the concepts of scoring forms processing systems and character classifiers, discusses the concepts and the algorithm used for dynamic string alignment, defines the files and their formats required as input to the Scoring Package, and documents how the Scoring Package software is installed and invoked.

This software release has the following features:

- supports both form-based and character-based scoring

- applicable to a wide variety of structured forms

- can be used in conjunction with NIST Special Databases (SD1, SD2, SD3, SD6, \& SD7)

- supports user-defined form structures

- includes scoring examples from forms and isolated characters

The NIST Scoring Package can be used to:

- determine whether OCR technology is economically advantageous to deploy for a specific application

- determine which OCR product is best suited for a specific application

- choose from a large variety of diverse algorithmic approaches when developing OCR systems

The NIST Scoring Package has the following attributes and requirements:

- written in the "C" programming language and UNIX shell languages

- developed to run on a UNIX system running SunOS 4.1.1

- distributed on a 5.25" CD-ROM

- requires a CD-ROM drive with ISO-9660 format software

- utilizes 5 megabytes of magnetic disk storage upon installation and compilation 



\section{NLT Standard Reference Data \\ ORDER form \& PRICE list}

The following database prices represent one location use. For distributor agreements, online agreements, and more than one location pricing, please contact Standard Reference Data. Special multiple pricing is available.

Name

Company

Address

City, State, Zip, Country

I would like more information on the databases checked.

I am ordering the databases checked. I am enclosing a check or purchase order payable to the National Institute of Standards and Technology.

I am charging to VISA or MasterCard.

Number

Expiration Date

1. NIST/EPA/NIH Mass Spectral

ASCII Version

1A. NIST/EPA/NIH Mass Spectral

PC Version 4.5 (with interactive software)

2. NIST Chemical Thermodynamics (NBS Tech Note 270)

3. NIST Crystal Data Identification File

Available from the JCPDS-International Centre for Diffraction Data, Newtown Square

Corporate Campus, 12 Campus Blvd., Newtown Square, PA 19073-3273. (215) 325-9810.

4. NIST Thermophysical Properties of Hydrocarbon Mixtures 
7. NIST Electron and Positron Stopping Powers of Materials

8. NIST X-Ray and Gamma-Ray Attenuation Coefficients and Cross Sections

10. NIST Thermophysical Properties of Water

11. DIPPR ${ }^{\circledR}$ Data Compilation of Pure Compound Properties Version 9.0

12. NIST Thermophysical Properties of Pure Fluids Version 3.0

without Source Code

with Source Code

13. NIST JANAF Thermochemical Tables

14. NIST Mixture Property Program

Discount available to GPA members.

15. NIST/Sandia/ICDD Electron Diffraction

Available from the JCPDS-International Centre for Diffraction Data,

Newtown Square Corporate Campus, 12 Campus Blvd., Newtown

Square, PA 19073-3273. (215) 325-9810.

16. NIST Corrosion Performance

COR $*$ SUR1

$\mathrm{COR} * \mathrm{SUR} 2$ 
17. NIST Chemical Kinetics

Version 5.0

$\$ 390$

18. NIST Estimation of the Thermodynamic Properties for Organic Compounds at $298.15 \mathrm{~K}$

Version 2.0

19A\&B. NIST Positive and Negative Ion Energetics with Structures and Properties Software

20. NIST X-Ray Photoelectron Spectroscopy

Version 1.0

21. NIST/NASA/CARB Biological Macromolecule Crystallization

Version 3.0

22. Tribomaterials I

Available from ACTIS Inc., 1118 Highgate Rd.,

Wilmington, DE 19808. (302) 998-8240.

23. NIST Thermodynamic Properties of

Refrigerants and Refrigerant Mixtures

Version 4.0

24. NIST Atomic Transition Probabilities Data File

25. NIST Structures and Properties

Database and Estimation Program

$\$ 390$

26. NIST Vibrational Electronic Energy Levels of Small Polyatomic Transient Molecules

Version 3.0 
27. NIST Molten Salts

Version 2.0

$\$ 240$

30. NIST Structural Ceramics

Version 2.0

$\$ 590$

34. Lipid Thermotropic Phase Transition

Database (LIPIDAT)

35. NIST/EPA Gas Phase Infrared

JCAMP Format

36. NIST/NIH Desktop Spectrum Analyzer

Program and X-Ray Database

Version 2.0

38. NIST Spectroscopic Properties of Atoms and Atomic Ions

39. NIST Wavenumber Calibration Tables

40. NDRL/NIST Solution Kinetics

Version 2.0

41. PICT/NIST Heat Capacities of Liquid Hydrocarbons

42. NIST Surface Structure

44. DIPPR ${ }^{\circledR} /$ NIST Properties of Aqueous Solutions

45. GRI/NIST Orifice Meter Discharge Coefficient 
46. NIST Critical Stability Constants of Metal Complexes

47. NIST Ceramic Tribomaterials Available from ACTIS Inc., 1118 Highgate Rd., Wilmington, DE 19808. (302) 998-8240.

48. NIST Spectroscopic Properties of Diatomic Molecules

50. NIST JANAF Thermochemical Tables Shomate Coefficients

51. NIST JANAF Thermochemical Tables -

NASA-Lewis Coefficients

\section{NIST SPECIAL DATABASES}

Special Database 1.

NIST Binary Images of Printed

Digits, Alphas, and Text

Special Database 2.

NIST Structured Forms Reference

Set of Binary Images (SFRS)

Special Database 3.

NIST Binary Images of Handwritten

Segmented Characters

Special Database 4.

NIST 8-Bit Gray Scale Images of

Fingerprint Image Groups

Special Database 5.

IVTANTHERMO PC 
NIST SPECIAL DATABASES (continued)

Special Database 6.

NIST Structured Forms Reference

Set of Binary Images II (SFRS2)

Special Database 7.

NIST Test Data 1: Binary Images of

Handprinted Segmented Characters (TSTI)

Special Database 8.

NIST Machine-Print Database of Gray

Scale and Binary Images (MPDB)

Special Database 9.

NIST Mated Fingerprint Card Pairs

(Volumes 1-5)

Special Database 10.

Supplemental Fingerprint Card Data

(SFCD) for NIST Special Database 9

Special Database 14.

NIST Mated Fingerprint Card Pairs 2

(MFCP2)

Special Database 15.

COMAR: International Databank on

Reference Materials

\section{NIST SPECIAL SOFTWARE}

Special Software 1.

NIST Scoring Package

Release 1.0 
Place orders by phone, mail, or FAX.

VISA and MasterCard accepted.

FURTHER INFORMATION Please contact:

Standard Reference Data

National Institute of Standards and Technology

221/A320

Gaithersburg, MD 20899

(301) 975-2208

879-2208 (FTS)

(301) 926-0416 (FAX)

SRDATA@enh.nist.gov (E-MAIL)

telnet gopher.nist.gov

login: gopher

(no password)

For Journal of Physical and Chemical Reference Data issues, reprints, and monographs, contact:

American Chemical Society

1155 16th Street, N.W.

Washington, D.C. 20036

(800) 227-5558 



\section{SRM Catalog}

The National Institute of Standards and

Technology has the function to develop, produce, and distribute Standard Reference

Materials (SRMs) that provide a basis for comparison of measurements on materials, and that aid in the control of production processes.

The NEW Standard Reference Materials catalog from NIST lists some 1100 SRMs in 70 major categories. SRMs are well-characterized materials produced to improve measurement science. SRMs serve major segments of industry, including those specializing in water analysis, ferrous and non-ferrous materials, mining, glass, rubber, plastics, primary chemicals, gases, organics, electronics, automotive and computer instrumentations.

To obtain a FREE NIST Standard Reference Materials Catalog call the SRM sales office at (301) $975-6776$, or write to the address below.

Standard Reference Materials Program

National Institute of Standards and Technology

Building 202, Room 204

Gaithersburg, MD 20899 

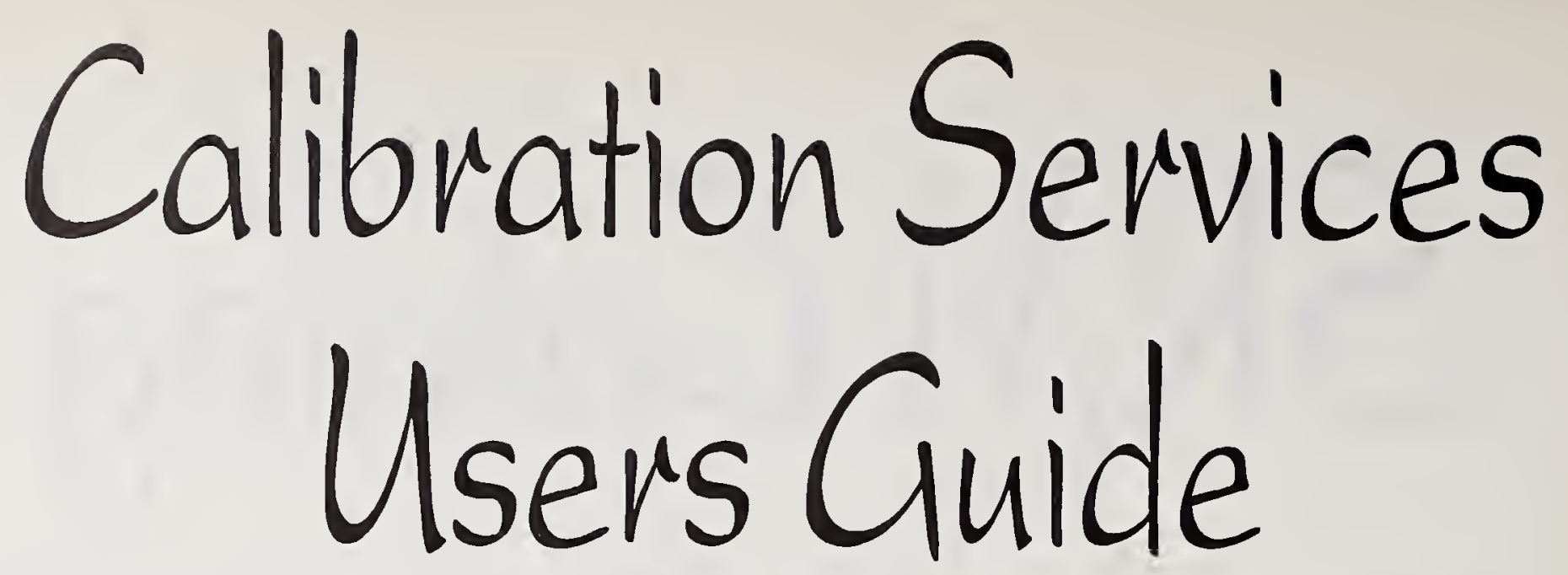

The National Institute of Standards and Technology (NIST) Calibration Services Users Guide provides detailed descriptions of currently available NIST calibration services, measurement assurance programs, and special-test services. The following measurement areas are covered: (1) dimensional; (2) mechanical, including flow, acoustic and ultrasonic; (3) thermodynamic; (4) optical radiation; (5) ionizing radiation; and (6) electromagnetic, including dc, ac, If, and microwave. A separate Fee Schedule is issued annually, providing current prices for the services offered, updates on points-of-contact, and information on measurement seminars.

The physical measurement services of the National Institute of Standards and Technology (NIST) are designed to help the makers and users of precision instruments achieve the highest possible levels of measurement quality and productivity. The hundreds of individual services you will find listed and described in this Users Guide constitute the highest order calibration services available in the United States. They directly link a customer's precision equipment or transfer standards to national measurement standards. These services are offered to public and private organizations and individuals alike.

This Users Guide is designed to make the task of selecting and ordering an appropriate calibration service as quick and easy as possible. Nevertheless, questions will arise. When they do, we urge you to call or write for immediate clarification. Address general questions and lengthy inquiries to:

$$
\begin{gathered}
\text { Calibration Program } \\
\text { National Institute of Standards and Technology } \\
\text { Building 411, Room A104 } \\
\text { Gaithersburg, MD 20899-0001 } \\
\text { Telephone: (301) 975-2002 } \\
\text { Telefax: (301) 976-2884 }
\end{gathered}
$$




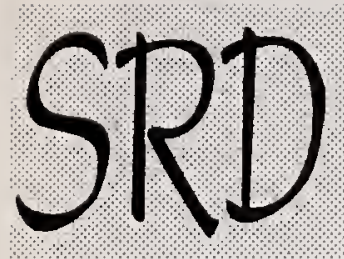

Databases

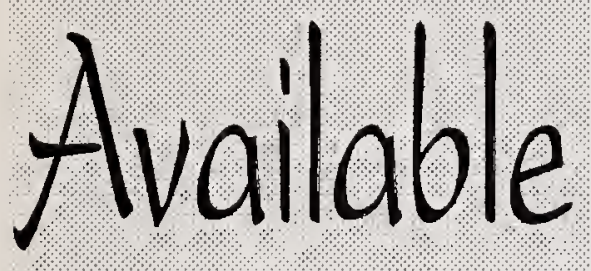

on the

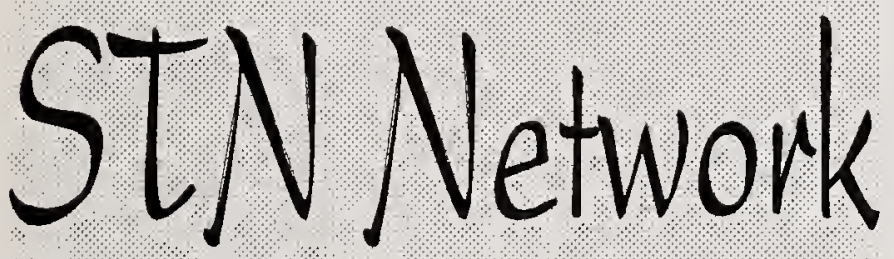

\section{- JANAF}

JANAF Thermochemical Tables

- NISTFLUIDS

MIPROPS Data Generation Package

\section{- NISTTHERMO}

NIST Tables of Chemical Thermodynamic Properties

- DIPPR $^{\circledR}$

Data Compilation of Pure Compound Properties

- NISTCERAM

Structural Ceramics Database (Also available via MPD network)
STN USA

STN International c/o CAS

2540 Olentangy River Rd.

P.O. Box 3012

Columbus, OH 43210-0012

Telephone: 800-848-6538

Telex: 6842086 CHMAB
STN Australia

CSIRO Information Resources Unit

314 Albert St., E. Melbourne

Victoria, 3002

Australia

Telephone: (03) 4187253

Telex: AA 30236
STN Europe

STN International c/o FIZ Karlsruhe

Postfach 2465

W-7500 Karlsruhe 1

Federal Republic of Germany

Telephone: $(+49)$ 7247/808-131

Telex: $17724710+$
STN Japan

STN International

c/o JICST

5-2, Nagatacho 2-chome

Chiyoda-ku, Tokyo 100

Japan

Telephone: $(+81)$ 03-3581-6411

Telex: 02223604 JICST J 


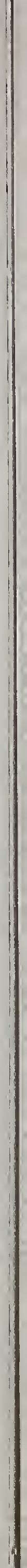




\section{$\overline{N I S T}_{\text {Technical Publications }}$}

\section{Periodical}

Journal of Research of the National Institute of Standards and Technology-Reports NIST research and development in those disciplines of the physical and engineering sciences in which the Institute is active. These include physics, chemistry, engineering, mathematics, and computer sciences. Papers cover a broad range of subjects, with major emphasis on measurement methodology and the basic technology underlying standardization. Also included from time to time are survey articles on topics closely related to the Institute's technical and scientific programs. Issued six times a year.

\section{Nonperiodicals}

Monographs-Major contributions to the technical literature on various subjects related to the Institute's scientific and technical activities.

Handbooks - Recommended codes of engineering and industrial practice (including safety codes) developed in cooperation with interested industries, professional organizations, and regulatory bodies.

Special Publications - Include proceedings of conferences sponsored by NIST, NIST annual reports, and other special publications appropriate to this grouping such as wall charts, pocket cards, and bibliographies.

Applied Mathematics Series-Mathematical tables, manuals, and studies of special interest to physicists, engineers, chemists, biologists, mathematicians, computer programmers, and others engaged in scientific and technical work.

National Standard Reference Data Series - Provides quantitative data on the physical and chemical properties of materials, compiled from the world's literature and critically evaluated. Developed under a worldwide program coordinated by NIST under the authority of the National Standard Data Act (Public Law 90-396). NOTE: The Journal of Physical and Chemical Reference Data (JPCRD) is published bimonthly for NIST by the American Chemical Society (ACS) and the American Institute of Physics (AIP). Subscriptions, reprints, and supplements are available from ACS, 1155 Sixteenth St., NW, Washington, DC 20056.

Building Science Series-Disseminates technical information developed at the Institute on building materials, components, systems, and whole structures. The series presents research results, test methods, and performance criteria related to the structural and environmental functions and the durability and safety characteristics of building elements and systems.

Technical Notes-Studies or reports which are complete in themselves but restrictive in their treatment of a subject. Analogous to monographs but not so comprehensive in scope or definitive in treatment of the subject area. Often serve as a vehicle for final reports of work performed at NIST under the sponsorship of other government agencies.

Voluntary Product Standards - Developed under procedures published by the Department of Commerce in Part 10, Title 15, of the Code of Federal Regulations. The standards establish nationally recognized requirements for products, and provide all concerned interests with a basis for common understanding of the characteristics of the products. NIST administers this program in support of the efforts of private-sector standardizing organizations.

Consumer Information Series-Practical information, based on NIST research and experience, covering areas of interest to the consumer. Easily understandable language and illustrations provide useful background knowledge for shopping in today's technological marketplace.

Order the above NIST publications from: Superintendent of Documents, Government Printing Office, Washington, DC 20402.

Order the following NIST publications-FIPS and NISTIRs-from the National Technical Information Service, Springfield, VA 22161.

Federal Information Processing Standards Publications (FIPS PUB) - Publications in this series collectively constitute the Federal Information Processing Standards Register. The Register serves as the official source of information in the Federal Government regarding standards issued by NIST pursuant to the Federal Property and Administrative Services Act of 1949 as amended, Public Law 89-306 (79 Stat. 1127), and as implemented by Executive Order 11717 (38 FR 12315, dated May 11, 1973) and Part 6 of Title 15 CFR (Code of Federal Regulations).

NIST Interagency Reports (NISTIR) - A special series of interim or final reports on work performed by NIST for outside sponsors (both government and non-government). In general, initial distribution is handled by the sponsor; public distribution is by the National Technical Information Service, Springfield, VA 22161, in paper copy or microfiche form. 


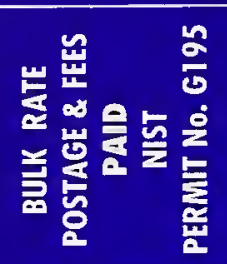

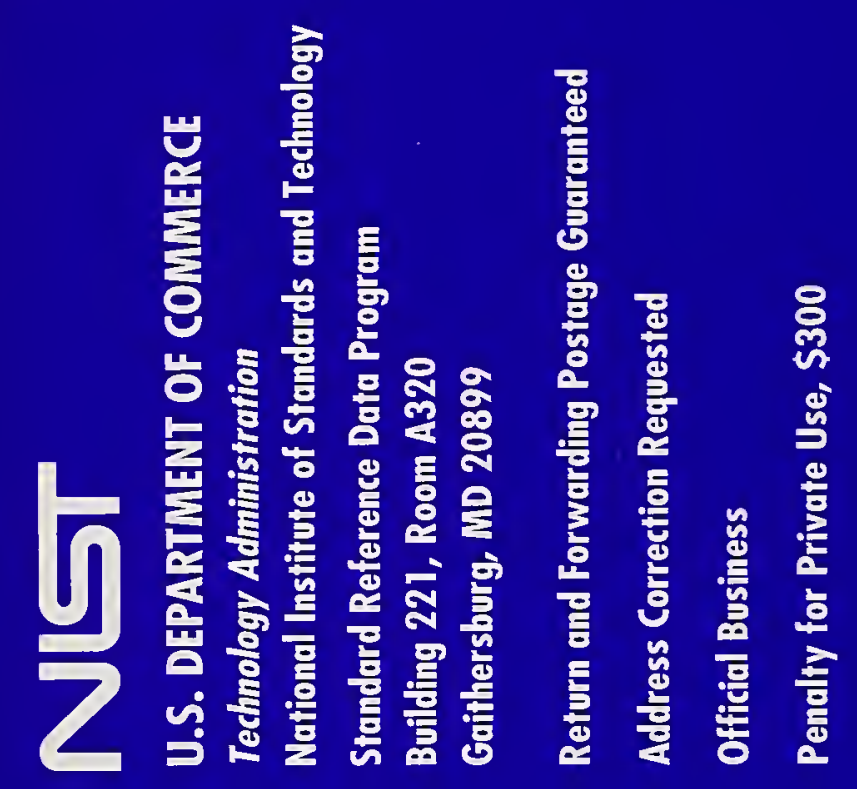

